LBL -32390

DE92 041206

\title{
The Effect of Low Au Concentrations on the Properties of Eutectic Sn/Pb
}

\author{
Pamela Ann Kramer
}

M.S. Thesis

\begin{abstract}
Departrnent of Materials Science and Mineral Engineering, University of California
\end{abstract}

and

Center for Advanced Materials

Materials Science Division

Lawrence Berkeley Laboratory

1 Cyclotron Road.

Berkeley, CA 94720

May, 1992

This work is supported by the Director, Office of Energy Research, Office of Basic Energy Sciences, Materials Sciences Division of the U.S. Department of Energy under Contract No. DE.AC03-76F00098.

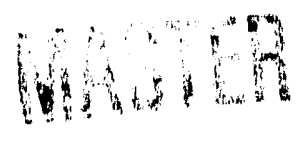




\title{
The Effect of Low Au Concentrations on the Properties of Eutectic $\mathrm{Sn} / \mathrm{Pb}$
}

by

\author{
Pamela Ann Kramer
}

\begin{abstract}
The objective of this study was to determine the effects moderately low Au concentrations $(\leq 10 \mathrm{wt} \%$ ) have on the mechanical properties and the microstructure of an eutectic $\mathrm{Sn} / \mathrm{Pb}$ alloy. Vibration $(60-90 \mathrm{~Hz}$ swept sine wave for 30 hours) and thermal cycling $\left(0^{\circ} \mathrm{C}-110^{\circ} \mathrm{C}\right.$ for 1450 cycles) reliability tests were performed on fine pitch leaded chip carriers using eutectic $\mathrm{Sn} / \mathrm{Pb}$ solder on PCBs (printed circuit boards) with $0 \mu \mathrm{in}, 5$ $\mu \mathrm{in}, 10 \mu \mathrm{in}, 20 \mu \mathrm{in}$, and $50 \mu \mathrm{in}$ nominal Au thicknesses. Testing was also performed on double shear creep specimens consisting of arrays of regular pitch joints with nominal Au plating thicknesses the same as for the reliability joints.

Two interesting microstructural features were observed. First, there was a dramatic increase in the number of joints containing voids with increasing Au concentration, an effect more pronounced in the creep joints than in the reliability joints. These voids tended to coalesce and grow during rework simulation of the reliability joints. Second, AuSna intermetallics present in the toe of the $4.8 w t \%(50 \mu \mathrm{in})$ Au vibration joints rotated from their initial, generally vertical (where vertical indicates perpendicular to the surface of the PCB metallization), solidification positions to roughly horizontal (where horizontal indicates parallel to the plating surface) orientations during rework simulation and during aging of the parts. In addition, the AuSn 4 intermetallics in the toe of the $4.8 w t \%$ (50 $\mu \mathrm{in})$ Au reflowed joints were observed to have rotated after vibration testing.

No failures of the joints were observed in either the vibration tested or the themally cycled specimens for any of the conditions tested. Cracks formed in some of the vibration tested specimen joints under the heel of the gull-wing lead at Pb-rich phases. Thermally cycled specimens showed evidence of eutectic microstructure and intermetallic coarsening without crack formation. Creep rests showed a loss of the superplasticity regime in eutectic
\end{abstract}


$\mathrm{Sn} / \mathrm{Pb}$ alloys with even the lowest Au concentration tested of $0.2 \mathrm{wt} \%$ Au. Intermetallic rotation was not found to be a factor in crack propagation, but void presence was. Cracks tended to form in joints containing voids before forming in void-free joints. Crack propagation followed $\mathrm{Sn} / \mathrm{Sn}$ grain boundaries ar. Sn/Pb phase boundaries from $\mathrm{Pb}$-rich phase to Pb-rich phase. 


\section{Dedication}

I would like to dedicate this thesis to my grandmothers, Anna Kramer and Marje Eck. Oma Kramer was an incredibly fun and energetic woman who passed from this world far too young. Her sense of adventure in everything we did together and the love she passed on to me is something I will never forget and always cherish. Oma Re is a wonderful, loving woman who brought up her two daughters to be as strong as she is. I am grateful that I have had so many years in which to truly get to know her. 
Dedication

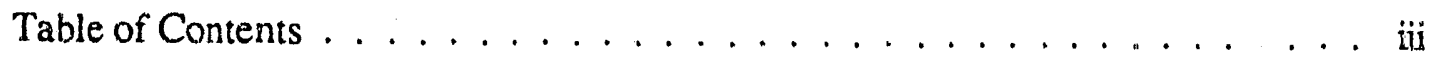

List of Figures $\ldots \ldots \ldots \ldots \ldots \ldots \ldots \ldots$

List of Tables $\ldots \ldots \ldots \ldots \ldots \ldots$ viii

Acknowledgments ..................... ix

1.0 introduction $\ldots \ldots \ldots \ldots \ldots \ldots \ldots$

1.1 Purpose $\ldots \ldots \ldots \ldots \ldots \ldots \ldots \ldots \ldots$

1.2 Background ...................... 1

1.2 .1 Why Use Au? . . . . . . . . . . . . . . 1

1.2 .2 Use of Au by Industry . . . . . . . . . . . . . 3

1.2 .3 Research on $\mathrm{Sn} / \mathrm{Pb} \ldots \ldots \ldots \ldots$

1.2.4 Research of $\mathrm{Au}$ in $\mathrm{Sn} / \mathrm{Pb}$ Alloys . . . . . . . . . . . . . . 4

1.2.4.1 Material Properties .................. . 4

1.2.4.2 Microstructural Properties . . . . . . . . . . . . . 7

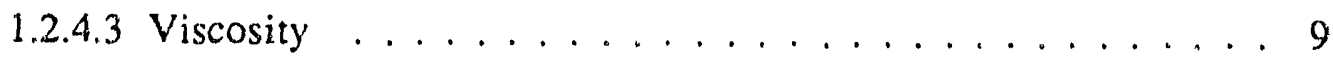

1.3 Surface Mount Work Environment . . . . . . . . . . . . . . . . . 10

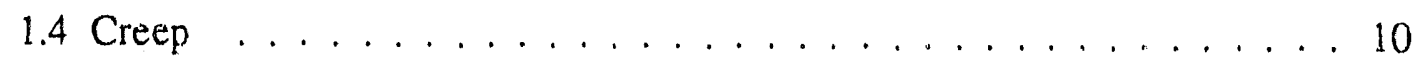

1.5 Superplasticity . . . . . . . . . . . . . . . . 11

2.0 Experimental Procedure . . . . . . . . . . . . . . 13

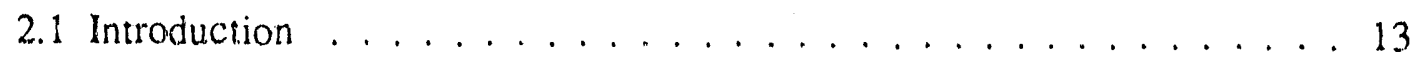

2.2 Materials Processing . . . . . . . . . . . . . . . . . . . 13

2.2 .1 Surface Mount . . . . . . . . . . . . . . . . 13

2.2 .1 .1 Materials ...................... 13

2.2 .1 .2 Processing ........................ 14

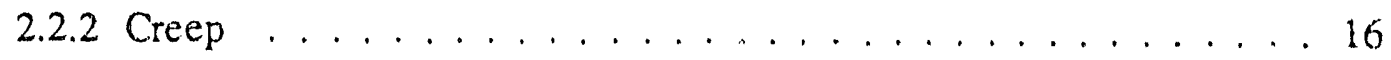

2.2.2.1 Materials ....................... 16

Page iii 


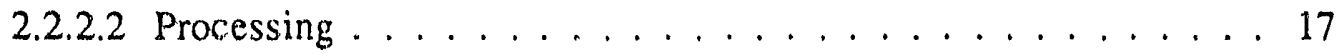

2.3 Testing . . . . . . . . . . . . . . . . . 19

2.3.1 Shock and Vibration . . . . . . . . . . . . . . . . . . . 19

2.3.2 Thermal Cycling . . . . . . . . . . . . . . . 19

2.3 .3 Creep . . . . . . . . . . . . . . . . . 20

2.4 Metallography. . . . . . . . . . . . . . . . . . . 21

3.0 Results . . . . . . . . . . . . . . . . . . . 23

3.1 Shock and Vibration . . . . . . . . . . . . . 23

3.2 Thermal Cycling . . . . . . . . . . . . . . . . . 23

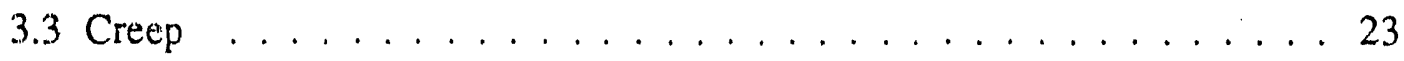

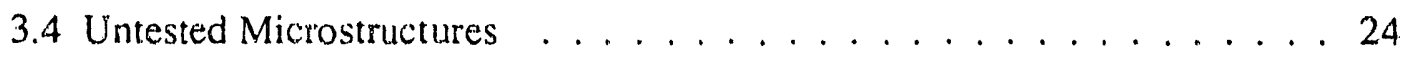

3.5 Tested Microstructures . . . . . . . . . . . . . . . . . 25

3.5.1 Vibration Tested Joints . . . . . . . . . . . . . . 25

3.5 .2 Thermally Cycled Joints . . . . . . . . . . . . . . 26

3.5 .3 Creep Tested Joints . . . . . . . . . . . . . . . . . 26

4.0 Discussion . . . . . . . . . . . . . . . . . . 28

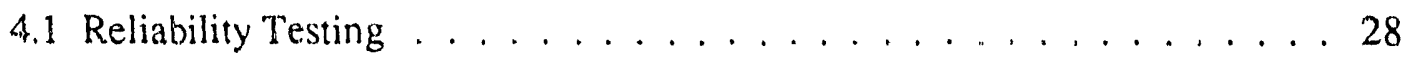

4.1 .1 Vibration Testing $\ldots \ldots \ldots \ldots \ldots \ldots \ldots$

4.1 .2 Thermal Cycling . . . . . . . . . . . . . . . . . 29

4.2 Creep Testing . . . . . . . . . . . . . . . . 30

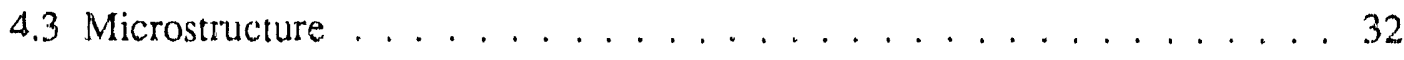

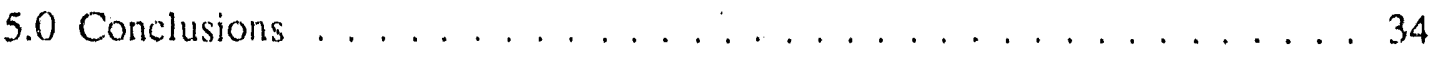

6.0 Future Work $\ldots \ldots \ldots \ldots \ldots \ldots \ldots \ldots \ldots \ldots$

7.0 References . . . . . . . . . . . . . . . . 36

8.0 Figures $\ldots \ldots \ldots \ldots \ldots \ldots \ldots \ldots \ldots \ldots \ldots \ldots \ldots \ldots$ 


\section{List of Figures}

Figure 1 a) Top view schematic of land pattern and chip carrier. b) Schematic showing desired contact between land pattern pad, solder paste, and chip carrier lead. c) Schematic showing missed contact between land pattern pad and solder paste and chip carrier lead resulting from possible distortion of the land pattern from thermal shock.

Figure 2 Plot of elongation and reduction in area vs. Au concentration.

Figure 3 Pseudo-binary phase diagram of eutectic $\mathrm{Sn} / \mathrm{Pb}+\mathrm{Au}$.

Figure 4 a) Cross-sectional side view of chip carrier with gull-wing leads, b) Stress effects on the solder joint on heating of the board (turning on the component) originating from different therrnal expansion coefficients of the PC board, the solder, the lead, and the chip carrier. c) Stress effects on the solder joint on cooling of the board (turning off the component) originating from different thermal expansion coefficients of the PC board, the solder, the lead, and the chip carrier.

Figure 5 Characteristic creep curve showing steady state creep.

Figure 6 Enlarged schematic showing daisy chain pattern between the board and the chip carrier. This pattern allowed the recording computer to recognize when there was an open in the circuit, i.e., a failure in a joint or a lead.

Figure 7 Schematics showing top and side view's of the stencil paster used to paste the PC boards. The squeegee sweeps across the stencil, pushing the paste through the etched holes in the stencil onto the board beneath.

Figure 8 Schematic diagram of double shear specimen and creep test machine.

Figure 9 Top and side view of vibration specimen. The side view shows the flexion the board and spacer undergo during testing.

Figure $10 \quad 0 \mu$ in, $5 \mu$ in $(0.2 \mathrm{wt} \%)$, and $10 \mu$ in $(1.0 \mathrm{w} / \%)$ Au creep tests at $90^{\circ} \mathrm{C}$.

Figure $110 \mu \mathrm{in}, 5 \mu \mathrm{in}(0.2 \mathrm{wt} \%)$, and $10 \mu \mathrm{in}(1.0 \mathrm{wt} \%)$ Au creep tests at $65^{\circ} \mathrm{C}$.

Figure $1220 \mu \mathrm{in}(1.5 \mathrm{wt} \%) \mathrm{Au}$ creep tests at $90^{\circ} \mathrm{C}$ and $0 \mu$ in and $5 \mu \mathrm{in}(0.2 \mathrm{wt} \%)$ Au creep tests at $20^{\circ} \mathrm{C}$.

Figure $13 \quad 0 \mu$ in and $5 \mu$ in $(0.2 w t \%)$ Au and $10 \mu \mathrm{in}(1.0 w t \%)$ and $20 \mu$ in (1.5 wt\%) Au In shear stress vs. In steady state shear strain rate at $90^{\circ} \mathrm{C}$.

Figure 14 Ln shear stress vs. In steady state shear strain rate of $0 \mu \mathrm{in}, 5 \mu \mathrm{in}(0.2 \mathrm{w} \%)$, and $10 \mu \mathrm{in}(1.0 \mathrm{wt} \%)$ Au at $65^{\circ} \mathrm{C}$ and $0 \mu$ in and $5 \mu$ in $(0.2 \mathrm{wt} \%)$ Au at $20^{\circ} \mathrm{C}$.

Figure 15 Optical photographs showing a) joint and b) microstructure components. (XBB917-5144) 
Figure 16 Untested a) $0 \mu \mathrm{in}, \mathrm{b}) 10 \mu \mathrm{in}(1.0 \mathrm{wt} \%)$, c) $20 \mu \mathrm{in}(1.5 \mathrm{wt} \%$ ), and d) $50 \mu \mathrm{in}$ $(4.8 \mathrm{wt} \%)$ Au vibration joints showing microstructural variation throughout the joint. (XBB924-2748)

Figure 17 Untested a) $0 \mu$ in, b) $5 \mu$ in $(0.5 w t \%)$, c) $10 \mu$ in $(1.8 w t \%)$, d) $20 \mu$ in $(2.7$ $w t \%)$, and e) $50 \mu$ in $(9.0 \mathrm{wt} \%)$ Au thermal cycling joints showing microstructural variation throughout the joint. (XBB924-2755)

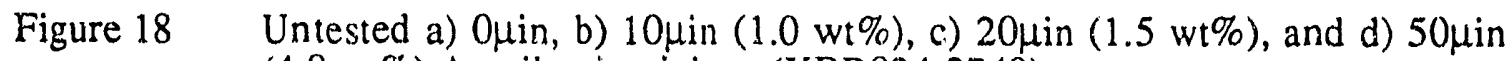
(4.8 wt\%) Au vibration joints. (XBB924-2749)

Figure 19 Untested a) $0 \mu$ in, b) $5 \mu$ in $(0.5 w t \%)$, c) $10 \mu$ in $(1.8 w t \%)$, d) $20 \mu$ in $(2.7$ $w t \%)$, and e) $50 \mu$ in (9.0 wt\%) Au thermal cycling joints. (XBB924-2756)

Figure $20 \quad$ Untested a) $0 \mu \mathrm{in}$, b) $5 \mu$ in $(0.2 \mathrm{wt} \%)$, c) $10 \mu$ in $(1.0 \mathrm{wt} \%)$, d) $20 \mu$ in $(1.5$ $w t \%)$, and e) and f) $50 \mu$ in $(5.3 w t \%)$ Au creep joints. (XBB924-2765)

Figure 21 Rework simulated a) $0 \mu \mathrm{in}$, b) $5 \mu$ in $(0.5 \mathrm{wt} \%)$, c) $10 \mu \mathrm{in}(1.0 \mathrm{wt} \%)$, d) $20 \mu$ in $(1.5 \mathrm{wt} \%)$, and e) $50 \mu \mathrm{in}(4.8 \mathrm{wt} \%)$ Au untested vibration joints. (XBB924-2750)

Figure 22 Rework simulated a) $0 \mu \mathrm{in}$, b) $5 \mu$ in $(0.5 \mathrm{wt} \%)$, c) $10 \mu \mathrm{in}(1.8 \mathrm{wt} \%)$, d) $20 \mu$ in $(2.7 \mathrm{wt} \%$ ), and e) $50 \mu \mathrm{in}(9.0 \mathrm{wt} \%)$ Au untested thermal cycling joints. (XBB92.4-2757)

Figure 23 Aged 3 days at $110^{\circ} \mathrm{C}$ a) $\left.0 \mu \mathrm{in}, \mathrm{b}\right) 5 \mu \mathrm{in}(0.5 \mathrm{wt} \%)$, c) $10 \mu$ in $(1.0 \mathrm{wt} \%)$, e) $20 \mu \mathrm{in}(1.5 \mathrm{wt} \%)$, and e) $50 \mu \mathrm{in}(4.8 \mathrm{wt} \%)$ Au untested vibration joints. (XBB924-2751)

Figure 24 Aged 3 days at $110^{\circ} \mathrm{C}$ a) $0 \mu$ in, b) $5 \mu$ in $(0.5 w t \%)$, c) $10 \mu$ in $(1.8 w t \%)$, d) $20 \mu$ in $(2.7 \mathrm{wt} \%$ ), and e) $50 \mu$ in $(9.0 \mathrm{wt} \%)$ Au untested thermal cycling joints. (XBB924-2758)

Figure 25 Plot of the percentage of creep joints containing voids.

Figure 26 Top view of $50 \mu$ in $(5.3 \mathrm{wt} \%)$ Au creep joints containing voids. Voids are shown by arrows. (X.BB925-3172)

Figure 27 a) As-reflowed and b) rework-simulated $50 \mu$ in $(9.0$ wi\%) Au thermal cycling joints showing void coalescence and growth. (XBB911-246)

Figure $28 \quad X$-ray laminography of a) as-reflowed and b) rework simulated $50 \mu$ in (4.8 wt\%) Au vibration reliability joints. Voids are shown by arrows.

Figure $29 \quad$ a) $0 \mu \mathrm{in}$, b) $5 \mu \mathrm{in}(0.5 \mathrm{wt} \%)$, c) $10 \mu \mathrm{in}(1.0 \mathrm{wt} \%)$, d) $20 \mu \mathrm{in}(1.5 \mathrm{wt} \%)$, and e) $50 \mu$ in (4.8wt\%) Au vibration tested joints (XBB924-2752)

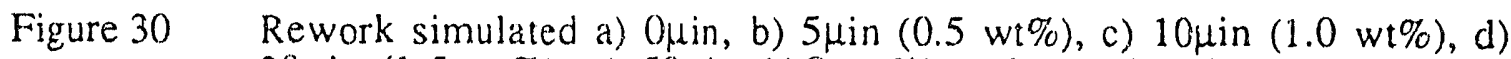
$20 \mu \mathrm{in}(1.5 \mathrm{wt} \%)$, e) $50 \mu \mathrm{in}(4.8 \mathrm{wt} \%)$ and $\mathrm{Au}$ vibration tested joints. (XBB924-2753)

Figure 31 Aged 3 days at $110^{\circ} \mathrm{C}$ a) $0 \mu \mathrm{in}$, b) $5 \mu \mathrm{in}(0.5 \mathrm{wt} \%)$, c) $10 \mu \mathrm{in}(1.0 \mathrm{wt} \%)$, and d) $20 \mu$ in (1.5 wt\%) Au vibration tested joints. (XBB924-2754) 
Figure 32

a) Untested and b) tested $50 \mu$ in $(4.8 \mathrm{wt} \%)$ Au vibration joints showing intermetallic rotation in the tested joint. (XBB911-245)

Figure 33 a) $0 \mu \mathrm{in}$, b) $5 \mu \mathrm{in}(0.5 \mathrm{wt} \%)$, c) $10 \mu \mathrm{in}(1.8 \mathrm{wt} \%)$, d) $20 \mu \mathrm{in}(2.7 \mathrm{wt} \%) \mathrm{Au}$ thermal cycling joints tested 275 cycles, and e) $50 \mu$ in $(9.0 \mathrm{wt} \%)$ Au thermal cycling joint tested 218 cycles. (XBB924-2759)

Figure 34 Rework simulated b) $5 \mu$ in $(0.5 \mathrm{wt} \%)$, c) $10 \mu$ in $(1.8 \mathrm{wt} \%)$, and d) $20 \mu$ in (2.7 wt\%) Au thermil cycling joints tested 275 cycles, and a) $0 \mu$ in and e) $50 \mu$ in $(9.0 \mathrm{wt} \%)$ thermal cycling joints tested 218 cycles. (XBB924-2760)

Figure $3: \quad$ a) $0 \mu \mathrm{in}, \mathrm{b}) 5 \mu \mathrm{in}(0.5 \mathrm{wt} \%)$, c) $10 \mu \mathrm{in}(1.8 \mathrm{wt} \%)$, d) $20 \mu$ in $(2.7 \mathrm{wt} \%)$, and e) $50 \mu$ in $(9.0 \mathrm{wt} \%)$ Au thermal cycling joints tested 784 cycles. (XBB9242761)

Figure 36 Rework simulated a) $0 \mu \mathrm{in}$, b) $5 \mu \mathrm{in}(0.5 \mathrm{wt} \%)$, c) $10 \mu \mathrm{in}(1.8 \mathrm{wt} \%)$, d) $20 \mu$ in $(2.7 \mathrm{wt} \%)$, and e) $50 \mu$ in $(9.0 \mathrm{wt} \%)$ Au thermal cycling joints tested 784 cycles. (XBB924-2762)

Figure $37 \quad$ a) $0 \mu$ in, b) $5 \mu$ in $(0.5 w t \%)$, c) $10 \mu \mathrm{in}(1.8 \mathrm{wt} \%)$, d) $20 \mu$ in $(2.7 \mathrm{wt} \%)$, and e) $50 \mu$ in $(9.0 w t \%)$ Au thermal cycling joints tested 1450 cycles. (XBB9242763)

Figure 38 Rework simulated a) $0 \mu$ in, b) $5 \mu$ in $(0.5 \mathrm{wt} \%)$, c) $10 \mu$ in $(1.8 \mathrm{wt} \%)$, d) $20 \mu$ in $(2.7 \mathrm{wt} \%)$, and e) $50 \mu$ in $(9.0 \mathrm{wt} \%)$ Au thermal cycling joints tested 1450 cycles. (XBB924-2764)

Figure 39 a) $0 \mu \mathrm{in}$, b) $5 \mu \mathrm{in}(0.2 \mathrm{wt} \%)$, c) $10 \mu \mathrm{in}(1.0 \mathrm{wt} \%)$, and d) $20 \mu \mathrm{in}(1.5 \mathrm{wt} \%)$ Au creep specimens tested at $90^{\circ} \mathrm{C}$. (XBB925-3174)

Figure $40 \quad$ Crack formation in a) $0 \mu$ in and $10 \mu$ in $(1.0 \mathrm{wt} \%)$ Au creep joints rested at $90^{\circ} \mathrm{C}$ and in $5 \mu$ in $\left(0.2\right.$, wt \%) Au creep joints tested at c) $65^{\circ} \mathrm{C}$ and d) $20^{\circ} \mathrm{C}$. (XBB925-3173) 


\section{List of Tables}

Table 1 Vibration reliability joints nominal and measured Au thicknesses, and $\mathrm{Au}$ concentrations. Au concentrations, shown as an average and as a range, are calculated from the measured Au thicknesses and the known solder paste volume.

Table 2 Thermal cycling reliability joints nominal and measured Au thicknesses, and Au concentrations. Au concentrations, shown an average and as a range, are calculated from the measured Au thicknesses and known solder paste volume.

Table 3 Double shear creep specimen nominal and measured Au thicknesses, and Au joint concentrations. Au concentrations, average and (range), are calculated from measured Au thicknesses and observed nominal joint thicknesses.

Table 4 Test matrix of double shear creep specimen tests. The matrix shows the temperatures at which each Au concentration specimen was tested for each shear stress. 


\section{Acknowledgmeats}

I would like to thank my parents for their understanding and support through this venture. I greatly value their opinions and advice, and it made it much easier that they have both been through this themselves. In addition I would like to thank all my friends for their support. I could not have completed this work without the help I received at the beginning from everyone in the PGP division at Hewlett-Packard and throughout from everyone in the Morris Group. Special thanks go to Judy Glazer, Jin Chan, Zequn Mei, and Prof. Morris. Judy provided the opportunity for me to work with a wonderful group of people and learn first-hand what one part of the electronics industry is like. Jin and Mei were always there to help with experimental details, ideas, and constructive criticisms. Prof. Morris gave me the wonderful opportunity to return to his group and work with an incredible set of people.

This work is supported by the Director, Office of Energy Research, Office of Basic Energy Science, Materials Sciences Division of the U.S. Department of Energy under Contract No. DE-AC03-76SF(00098. 


\subsection{Introduction}

\subsection{Purpose}

Eutectic $\mathrm{Sn} / \mathrm{Pb}$ solder joints with Au concentrations $\leq 10 \mathrm{wt} \%$ were studied to determine the effects Au has on the reliability and creep properties of these joints. As surface mount electronics joints continue to decrease in size while Au plating thicknesses on $\mathrm{PCBs}$ (printed circuit boards) remain constant, the relative concentration of $\mathrm{Au}$ in these joints increases and the reliability of these joints is called into question. Studying the effects of $\mathrm{Au}$ on the $\mathrm{Sn} / \mathrm{Pb}$ system allows a comparison to the comparatively well-known eutectic and near-eutectic properties of the $\mathrm{Sn} / \mathrm{Pb}$ system.

\subsection{Background}

Solder joints in use today are expected to satisfy four main requirements. They are expected to 1) provide an electrical contact between the cormponent and the PCB (Printed Circuit Board), 2) provide enough mechanical strength so that the component is attached adequately to the board, 3 ) provide enough durability and reliability that the lifetime of use of the board is as desired, and 4) be easy to assemble.[59] Over the years standards have been developed to help fulfill these parameters ranging from surface joint appearance to reliability testing, and processes ranging from wave soldering to surface mount. As the industry requirements change, these standards and processes must be reviewed and revised. $[46,54,55,58,61]$ One area of continuing interest is the effect that various metallizations, i.e., the plating on the land pattern pad on the $\mathrm{PCB}$, have on the properties and reliability of solder joints. Specific interest has been focused on $\mathrm{Au}$, as it is commonly used as the top plating layer over Cu.Ni plating on PCBs.

\subsubsection{Why use Au?}

There are various reasons why $\mathrm{Cu}-\mathrm{Ni}$-Au metallization is used on PCBs by the electronics industry. In many cases the requirement is part-specific, e.g., for edge connectors or wire-bondable parts, and at this time it is easier to plate the entire board with Au than just one small area on it. $[4,34]$ Another reason is an increase in the number of 
rework cycles the board can be allowed to undergo with this metallization compared to the number of cycles allowed using SMOBC (Solder Mask Over Bare Copper) preparation. This increase comes from the extra constraint on the thermal expansion of the board provided by the Ni metallization. During rework of a soldered board the thermal expansion of the fiberglass in the board is greater than the thermal expansion of the metallization on the board. In plated through-holes the board undergoes a net compression resulting from the constraining action of the metal plating, while the plating is loaded by a net tensile force. This tensile force may result in crack initiation and propagation to failure through the metallization, resulting in an unusable board. When a second layer of metallization is added over the $\mathrm{Cu}$, in this case $\mathrm{Ni}$, the net tensile stress on the $\mathrm{Cu}$ plating is reduced. This reduction means that the board can experience a greater number of thermal rework cycles before cracks initiate in the softer $\mathrm{Cu}$ and grow to failure. This increase in rework cycles can result in a large cost savings.

Another advantage of $\mathrm{Cu}-\mathrm{Ni}-\mathrm{Au}$ metallization is the absence of thermal shock. experienced by the board during processing. This is important because thermal shock may distort the land pattern on the board. In SMOBC processing once the $\mathrm{Cu}$ layer on the board has been etched to acquire the desired pattern the board is coated with solder mask in the areas that are not to be exposed to form solder joints. The Cu land pattern quickly oxidizes and will not wet solder unless first coated with some metallization that will form a bond with the solder being used. The HAL (Hot Air Leveling) process provides coverage of the exposed areas by means of a solder dip. To remove excess solder from the pads the board is then run through a hot air knife step which biows excess solder off of the pads. Both the solder dip and the hot air knives thermally shock the board. These thermal shocks may distort both the board and the land pattern on the board. Thermal shocking of a board is increasing in importance, for as pitch size (the center.to-center pad distance) decreases, distortion of the land pattem to the point where the board becomes unusable is a distinct possibility. A board is considered unusable when there is not enough overlap between the 
land pattern and the chip carrier leads, if leaded, or chip carrier contact pads, if leadless (Figure 1). Since pitches of $0.65 \mathrm{~mm}(0.0256 \mathrm{in})$ and even finer are currently being investigated, the need for a minimal-distortional board process cannot be overemphasized. In addition to the importance of the land pattern, as the pitch size decreases the size of the solder joint also decreases. As the size decreases the volume of solder paste on the pad decreases and the relative concentration of $\mathrm{Au}$ in the joint increases. Based on the results of research into large Au concentrations, it is expected that the properties of these joints may be inferior to Au-free eutectic $\mathrm{Sn} / \mathrm{Pb}$ joints.[11, 27, 77]

\section{2 .2 Use of Auby Industry}

Cu-Ni-Au plating was common during the late 1970's and early 1980's before the HAL process was developed.[100] The development and increasing use of HAL in addition to the increasing price of gold, which reached over $\$ 800$ per troy oz at one point and still hovers around $\$ 350$ per troy oz today, contributed to the decreasing use of $\mathrm{Cu} \cdot \mathrm{Ni}$ Au boards. In addition to the cost impetus, difficulties are inherent in the Cu-Ni-Au plating process. Unevenness of the Au plating thickness across the panel, possible contaminants from the plating bath, and over-etching of the $\mathrm{Cu}$ and Ni layers under the Au plating are some examples. With uneven plating of an already very thin layer of Au over the Ni layer comes the possibility of oxidation of the underlying Ni layer, and hence a reduction in the solderability of the contact pads to the leaded or leadless chip carrier. Contaminants in the Au plating bath may reduce solderability and joint reliability.[21] Over-etching of the $\mathrm{Cu}$ and $\mathrm{Ni}$ under-layers, on the other hand, results in whiskers which could break off and result in shorts between contact pads. This is prevented for the most part by brushing the board after etching to break off and remove the Au whiskers. Addition-"y, the Ni plating itself is relatively thick and may not plate evenly, e.g., resulting in a pad thicker at the edges and thinner in the middle. This results in uneven joint thickness, and may promote uneven Au thickness from varying current densities. Despite this, it appears that the number of boards with part-specific requirements for $\mathrm{A} u$ use may be increasing. Cu-Ni-Au 
plating is used today for 1) old board types that would cost too much to redesign to HAL process standards and 2) new boards that need Au for part-specific purposes.[100]

\section{2 .3 Research of $\mathrm{Sn} / \mathrm{Pb}$ Solder}

It was research on the effects of $\mathrm{Cu}$ in $\mathrm{Sn} / \mathrm{Pb}$ solder that lead to $\mathrm{Cu}-\mathrm{Ni}$ plating. When joint reliability resulting from $\mathrm{Cu} / \mathrm{Sn}$ intermetallics was in question, it was discovered that a $\mathrm{Ni}$ layer in between the $\mathrm{Cu}$ and the solder inhibited $\mathrm{Sn}$ diffusion and $\mathrm{Cu} / \mathrm{Sn}$ compound formation. In addition, $\mathrm{Ni}$ undercoating was found to promote adhesion, provide leveling, maintain solderability, and enhance corrosion protection. [99] Slower growing $\mathrm{Ni}_{3} \mathrm{Sn}_{4}$ in the joint extended the joint life.[52] An additional metallization is needed on top of the $\mathrm{Ni}$, however, to keep it from oxidizing, and, as with plating over $\mathrm{Cu}$, Au was chosen because of its low oxidation properties.

There has been quite a bit of research into the mechanical and microstructural properties of both bulk and joint $\mathrm{Sn} / \mathrm{Pb}$ solder. Both creep and fatigue mechanisms have been extensively studied. $[7,8,19,20,28-31,35,36,56,57,63-65,67,70,75,79,80$, $83-88,93,94,97]$ One of the main advantages of the use of $\mathrm{Sn} / \mathrm{Pb}$ solder in the electronics industry is its tendency to perform in a superplastic manner at elevated temperature and moderate strain rates. This property has been observed both in bulk solder under tension and in quenched small solder joints under shcar loading. $[49,63,64,70]$

\subsection{Research of Au in Sn/Pb Alloys}

\subsubsection{Material Properties}

Research on the effects of cladding metals, in particular $\mathrm{Au}$, on $\mathrm{Sn} / \mathrm{Pb}$ alloys began approximately 30 years ago.[27] Initial process concerns of the electronics industry involved soldering to an oxide-free surface and the resulting reliability of the joint.[1, 4 , $27,53,76,82,99]$ In general, research of the effects of Au on Sn/Pb alloys has been limited to Au thicknesses rather than concerturations. $[13,21,37,39,51,53,60,98]$ This research was performed on both small and large Au thicknesses with some of the larger $\mathrm{Au}$ thicknesses requiring a double soldering process to lower the amount of $A u$ in the joint, 
making determination of the actual Au concentrations by the respective researchers difficult. Results gathered from known Au concentrations are explored below.

Foster performed bend tests and lap joint tests on $2.5,5,10$, and $15 \mathrm{wt} \% \mathrm{Au}$ specimens in a $60 \mathrm{Sn} / 40 \mathrm{~Pb}$ alloy.[27] The 10 and $15 \mathrm{wt} \%$ Au bend specimens broke to the touch, while the $5 \mathrm{wt} \%$ Au specimen broke at a $60^{\circ}$ bend and the $2.5 \mathrm{wt} \%$ Au specimen broke at a $90^{\circ}$ bend. The lap joints showed a maximum average strength at $2.5 \mathrm{wt} \%$ Au. Foster believed that Au dissolved in $\mathrm{Sn} / \mathrm{Pb}$ solder in amounts greater than $5 \mathrm{wt} \%$ caused brittleness while a small amount of Au may be suitable in many types of joints.

Bester researched UTS (ultimate tensile strength), shear, peel, bend, and impact strengths.[11] Although shear, peel, and UTS tests gave results that were acceptable to 10 $w t \% \mathrm{Au}$, the severe reduction in elongation and reduction in area in the $4-5 \mathrm{wt} \% \mathrm{Au}$ specimens predicted lower reliability in joints with higher Au concentrations (Figure 2). Bester also predicted that Au presence in joints in concentrations greater than 4 wt\% or joints with massive Au/Sn phases may be sensitive to vibration and shock environments.

Wild tested $\mathrm{Sn} / \mathrm{Pb}$ eutectic specimens containing $0.2,0.4,0.6,1.0$, and $2.5 \mathrm{wt} \%$ Au.[92] He studied wetting and tensile properties; performed bend, compression, and single lap shear joint tests; and attempted to discover if the increase in Au concentration resulted in a change in the thermal expansion coefficient of the material. No dramatically detrimental changes in the wetting or physical properties were found up to $1 \mathrm{wt} \% \mathrm{Au}$, and the ductility and toughness of the material improved up to 2.5 wt\% Au. This increase in ductility resulted in the theory that the strain sensitivity of the material increased as a result of the fine dispersion of Au compounds throughout the matrix. Peak joint strengths tended to fall around $1 \mathrm{wt} \% \mathrm{All}$, with a slight loss in strength showing at elevated temperatures with Au specimen concentrations greater than 1 wt\%. Shear joint stress deflection curves showed that the material was tougher and more ductile up to $2.5 \mathrm{wt} \% \mathrm{Au}$, indicating that Au additions up to this concentration, solidified in a reasonable time, should not embrittle the solder joints. To deternine temperature effects on the material with and without $\mathrm{Au}$, the 
thermal expansions of specimens of eutectic $\mathrm{Sn} / \mathrm{Pb}$ and eutectic $\mathrm{Sn} / \mathrm{Pb}$ containing $0.4 \mathrm{wt} \%$ Au were measured and found to be similar.

Becker observed that less than $5 \mathrm{wt} \%$ Au increased the pull strength of specimens considerably. [9] He found both strength and ductility of less than 4 wt\% Au specimens to be better than any concentration of $\mathrm{Cu}$ in $60 \mathrm{Sn} / 40 \mathrm{~Pb}$ solder. Interestingly, all joints he tested were rejected on the standard inspection basis of "not acceptable surface appearance" where bright to semi-bright was considered acceptable. This rejection of joints that performed well shows the inadequacy of the surface appearance inspection requirement. Karnowsky has been quoted as finding greater than $7.5 \mathrm{wt} \% \mathrm{Au}$ in tension to be brittle.[77]

Most authors agreed with Bester's recommendation of $\leq 5$ wt\% Au in joints, while some lowered the recommendation to $\leq 4 \mathrm{wt} \%$ Au. $[21,27]$ These recommendations may or may not be appropriate as the cooling rates experienced by today's SMT' (surface mount technology) joints are faster than those seen by earlier researchers. This is likely because today's joints are much smaller than those tested previously. The faster cooling rate results in a much finer size of evenly distributed $\mathrm{AuSn}_{4}$ intermetallics as well as a finer, equiaxed grain structure.[64] Evans, et al., asserted that it is not the absolute value of the Au concentration but its distribution within the joint that can significantly affect joint strength.[24] A thick iniermetallic layer along the interface is considered to be more critical than the same amount distributed evenly in the bulk of the joint. $[3,11,68]$ In O'Clock, et al.'s experiments no reliability problems were observed, even with two rework cycles to coarsen the intermetallics.[68] Keeping this in mind, various researchers recommend designing the joint such that the interconnect material can easily handle the observed stresses.[2, 3, 14, 97]

One of the best and the worst properties of Au is its extremely rapid dissolution rate into $\mathrm{Sn} / \mathrm{Pb}$ eutectic and near-eutectic alloys. $[1,5,19,42,44,78,82]$ A beneficial result is that $\mathrm{Ni}$ and $\mathrm{Sn}$ form a cohesive wetting layer while a detrimental result is the formation of 
$\mathrm{AuSn}_{4}$ intermetallics. Too thick a layer of plated Au may result in the formation of a continuous layer of AuSn4.[19,77] Walker, et al., found that Au undergoes solid state diffusion and reacts significantly with $60 \mathrm{Sn} / 40 \mathrm{~Pb}$ at $150^{\circ} \mathrm{C}$, below the melting temperature of that alloy.[91] Au disperses immediately into the solder, before melting, while Ni and $\mathrm{Cu}$ tended to form continuous layers of intermetallics at the interfaces upon melting, resulting in high stress regions in the joints in the interfacial areas. De-wetting may occur when the Au plated over the $\mathrm{Ni}$ is completely consumed at a low enough temperature.[91] Presumably after the $\mathrm{Au}$ is consumed by the solder, the $\mathrm{Ni}$ forms an oxide layer that causes de-wetting. Stephens, et al, also stated that there was a potential for solid state Au/Sn growth, at $\geq 60^{\circ} \mathrm{C}$.[77] Au has been found to diffuse interstitially in both $\mathrm{Sn}$ and $\mathrm{Pb} \cdot[22$, $23,43]$ Walker and DeHaven found that the initial stages of wetting control intermetallic formation, its dispersion in the $\mathrm{Sn} / \mathrm{Pb}$ alloy, and the alloy's wetting characteristics.[90]

\subsubsection{Microstructural Properties}

Foster found that $\mathrm{AuSn}_{4}$ intermetallics form in increasing amounts as the Aus content increases, resulting in a "coarsened" eutectic microstructure.[27] He felt that $\mathrm{AuSn}_{4}$ solidifies first and the rest of the joint forms around it. He concluded that the intermetallics provide a structure on which subsequent solidifying metal may adhere, thereby resulting in a rough surface. He also felt that the needle-like Au-rich constituent may result in porous joints; and that increasing amounts of Au form increasing amounts of intermetallics which in turm produce lines of weakness. These lines of weakness, presumably from stacking intermetallics end-to-end, may allow rapid crack propagation through the joint along the $\mathrm{Sn} / \mathrm{AuSn}_{4}$ interfaces. To produce sound joints between heavily plated componenis, he recommended that most of the Au in areas to be joined should be removed by abrasion, or by dissolving the $\mathrm{Au}$ in molten solder and removing the subsequently contaminated Au layer. This recommendation is currently in practice today with heavily Au plated leads. 
Bester postulated that $\mathrm{AuSn}_{2}$ forms first, changing to $\mathrm{AuSn}_{4}$ when a tin-rich balance is outained.[11] The remaining excess Au from the AuSn 2 goes into the melt to complete the formation of $\mathrm{AuSn}_{4}$. He believed a quench would preserve the AuSn2 phase, but he did not find that to be the case. The extent of formation of Au-solder intermetallics, as well as the concentration gradient of $\mathrm{Au}$, were found to be affected by the time and temperature of exposure and by agitation of the solder melt.

Marshall, et al., found cracking between undissolved $\mathrm{Au}$ and the $\mathrm{Sn} / \mathrm{Pb}$ joint.[60] Where the Au had completely dissolved it was shown that the alloy had bonded to the $\mathrm{Ni}$ and there were no such cracking problems. Metastable NiSn 3 was shown to decrease with increasing $\mathrm{Pb}$ content in the alloy, however, casting some doubt on the reliability performance of these joints.[38] Stephens, et al., found a detectable intermetallic phase with 1 wt\% Au.[77] Keller stated that various Au/Sn compounds could be responsible for dewetting and cause some of the pits and other discontinuities in the joints. [53] He claimed that Au has poor wetting qualities because of intermetallic formation. Keller observed that $\mathrm{AuSn}_{4}$ intermetallics disappeared during accelerated temperature aging and found $\mathrm{Au}$ in the $\mathrm{Cu}-\mathrm{Sn}$ intermetallic layer at the terminal interface. [51] He also found that only after long aging did the AuSn 4 grow sufficiently thick to become weak enough to fail instead of the solder. Duckett and Ackroyd performed dip soldering to form joints and found that entrapment of flux within the joints became a problem.[21] For specimens that had been Au-plated in an acid bath, voids were found at the solder/Au interface resulting from decomposition of organic compounds within the Au from addition of agents to the plating baih. Voids were observed by Ross and Lee in $15 \mathrm{wt} \%$ Au joints solòered at $250^{\circ} \mathrm{C}$, but not in joints soldered at $240^{\circ} \mathrm{C} .[72]$

Prince used thermal analysis, metallography, microhardness, and X-ray techniques to determine the Au-Sn-Pb system up to 38 wt\% Sn.[69] Karnowsky and Rosenzweig determined the entire ternary phase diagram as well as a number of pseudo-binary phase diagrams, including eutectic $\mathrm{Sn} / \mathrm{Pb}$ with $\mathrm{Au}$ shown in Figure 3, using DTA (differential 
thermal analysis).[50] Prince found the Au-Sn-Pb ternary eutectic to be at $3 \mathrm{wt} \% \mathrm{Au} / 64.5$ $w t \% \mathrm{Sn} / 32.5 \mathrm{wt} \% \mathrm{~Pb}$ at $177^{\circ} \mathrm{C}$, and stated that no Au-Pb phase occurs in soft-soldered joints to gold-plated surfaces.[69] He also found that four main solidification reactions take place. Initially AuSn forms from the $\mathrm{Sn}+\mathrm{Pb}+\mathrm{Au}$ melt. The AuSn then combines with the melt in a binary peritectic reaction to form $\mathrm{AuSn}_{2}$, and $\mathrm{Pb}+\mathrm{AuSn}_{2}$ formation takes place in a ternary quasi-peritectic reaction. As the temperature continues to decrease, $\mathrm{Pb}+\mathrm{AuSn}_{4}$ is formed at a second ternary quasi-peritectic reaction. This part of the solidification procedure is similar to what was postulated by Bester.[11] At this point the liquid deposits a mixture of $\mathrm{Pb}$ and $\mathrm{AuSn}_{4}$ until the ternary eutectic point is reached and $\mathrm{Pb}$ $+\mathrm{Sn}+\mathrm{AuSn}_{4}$ are deposited. Prince found that secondary AuSn 4 was larger than ternary AuSn, both of which were plate-like in form. [69] This slender platelet form of the ternary AuSn 4 seen in cross section during metallography gives the impression that the intermetallic is acicular in structure, as is quoted by other observers. [11,27]

The structure of the $\mathrm{Sn}$-rich phase in eutectic $\mathrm{Sn} / \mathrm{Pb}$ solder is tetragonal while that of the $\mathrm{Pb}$-rich phase is face centered cubic. Schubert, et al, found the AuSn 2 crystal structure to be orthorhombic with lattice parameter $a=6.909, b=7.037$, and $c=11.789 \pm 0.005 \AA$ at $180^{\circ} \mathrm{C}$, which results in a stacking variant of the $\mathrm{FeS}_{2}(\mathrm{C} 2)$ type.[73] Both and Schließer quote $\mathrm{AuSn}_{4}$ as having an orthorhombic structure with $\mathrm{a}=6.446 \AA, \mathrm{b}=6.484 \AA$, and $\mathrm{c}=$ $11.599 \AA . .[12]$

\subsubsection{Viscosity}

There have been a number of investigations into the viscosity of $\mathrm{Sn} / \mathrm{Pb}$ alloys using an oscillating-cup viscometer.[16 - 18, 26, 48,49] The majority of this work took place at the Canada Department of Energy, Mines, and Resources, Mines Branch, Ottawa, in the Physical Metallurgy Division. Detailed descriptions of the viscometer are included in a number of the papers. $[26,49,81]$ Reseitrchers at Fry have also performed some viscosity measurements on $\mathrm{Sn} / \mathrm{Pb}$ alloys using an oscillating bob immersed in the molten alloy.[32] Unfortunately there appears to be a lack of investigations into the viscosity of the ternary 
$\mathrm{Au}-\mathrm{Sn} / \mathrm{Pb}$ alloys, however, increased sluggishness of the solder with increasing $\mathrm{Au}$ content has been reported by some authors, while others have stated that "it is known" that the viscosity increases with increasing Au content.[40, 42, 92]

\subsection{Surface Mount Work Envirorment}

Shear loading is the predominart cause of failure in surface mount electronics joints. A surface mount joint undergoes shear loading as a result of different thermal expansion coefficients of: 1) the PCB, 2) the chip carrier, 3) if leaded the chip carrier lead, and 4) the solder itself. $[19,20]$ As shown in Figure 4, these different expansions lead to a shear load on the joint, cycling one way on heating (turning on the device) and the opposite way with cooling (turning off the device). While leaded chip carriers have the disadvantage of yet another expansion possibility, i.e., the lead itself, they have the advantage that the compliance of the lead is greater than that of the solder, resulting in the lead taking up much of the strain. Leadless chip carriers do not have this advantage and thus the solder, the "softest" link in the connection, reacts the most to the applied stresses. In addition to shear from thermal reactions, the boards in a computer may undergo vibration and possible shock loading during transportation and setup operations. In addition the environment for some applications, such as in aircraft, involve vibration during service. In these cases, the most compliant portion of the joint is again either the lead, if leaded, or the solder, if leadless. The reliability tests performed in this study represent the leaded chip carrier case while the experimental joints tested in creep represent the more severe leadless chip carrier case.

\subsection{Creep}

Although the list of mechanical properties of $\mathrm{Au}$ in $\mathrm{Sn} / \mathrm{Pb}$ solder tested over the years is impressive, i.e., UTS [11], bend strength [11, 27], hardness [40], shear strength $[11,13,27,96]$, peel strength $[9,11,21,24,25,37,51,53,72]$, wettability $[10,13,40$,

$42,53,66,83,92]$, impact strength [11], thermal cycling [24, 34], torque [24], shock $[24,34]$, and vibration $[24,34]$, data on isothermal creep properties is lacking. This lack 
of creep test information is disturbing, since creep is the major deformation mechanism at room temperature and above for the eutectic and near-eutectic $\mathrm{Sn} / \mathrm{Pb}$ alloys, as these temperatures are greater than half the absolute melting temperature of such alloys $\left(T_{m}=\right.$

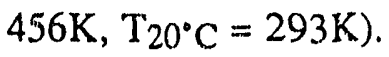

The simplest form of the hear creep equation is

$$
\dot{\gamma}=\mathrm{K} \tau^{\mathrm{n}}
$$

where $\dot{\gamma}$ is the steady state shear strain rate, $K$ is a constant at a given temperature, $\tau$ is the shear stress, and $n$ is the shear stress exponent (Figure 5). [89] The $n$ value is important because it indicates the mode of deformation of the material. For example, $n=1$ is Newtonian viscous flow, $n=2$ is superplastic creep with the mechanism of grain boundary sliding, and $n \geq 3$ is bulk creep, which takes place with dislocation mechanisms. The $n$ value may be obtained from a plot of $\ln \dot{\gamma}$ vs. $\ln \tau$ at a single temperature.

\subsection{Superplasticity}

One of the advantages of eutectic and near-eutectic $\mathrm{Sn} / \mathrm{Pb}$ alloys widely used in the electronics industry today is their tendency toward superplasticity at moderate strain rates. Current theories of superplasticity involve grain boundary sliding. For grain boundaries to slide without loss of coherency and cavitation, the grains themselves must rotate and/or deform in some way. The theories on how this deformation takes place range from different types of diffusion to slip.[15, 33, 35, 41,74] None of the models can accurately predict whether or not a material will be superplastic in nature, however some general features have been noted. General microstructural features observed in superplastic alloys include: 1) a fine grain size ( $\leq 10 \mu \mathrm{m}) ; 2)$ an equiaxed microstructure; and 3) a) a dual phase "eutectic" microstructure, or b) a microstructure with a fine dispersion of precipitates that i) stabilize the grain size, presumably by pinning grain boundaries, or ii) result in recrystallization. It has been found that the fast-solidified eutectic and near-eutectic $\mathrm{Sn} / \mathrm{Pb}$

allcys with a fairly equiaxed microstructure exhibit superplastic creep at certain 
iemperatures and strain rates. $[63,64]$ These microstructures have been shown to exhibit longer fatigue lives than lamellar, non-superplastic microstructures. [65] 


\subsection{Experimental Procedure}

\subsection{Introduction}

Three series of tests were planned. The firist two sets of tests involved vibration and shock testing, and thermal cycling, while the third set of tests involved creep testing. The first two sets of tests, i.e., reliability testing, were performed to compare the behavior of SMT joints on $\mathrm{Cu}-\mathrm{Ni}$-Au plating to the behavior of joints on SMOBC. These tests were performed while the author was working as a SEED (Student Educational Employment Development) employee at Hewlett-Packard under a proprietary agreement. The creep testing was planned both to compare Au-free and Au-containing joint behavior and to see if there was any correlation between the creep behavior of the joints and the reliability behavior of the joints. These tests were performed after the author returned to LBL/UCB. The planned tests allowed comparison to the relatively well known eutectic $\mathrm{Sn} / \mathrm{Pb}$ system.

\subsection{Materials and Processing}

\subsubsection{Surface Mount}

\subsubsection{Materials}

Two different FR-4 printed circuit board thicknesses were used: $0.8 \mathrm{~mm}(0.031 \mathrm{in})$ for vibration testing, and $1.6 \mathrm{~mm}(0.063 \mathrm{in})$ for thermal cycling. In addition to the two different board thicknesses and land pattern designs used for shock/vibration and thermal cycling, the thermal cycling boards contained two patterned $\mathrm{Cu}$ inner layers in the FR-4. Individual specimens consisted of a leaded chip carrier plus all the joints connecting the carrier leads to the board. Both the shock/vibration and the thermal cycling board land patterns had a daisy chain configuration that linked with a daisy chain configuration within the chip so that complete failure of one joint or lead would show as an open circuit on the controlling computer (Figure 6). The chip carriers used were fine pitch $0.65 \mathrm{~mm}(0.0256$ in) EIAJ (Electronic Industry Associates of Japan) standard 160-pin MQFPs (Metric plastic Quad Flat Packs). The lead-frames of the carriers used for shock and vibration testing were $\mathrm{Cu}$, while those used for thermal cycling were Alloy $42(\mathrm{Fe} / 42 \mathrm{Ni})$. Nominal $\mathrm{Au}$ 
plating thicknesses were $0,0.13,0.25,0.5$, and $1.3 \mu \mathrm{m}(0,5,10,20$, and $50 \mu \mathrm{in}$, respectively). Actual Au thicknesses were measured at the same locations on each board using $X$-ray fluorescence, inherently a very precise method of measurement.[95] Electrolytic Au plating thickness is a sensitive function of current density, however, and may vary greatly across the board. The control boards were SMOBC with HAL solder processing. The solder paste composition was $63 \mathrm{Sn} / 37 \mathrm{~Pb}(\mathrm{wt} \%)$ with a metal content of $90.3 \mathrm{wt} \%$ (52 vol\%) and an RMA (mildly activated rosin) flux. The pad geometries were $2.5 \mathrm{~mm} \times 0.4 \mathrm{~mm}(0.100 \mathrm{in} \times 0.015 \mathrm{in})$. The solder volumes per contact pad, determined from the pattern etched through the pasie stencil, were $0.14 \mathrm{~mm}^{3}\left(8700 \mathrm{mils}^{3}\right)$ for shock and vibration and $0.08 \mathrm{~mm}^{3}\left(5000 \mathrm{mils}^{3}\right)$ for thermal cycling.

\subsubsection{Processing}

Both board types were built using standard surface mount assembly processes.[54, 58] The process consisted of five steps. First, eutectic solder paste was applied with an automated paste machine using a metal stencil (Figure 7). Paste was put along one edge of the stencil panel then a squeegee swept the paste across the stencil, pushing paste through the holes etched in the stencil onto the land pattern of the board beneath. Second, after the board was pasted it was both visually checked and put into an X-ray laminography machine with a resolution of 2 mils to check the integrity of the paste, i.e., did the paste end up on the pads or halfway off the pads, was too much paste pushed through the stencil onto the pads causing shorts, etc. $[6,62,71]$ Third, after a board passed paste inspection it was placed into a high-precision automated placement ("pick and place") machine, which placed the test chip carriers in the proper configuration, i.e., with the leads on the proper pads. Fourth, the paste joints were reflowed in an IR (infrared) oven. The thermal profile used had a dwell of 2 minutes between 130 and $160^{\circ} \mathrm{C}$ to vaporize the organic solvents in the solder paste, approximately 100 seconds above the $183^{\circ} \mathrm{C}$ liquidus temperature for the eutectic solder to ensure full melting of the paste, and an average cooling rate from the peak temperature of approximately $220^{\circ} \mathrm{C}$ to $100^{\circ} \mathrm{C}$ of $0.5^{\circ} \mathrm{C} / \mathrm{sec}$ for the vibration test board and 
$0.8^{\circ} \mathrm{C} / \mathrm{sec}$ for the thermal cycling test board. The actual profiles were measured by thermocouples attached to test boards that were run through the IR oven. Last, after the boards were reflowed and had cooled, the joints were visually inspected for opens and for shorts. Shorted joints were reworked by hand by Dr. J. Glazer using a soldering iron and solder wick. To test the reliability of reworked joints, representative boards were sent through the IR oven a second time to simulate rework, with a mean temperature of $170^{\circ} \mathrm{C}$ and hold time of 2 minutes. It was also desired to test the vibrational reliability properties of thermally aged joints, so some specimens were aged for 3 days at $110^{\circ} \mathrm{C}$. Some thermal cycling reliability specimens were also aged at this time and temperature for comparison to the tested thermal cycling joints.

The difference in the solder paste volumes, as well as differences in the actual $\mathrm{Au}$ plating thicknesses, resulted in differences in the Au concentrations found for the same nominal metallizations on the vibration and the thermal cycling boards. Au concentrations, shown below in Tables 1 and 2, are based on the range of measured Au thicknesses. Both the Au thickness and the solder volume, however, will vary in practice, leading to a distribution of Au concentrations in the joints. As a result of differences in current density associated with the location on the panel and flight bar and circuit feature density, the electrolytic Au plating thickness on a board, or even a single land pattern, is not uniform. For typical electrolytically plated PCBs, a nominal Au thickness of $0.13 \mu \mathrm{m}$ (5 $\mu$ in) corresponds to an Au thickness range of $0.08-0.18 \mu \mathrm{m}(3-7 \mu \mathrm{in})$ with a mean of $0.10-$ $0.11 \mu \mathrm{m}(4-4.5 \mu \mathrm{in}) .[34]$ The assumptions used in calculating the Au concentrations are: 1) the solder volume is $50 \%$ of the paste volume, 2) all the Au on the pad is dissolved into the joint, and 3) the Au thickness on the pad is the measured mean Au thickness. These assumptions are fairly conservative since the paste did not flow to fully cover the plating, all of the Au on the pad did not actually dissolve into the joint. The average concentration is shown with the range of Au concentrations possible in brackets. Au concentration 
values have been rounded to the nearest $0.1 \mathrm{wt} \%$ and Au thickness values are quoted to the nearest $0.01 \mu \mathrm{m}(0.5 \mu \mathrm{in})$.

\section{Table 1}

Vibration reliability joints nominal and measured Au thicknesses, and Au concentrations. Au concentrations, shown as an average and as a range, are calculated from measured Au thicknesses and known solder paste volume.

\begin{tabular}{lcccc}
\hline Nominal $\mu \mathrm{m}(\mu \mathrm{in})$ & $0.13(5)$ & $0.25(10)$ & $0.51(20)$ & $1.27(50)$ \\
Measured $\mu \mathrm{m}(\mu \mathrm{in})$ & $0.16(7)$ & $0.32(13.5)$ & $0.48(19.5)$ & $1.63(71.5)$ \\
Concentration wt\% & $0.5[0.5-0.6] 1.0[0.9-1.3]$ & $1.5[1.3-2.0]$ & $4.8[4.2-6.6]$ \\
\hline
\end{tabular}

Table 2

Thermal cycling reliability joints nominal and measured Au thicknesses, and Au concentrations. Au concentrations, shown as an average and as a range, are calculated from measured Au thicknesses and known solder paste volume.

\begin{tabular}{lcccc}
\hline Nominal $\mu \mathrm{m}(\mu \mathrm{in})$ & $0.13(5)$ & $0.25(10)$ & $0.51(20)$ & $1.27(50)$ \\
Measured $\mu \mathrm{m}(\mu \mathrm{in})$ & $0.10(4)$ & $0.34(13.5)$ & $0.51(20)$ & $1.83(72)$ \\
Concentration wi\% & 0.5 & $1.8[1.5-2.1]$ & $2.7[2.3-3.0]$ & $9.0[7.9-10.5]$ \\
\hline
\end{tabular}

\section{2 .2 Creep}

\subsubsection{Materials}

The outer pieces of the double shear specimens were designed as part of the themal cycling boards. These pieces, at one end of the thermal cycling board, were not pasted during the thermal cycling build and were removed from the built boards after reflow. Additional specimens were removed from unused boards as needed. The double shear specimens consist of three pieces: two outer pieces $1.6 \mathrm{~mm}(0.063 \mathrm{in})$ thick and one inner piese $3.2 \mathrm{~mm}$ (0.125 in) thick (Figure 8). The epoxy fiberglass inner piece was made using a standard process at the LBL Plaring Shop. $[54,58]$ A Cu foil layer $19 \mu \mathrm{m}(0.75$ 
mils) thick was glued onto the epoxy; a photoresist was applied; $60 \mathrm{Sn} / 40 \mathrm{~Pb}$ wt\% was electroplated onto the areas that were not covered with the photoresist; and the remaining unplated $\mathrm{Cu}$ foil was etched off in a pattern of 9 rectangles of pad size $1.78 \mathrm{~mm} \times 0.76 \mathrm{~mm}$ ( 0.070 in $\times 0.030$ in). The solder paste composition used to build the specimens was $63 \mathrm{Sn} / 37 \mathrm{~Pb} w t \%$ with a metal content of $90 \mathrm{wt} \%$ (52 vol\%) with an RMA (mildly activated rosin) flux of $10 \mathrm{wt} \%$ (48 vol\%) specified to leave approximately $3 \mathrm{wt} \%$ waste solids.

\subsubsection{Processing}

All creep specimens were built in the following manner using a pneumatic solder paste dispenser and a programmable convection oven. 1) The majority of the electroplated $60 \mathrm{Sn} / 40 \mathrm{~Pb}$ coating was wicked off of the $3.18 \mathrm{~mm}(0.125 \mathrm{in})$ coupons using a soldering iron and solder wick. 2) The inside pads of a $1.6 \mathrm{~mm}(0.063 \mathrm{in})$ coupon were coated with a comparable amount of solder paste on each pad. 3) Drill bits were inserted in the alignment holes above and below the pad area. 4) $127 \mu \mathrm{m}$ (5 mil) spacers were placed between the rows and around the array of pasted pads. The desired joint thickness was $100 \mu \mathrm{m}$ ( 4 mils) and the total plating height from both the outer and inner coupons before pasting was $25 \mu \mathrm{m}$ (1 mil). 5) A $3.2 \mathrm{~mm}$ (0.125 in) coupon was pasted and slipped onto the drill bits with the pasted side facing up (non-pasted side therefore resting on the pasted side of the outer coupon). 6) Spacers were placed as in item if. 7) A second $1.6 \mathrm{~mm}$ (0.063 in) coupon was slipped onto the drill bits. 8) The assemily was clamped from each side over the pad area using two bulldog clips. 9) The alignment drill bits were removed. 10) The specimens were reflowed in a programmable convection oven.

The thermal profile was measured for three separate reflow batches using a thermocouple inserted into the middle drill hole of three similar specimens. The 0 and 0.13 $\mu \mathrm{m}(0$ and $5 \mu \mathrm{in})$ specimens had of a dwell of 4 minutes between $130^{\circ} \mathrm{C}$ and $160^{\circ} \mathrm{C}$ to vaporize the organic solvents in the solder paste, and were above the $183^{\circ} \mathrm{C}$ liquidus temperature for the eutectic alloy for approximately 6 minutes. The average cooling rate between the peak temperature, approximately $220^{\circ} \mathrm{C}$, and $20^{\circ} \mathrm{C}$ was measured to be 
$0.4^{\circ} \mathrm{C} / \mathrm{sec}$. The thermal profile used for the $0.25,0.5$, and $1.3 \mu \mathrm{m}(10,20$, and $50 \mu$ in) creep specimens was altered with the intent of reducing the observed increase in void concentration with increasing Au concentration. The revised thermal profile added dwell times of $5 \mathrm{~min}$ at both 100 and $185^{\circ} \mathrm{C}$. The average cooling rate remained the same as for the 0 and $0.13 \mu \mathrm{m}$ Au specimens. The spacers were removed before creep testing.

It should be noted that the different reflow parameters resulted in different nominal joint thicknesses, which were determined by cross-sectional mounts. The 0 and $0.13 \mu \mathrm{m}$ (0 and $5 \mu$ in) specimens had nominal joint thicknesses of $100 \mu \mathrm{m}(4 \mathrm{mils})$ while the increased time at elevated temperature for the $0.25,0.5$, and $1.3 \mu \mathrm{m}(10,20$, and $50 \mu \mathrm{in})$ specimens produced a nominal joint thickness of $76 \mu \mathrm{m}(3 \mathrm{mil})$. This difference resulted from the spacers sinking more deeply into the solder mask coating on the specimens because of the greater time at elevated temperatures than in the initial thermal profile. Within the 18 pads on one joint, joint thicknesses varied as much as $\pm 13 \mu \mathrm{m}(0.5 \mathrm{mil})$. The nominal Au concentrations calculated, based on the nominal joint thicknesses observed and the measured Au thicknesses, are shown in Table 3. The range of Au concentrations shown is based on the actual range of Au thicknesses measured and the possible joint variation of $\pm 13 \mu \mathrm{m}(0.5 \mathrm{mil})$.

Table 3

Double shear creep specimen nominal and measured Au thicknesses, and Au joint concentrations. Au concentrations, shown as an average and as a range, are calculated from measured Au thicknesses and observed nominal joint thicknesses.

Nominal $\mu \mathrm{m}(\mu \mathrm{in}) \quad 0.13(5) \quad 0.25(10) \quad 0.51(20) \quad 1.27(50)$

Measured $\mu \mathrm{m}(\mu \mathrm{in}) \quad 0.10(4) \quad 0.34(13.5) \quad 0.51(20) \quad 1.83(72)$

Concentration wt\% $0.2[0.2-0.3] 1.0[0.7-1.5] 1.5[1.1-2.0] \quad 5.3[4.0-7.5]$ 


\subsection{Testing}

\subsubsection{Shock and Vibration}

Shock and vibration reliability testing was performed at room temperature. Mechanical shock tests involved: 1) an out-of-plane displacement orientation perpendicular to the board base, 2) an amplitude of $7 \mathrm{~m} / \mathrm{sec}(275 \mathrm{in} / \mathrm{sec})$ at $425 \mathrm{~g}$ with a $3.6 \mathrm{msec}$ pulse length, and 3) a cycle of 3 drops. The mechanical vibration tests used: 1) an out-of-plane orientation perpendicular to the board base with an amplitude of $10 \mathrm{~g}$, and 2) a cycle of 30 hours with a $60-90 \mathrm{~Hz}$ frequency swept sine wave that resonated the sample boards, resulting in greater flexion. The vibration resulted in a flexion of the specimen boards to an angle of approximately $\pm 30^{\circ}$ from the clamped area at the edge of the test boards to the center of the chip carrier (Figure 9). Some of the specimens were mechanically shocked before the vibration tests while others were tested only in vibration.

\subsubsection{Thermal Cycling}

Thermal cycling of the built boards from 0 to $110^{\circ} \mathrm{C}$ was performed in a convection oven. The stress on the specimen joints on the board arose from the difference in the thermal expansion coefficients of: the board, the chip carrier, the solder, and the plating on the board. The minimum specimen temperature variation of any one specimen on the board was from 5 to $105^{\circ} \mathrm{C}$. All boards were constantly monitored throughout the testing by thermocouples and a multi-channel chart recorder. The boards heated at a rate of $-5.2^{\circ} \mathrm{C} / \mathrm{min}$ and cooled at a rate of $-3.3^{\circ} \mathrm{C} / \mathrm{min}$. The thermal cycle time was 83 minutes, with a minimum dwell time of 6 minutes at each temperature extreme of 0 and $110^{\circ} \mathrm{C}$. The objective was to simulate a lifetime of 10 years, requiring a minimum of 1100 thermal cycles. The test was allowed to run well beyond this specification to 1450 thermal cycles. Specimens were removed from the tested boards for microstructural comparison at 0,218 or 275,784 , and 1450 thermal cycles. The rework-simulated rested microstructures were compared to the as-reflowed tested microstructures and to the untested microstructures. 


\section{3 .3 Creep}

The double shear specimen and the creep test device are schematically illustrated in Figure 8. During testing the specimen is held by frictional grips consisting of two steel plates with ridged surfaces. The specimen test area is prevented from experiencing compression in two ways: 1) an Al spacer the width of the center coupon plus the two sets of joints is placed between the outer coupons, and 2) grip placement is around the area containing the Al spacer rather than over the pad area itself. Figure 8 shows that the bottom grip is joined to the compression stand base by means of a pin while the top grip is attached to a pull-rod in the same manner. The top end of the pull-rod is attached to a weight pan that transmits a load to the specimen via a steel wire and pulleys. The displacement of the top grip is monitored with a LVDT (linear variable differential transformer) that has a sensitivity of $9.63 \mathrm{mV}$ output / $5 \mathrm{~V}$ excitation / $25.4 \mu \mathrm{m}$ (1 mil) displacement. The output voltage signal is amplified and then recorded by a PC (personal computer) through a 12 bit analog-to-digital converter. The creep machine system has a displacement resolution of at least $1 \mu \mathrm{m}(0.39 \mathrm{mils})$. Testing temperatures are achieved by immersing the specimens in a silicone oil bath that is controllable to less than $\pm 1^{\circ} \mathrm{C}$. [65] The assembly was allowed to equilibrate at the desired temperature before testing.

Table 4

Test matrix of double shear creep specimen tests. The matrix shows the temperatures at which each Au concentration specimen was tested for each shear stress.

\begin{tabular}{|c|c|c|c|c|c|c|c|c|c|}
\hline $\begin{array}{l}\tau(\mathrm{psi}): \\
\text { (Test T) }\end{array}$ & $\begin{array}{l}2678 \\
\left({ }^{\circ} \mathrm{C}\right)\end{array}$ & $\begin{array}{l}1984 \\
\left({ }^{\circ} \mathrm{C}\right)\end{array}$ & $\begin{array}{l}1746 \\
\left({ }^{\circ} \mathrm{C}\right)\end{array}$ & $\begin{array}{l}1561 \\
\left({ }^{\circ} \mathrm{C}\right)\end{array}$ & $\begin{array}{l}1164 \\
\left({ }^{\circ} \mathrm{C}\right)\end{array}$ & $\begin{array}{l}767 \\
\left({ }^{\circ} \mathrm{C}\right)\end{array}$ & $\begin{array}{l}503 \\
\left({ }^{\circ} \mathrm{C}\right)\end{array}$ & $\begin{array}{l}344 \\
\left({ }^{\circ} \mathrm{C}\right)\end{array}$ & $\begin{array}{l}238 \\
\left({ }^{\circ} \mathrm{C}\right)\end{array}$ \\
\hline $\begin{array}{c}\text { Specimen } \\
(w t \% A u) \\
0\end{array}$ & 90 & & 90,65 & 20 & 90,65 & $90,65,20$ & $90,65,20$ & 90,65 & 90,65 \\
\hline 0.13 & 90,20 & 20 & $90,65,20$ & & 90,65 & 90,65 & 90,65 & 90,65 & 90,65 \\
\hline 1.0 & & & 90,65 & & 90,65 & 90,65 & 90,65 & 90,65 & 90,65 \\
\hline 1.5 & & & 90 & & 90 & 90 & 90 & 90 & 90 \\
\hline
\end{tabular}


The array of creep tests performed is shown in Table 4. 0 and $0.2 \mathrm{wt} \% \mathrm{Au}$ specimens were tested at $90^{\circ} \mathrm{C}$ at shear stresses of $2678,1746,1164,767,503,344$, and $238 \mathrm{psi}$. $1.0 \mathrm{wt} \%$ and $1.5 \mathrm{wt} \%$ Au specimens were tested at this temperature with shear stresses of $1746,1164,767,503,344$, and $238 \mathrm{psi}$. $0,0.2$, and $1.0 \mathrm{wt} \%$ Au specimens were tested at these six stresses at $65^{\circ} \mathrm{C}$. At $20^{\circ} \mathrm{C}, 0 \mathrm{wt} \%$ Au specimens were tested at shear stresses of 1561,767 , and 503 psi while $0.2 \mathrm{wt} \%$ Au specimens were tested at shear stresses of 2678,1984 , and 1746 psi.

Approximately half of the specimens were tested at a single shear stress while the other half were tested at more than one shear stress. Before the load was changed the specimen was allowed to relax for a few seconds. Generally, a maximum of three different loads were applied to a single specimen. The $1.3 \mu \mathrm{m}(50 \mu \mathrm{in}) \mathrm{Au}$ specimens were considered untestable, even with the revised build profile. As a result of the high concentration and large size of the voids present, the outer coupons had a tendency to snap off either on removal of the build spacers or on insertion of the Al test spacer. Void concentration and size were determined by viewing both the snapped joints and crosssectioned, polished joints. It was common for the outer coupons to curve slightly inward during reflow, resulting in a slight tensile load on the joints on initial insertion of the $\mathrm{Al}$ spacer before the specimen grips were tightened down. It should be noted that the stress levels given above are actually nominal values, calculated on the assumptions of no void formation and a solder cross sectional area matching that of the metallizations. For example, an 18 pad specimen would be considered to have a cross-sectional area of $18 *(0.030 \mathrm{in})(0.070 \mathrm{in})=0.0378 \mathrm{in}^{2}$, with the stress equal to the applied load divided by this cross-sectional area.

\subsection{Metallography}

Representative samples were cross-sectioned by a diamond wafering blade and cold mounted in epoxy. More than one solder joint of each condition was mounted to observe possible joint-to-joint microstructural variation. The mounted joints were 
metallographically prepared by light grinding and polishing. The final polish used was Mastermet $^{\mathrm{TM}}$, a colloidal silica polishing suspension which very lightly etches the microstructure. A few of the specimens were subsequently etched using a solution of 25 $\mathrm{ml}$ distilled $\mathrm{H}_{2} \mathrm{O}, 5 \mathrm{ml} \mathrm{HCl}$ (37\% concentration), and $5 \mathrm{~g} \mathrm{NH}_{4} \mathrm{NO}_{3}$. This chemical etch shows the $\mathrm{Sn}$ grain boundaries in addition to providing additional contrast between the $\mathrm{Sn}$ rich and $\mathrm{Pb}$-rich phases. Specimens were optically observed immediately after final polish or final polish plus chemical etch to lower the possibility of surface relaxation changing the appearance of the microstructure. 


\subsection{Results}

\subsection{Shock and Vibration}

No failures were observed in either the joints or the leads after shock testing. Only four of the 240 samples tested in vibration failed. All failures took place in the leads at the top of the solder joint rather than through the solder joint itself. Half of the failed samples had been mechanically shocked before being tested in vibration.

\subsection{Thermal Cycling}

None of the samples had failed when the test was stopped after 1450 thermal cycles.

\subsection{Creep}

Creep curves are shown in Figures 10 through 12. Both single stress and multiple stress test data was shifted to the origin for comparison by subtracting a constant from time and voltage. This shifting does not affect slope determination. Agreement between the single stress tests and the multiple stress tests was good. The portions of multiple-stress tests shown are evident by their lack of tertiary creep except for the lowest stress tested, which in most cases was stopped before tertiary creep was reached. The large amount of noise present in some of the longer tests, e.g., $1.0 \mathrm{wt} \%$ Au specimens tested at $90^{\circ} \mathrm{C}$ and $65^{\circ} \mathrm{C}$ at shear stresses of 238,357 , and 503 psi, was a result of water condensing on the micrometer brass end that the LVDT tip rested on. The slopes obtained from these curves were considered valid on the assumption that the noise averaged out over time.

The plots of log shear strain rate versus $\log$ shear stress for eutectic $\mathrm{Sn} / \mathrm{Pb}$ joints without Au show agreement with previous studies.[63,65] The change in slope from bulk creep, i.e., $n \approx 4$, to superplastic creep, i.e., $n \approx 2$, is clearly visible in both the $65^{\circ} \mathrm{C}$ and the $90^{\circ} \mathrm{C}$ plots in Figures 13 and 14. This change to superplastic creep at lower strain rates was not observed in any of the tested Au metallizations, which displayed characteristic bulk creep slopes of $n$ between 4 and 6 . 


\subsection{Untested Microstructures}

Figure 15 shows labeled reliability joint components and microstructural aspects that may be present in both the reliability and the creep joints. Representative untested asreflowed microstructures for the range of Au concentrations and different initial conditions, i.e., as-reflowed, rework-simulated, and aged, are shown in Figures 16 through 20. As expected, both $\mathrm{AuSn}_{4}$ intermetallics and $\mathrm{Pb}$-rich pro-eutectic phase were evident in increasing amounts with increasing Au concentration in both the reliability joints and the creep joints. A large jump in the visible $\mathrm{AuSn}_{4}$ is evident between the $0.51 \mu \mathrm{m}$ (20 $\left.\mu \mathrm{in}\right)$ and the $1.3 \mu \mathrm{m}(50 \mu \mathrm{in})$ Au metallization joints of all types.

Reflowed vibration and thermal cycling joints are shown at two different magnifications to illustrate the microstructural variations possible within a joint. Reworksimulated, i.e., 2 minutes at $170^{\circ} \mathrm{C}$, and aged, i.e., 3 days at $110^{\circ} \mathrm{C}$, reliability joint microstructures are shown in Figures 21 through 24. Both the eutectic microstructure and the intermetallics were observed to coarsen from the as-soldered state, i.e., reflowed, to the rework-simulated state and also from the reflowed state to the aged state. The intermetallics in the highest Au concentration reliability joints coarsened much more dramatically during the rework cycle than during the lower temperature aging process. In addition, the intermetallics in both of the heat-treated conditions changed orientation from their initial solidification positions of generally vertical in orientation compared to the metallization base, to generally horizontal orientations compared to the metallization base. Overall, both the eutectic microstructure and the intermetallics observed were coarser in the thermal cycling joints than in the vibration joints. In general, the vibration joints displayed a fine dispersion of $\mathrm{AuSn}_{4}$ intermetallics while the thermal cycling joints contained shorter, thicker intermetallics grouped together side by side in long lines.

No coarsening in the eutectic phase was observed with increasing Au concentration in etched samples, except for the increase in Pb-rich phases in the highest Au concentration samples, but there was an increase in the size and numbers of voids observed with greater 
Au concentration. In addition, different intermetallics were present in the vibrational and thermal cycling joints. The vibration joints contained mostly the slender, ternary AuSn 4 while the thermal cycling joints contained mostly the larger, secondary AuSn 4 described by Prince in addition to square $\mathrm{Ni} / \mathrm{Sn}$ intermetallics. [69] Figure 25 shows an analysis of voids present in the creep joints, which tended to have more severe void concentrations than the as-reflowed reliability joints. Voids in the reliability joints tended to be under the heel and at the toe of the lead. Voids smaller than the creep specimen joint thickness tended to be in the body of the joint, while larger voids equal to the joint thickness tended to run along some length of the joint interior. Figure 26 shows a top view of some $5.3 \mathrm{wt} \%(50 \mu \mathrm{in})$ Au creep joints where the outer coupon was snapped off. Voids are indicated by arrows. Void coalescence and growth was observed on rework simulation in the reliability joints (Figure 27). Scanned beam X-ray laminography pictures of 4.8 wt $\%$ Au vibration reliability joints show the increase in the number of joints containing large voids in the rework simulated joints when compared to the reflowed joints (Figure 28).

\subsection{Tested Microstructures}

\subsubsection{Vibration Tested Joints}

Representative microstructures of vibration tested joints are shown in Figures 29 through 31. The $4.8 \mathrm{wt} \%$ Au vibration tested reliability joint AuSn 4 intermetallics exhibited a change in orientation at the toe of the joint from disorganized, mostly vertical orientations relative to the metallization base, i.e., appearing to follow the solidification front, to lines of shear angling up to $\pm 30^{\circ}$ around the horizontal (Figure 32).

Small cracks were observed in a number of the vibration tested samples. The cracks tended to form in the joint under the heel of the gull-wing lead initiating at Pb-rich phases at the surface of the joint and at the bends in the lead, running through the pretinning and blunting out in the lead itself. One crack was observed to initiate in a 4.8 wt\% Au joint at an $\mathrm{AuSn}_{4}$ intermetallic lying perpendicular to the surface of the joint under the heel in the high-stress area. Both this and other cracks observed in various joints 
followed $\mathrm{Sn} / \mathrm{Sn}$ grain boundaries between $\mathrm{Pb}$-rich phases rather than preferentially following any AuSn $4 / \mathrm{Sn}$ interfaces that were present.

\subsubsection{Thermally Cycled Joints}

Representative microstructures of thermal cycling joints tested 218 or 275,784 , and 1450 thermal cycles are shown in Figures 33 through 38 . Coarsening of the eutectic microstructure was observed on thermal cycling, with an increased amount of coarsening observed following an increased number of thermal cycles. Coarser initial microstu uctures were exhibited by the rework simulated joints compared to the as-reflowed joints, but after $218 / 275$ cycles, the microstructures of the as-reflowed tested joints and the reworksimulated tested joints were indistinguishable. The tested thermal cycling joints all surpassed the coarsening of the aged joints between 784 and 1450 cycles. Intermetallics coarsened and reduced in apparent volume with increasing numbers of cycles, agreeing with Keller's observation.[51]

\subsubsection{Creep Tested Joints}

Representative microstructures of creep joints tested at $90^{\circ} \mathrm{C}$ are shown in Figure 39. Tested creep joints show a breaking-up and coarsening of the microstructure at elevated temperatures. The $90^{\circ} \mathrm{C}$ test microstructures display a greater amount of overall coarsening than the $65^{\circ} \mathrm{C}$ microstructures while the $20^{\circ} \mathrm{C}$ test microstructures did not show appreciable coarsening. It was not possible to determine if the AuSn4 intermetallics changed orientation during creep testing, as their concentration was not large, and their distribution appeared random both before and after testing. In a specimen where some of the joints contained voids, cracks initiated and propagated through these before the voidfree joints in the specimen showed crack initiation. Crack initiation took place at both interior void surfaces and at the outside surface boundary of the joint. The cracks initiated at these surfaces at either $\mathrm{Sn}$-rich/Pb rich boundaries or within larger $\mathrm{Pb}$-rich phases and followed $\mathrm{Sn}$-rich/Sn-rich grain boundaries from $\mathrm{Po}$-rich island to $\mathrm{Pb}$-rich island rather than following $\mathrm{AuSn}_{4}$ intermetallics (Figure 40). The preferential propagation of the crack 
followed two methods. In smaller, equiaxed microstructural areas the crack propagated along $\mathrm{Sn}$-rich/Pb-rich phase boundaries; when a partial colony structure was present, the crack tended to follow the colony boundaries. In areas where the Pb-rich phases were large and globular the crack preferentially ran directly through these phases, or, similar to the smaller phases, along the Sn-rich/Pb-rich boundary. This preference was so strong that at times the crack deviated from a straight-line path to follow the Pb-rich phase.

The $0.2 \mathrm{wt} \% \mathrm{Au}$ specimens tested $90^{\circ} \mathrm{C}$ at a shear stress of 238 psi did not achieve steady state creep within the time they were tested. In addition, for $0 \mathrm{wt} \%$ and $1.5 \mathrm{wt} \% \mathrm{Au}$ specimens tested at $90^{\circ} \mathrm{C}$ at a shear stress of 2678 and 1746 psi, respectively, the tests proceeded too quickly for the data collection rate of 1 point per second for a reliable steady state strain rate to be obtained. 


\subsection{Discussion}

\subsection{Reliability Testing}

It is generally known that greater than $\sim 4 \mathrm{wt} \% \mathrm{Au}$ in $\mathrm{Sn} / \mathrm{Pb}$ specimens causes a dramatic decrease in tensile elongation and reduction in area properties.[11] Based on this, it was expected that the vibrational and thermal cycling properties of the highest $\mathrm{Au}$ concentrations would be worse than the Au-free and lower-Au concentration specimens, i.e., more failures were expected in the higher $\mathrm{Au}$ concentration specimens. Microstructural analyses were expected to confirm this by showing a greater percentage of cracking/larger cracks in the unfailed higher Au specimens. The reliability testing itself did not confirm these expectations, since none of the solder joints failed. It appears, in this study, that the ductility and volume fraction of the solder, combined with the presence of fairly ductile gull-wing leads, were sufficient to overcome the brittleness of the AuSn 4 intermetallics present in the joints.

\subsubsection{Vibration Testing}

In the toe region of vibration tested joints of $4.8 \mathrm{wt} \% \mathrm{Au}$ the $\mathrm{AuSn}_{4}$ intermetallics rotated, or changed orientation, from their initial solidification positions to align with the lines of shear in the joint. In this manner, i.e., after the rotation, the intermetallics provide minimum resistance to plastic deformation of the solder. In general, their solidification position in the as-reflowed joint, generally perpendicular to the metallization base, followed the direction of the solidification front. The rotation of the intermetallics appears to take place as hard sticks moving through a soft matrix. The additional rotation of the intermetallics observed in the $4.8 \mathrm{wt} \%$ Au vibration reliability joints on rework simulation and on aging indicates that the AuSn 4 intermetallics are highly mobile in the $\mathrm{Sn} / \mathrm{Pb}$ eutectic microstructure. This rotation ability could seriously affect crack propagation in high-Au concentration joints where the intermetallics might rotate to form a planar front for the crack to follow. This was not the case of the propagation of the crack in the heel of the $4.8 \mathrm{wt} \%$ $\mathrm{Au}$ joint, however, which followed that of the lower $\mathrm{Au}$ joints in moving from $\mathrm{Pb}$-rich 
phase to $\mathrm{Pb}$-rich phase along $\mathrm{Sn} / \mathrm{Sn}$ grain boundaries rather than specifically following a path from $\mathrm{AuSn}_{4}$ intermetallic to $\mathrm{AuSn}_{4}$ intermetallic. Wild observed this type of propagation in fatigued $\mathrm{Sn} / \mathrm{Pb}$ joints. [93] This tendency of a crack to not preferentially follow $\mathrm{AuSn}_{4} / \mathrm{Sn}$ interfaces suggests that these boundaries are stronger and more resistant to fracture than $\mathrm{Sn} / \mathrm{Sn}$ and/or $\mathrm{Pb} / \mathrm{Sn}$ boundaries. This supposition would best be tested using a void-free 4.0 or $5.0 \mathrm{wt} \%$ Au specimen in shear. These concentrations of Au have proven to form a high density of evenly spaced AuSn 4 ternary intermetallics when the specimen cools faster than or equal to $0.5^{\circ} \mathrm{C} / \mathrm{sec}$. The shear should result in a re-orientation of the intermetallics from their solidification positions to positions parallel to the crack direction.

\subsubsection{Thermal Cycling}

The size and composition of the intermetallics observed in the thermal cycling specimens were different than those in the vibration specimens. The Kovar lead-frame resulted in the presence of square $\mathrm{Ni} / \mathrm{Sn}$ intermetallics in addition to $\mathrm{Al} / \mathrm{Sn}$ intermetallics. The $\mathrm{Au} / \mathrm{Sn}$ intermetallics were comparatively coarser than in the vibration specimens as a result of the longer cooling time. It is possible that the additional intermetallics might act as crack nucleation sites and result in additional internal strain in the joint, but no cracking was seen in any of the tested specimens. It was observed that a higher percentage of the highAu thermal cycling joints, compared to the vibration joints, had large voids running under the center of the lead. These voids are most likely a result of the additional viscosity from the Alloy 42 leadframe, the higher, almost double, Au concentration, for the same nominal metallization thicknesses, allowing less outgassing, and the longer solidification time of the joints, allowing the voids more time to coalesce and grow. The eutectic $\mathrm{Sn} / \mathrm{Pb}$ microstructure coarsened on thermal cycling, showing an increase in the eutectic grain size with increasing thermal cycles. The reflowed joints exhibited intermetallic coarsening and a reduction in the concentration of $\mathrm{AuSn}_{4}$ intermetallics in the joint. The rework-simulated joints, which started the tests with coarser intermetallics than the reflowed joints, did not

Page 29 
exhibit as much intermetallic coarsening, but did exhibit the dissolution of the intermetallics. If the test had been allowed to continue, it is likely that the $\mathrm{AuSn}_{4}$ intermetallics would disappear, as observed by Keller.[51]

\subsection{Creep Testing}

The most interesting observation that arose from the creep tests was the removal of the superplasticity characteristic of eutectic and near-eutectic $\mathrm{Sn} / \mathrm{Pb}$ joints that contained $\mathrm{Au}$. It is generally believed that superplasticity requires a smail grain size of around $10 \mu \mathrm{m}$ (4 mils) or smaller and an equiaxed, stable microstructure. Both of these requirements are fulfilled by the rapid cooling rate experienced by surface mount solder joints, and were also observed in the varous double shear creep specimen joints. The removal of superplasticity could be a result of pinning of grain boundaries by the $\mathrm{AuSn}_{4}$ intermetallics present in the proeutectic microstructure of the Au-comaining joints. The 0.2 wt\% Au joints, however, do not have a very large distribution of intermetallics present to do this. The high percentage of voids present in the joints may also have had some effect both by increasing the local concentration of $A u$ in the remainder of the joint and by interfering with deformation of the surrounding matrix.

Creep testing was expected to reveal results similar to tensile results previously recorded, i.e., an increase in the shear strength of the joints up to -4 wt\% Au concentration and then a decrease at concentrations greater than 4 wi\% Au. $\{9,11,27\}$ An increase was observed in the relative shear strength of the creep specimens from 0 wt\% Au to 0.2 wt\% Au, but the 1.0 wt\% Au creep specimens showed relative strength results the same as the 0.2 wt\% Au specimens and the $1.5 \mathrm{wt} \%$ Au specimens actually decreased in relative strength compared to the other tested creep specimens. The highest Au concentration specimens of 5.3 wt\% Au were not tested at all, so it is unknown at this time what their relative strength would be. This increase then "early" decrease in the relative shear strengths of the creep joints, compared to tensile strength data, most likely results from the fact that the data was not normalized to account for the increased void content of the higher 
Au creep joints. In addition, very few of the specimens were tested to failure, so it was not possible to use final time to failure as a strength-determining mechanism.

It was also expected that $\mathrm{AuSn}_{4}$ intermetallic rotation might be a factor in crack propagation through the double shear specimen joints. This was expected because of the movement of the $\mathrm{AuSn}_{4}$ intermetallics in the $4.8 \mathrm{wt} \%$ Au joints tested in vibration. This was not found to be the case. It is unknown at this time if this would be a factor in a voidfree $5.3 \mathrm{wt} \%$ Au creep joint with a large, even distribution of $\mathrm{AuSn}_{4}$ intermetallics, but from the crack propagation observed in the both the lower Au concentration creep joints and under the heel of the vibration tested joints, it is doubtful that this would be the case.

While not noticeably being influenced by intermetallic presence, the side effects of the increased Au concentration, i.e., increased void concentration and increased $\mathrm{Pb}$-rich phase concentration, did effect crack initiation and propagation. Voids present within the bulk of the joint tended to act as crack nucleation sites, just as external joint surfaces did. Joints containing voids initiated and propagated cracks along the entire length of the joint before void-free joints in the same specimen initiated cracks. Crack propagation generally took place through the softer regions in the joint, i.e., along $\mathrm{Sn}$-rich/Pb-rich phase boundaries, through $\mathrm{Pb}$-rich phases, and along colony boundaries, if colonies were present. It is possible that these softer regions see a higher strain than the Sn-rich regions in the joint, i.e., $\mathrm{Sn} / \mathrm{Sn}$ grain boundary sliding may accommodate the strain within the joint better than any of the three regions mentioned above. The relative ease of coherent deformation in the Sn-rich regions compared to in the other regions results in those other regions seeing a relatively higher strain. Thus the softness of a phase may combine with the relative higher strain to direct the crack preferentially along these regions. Interestingly, the coarsened-band phenomenon seen in joints with lamellar, highly defined colony structures, did not occur in these joints. [64] In addition, the cracks did not tend to form at a particular distance from the joint/metallization interface. It is possible that the fact that the 
joints are highly equiaxed to start with removes the necessity of forming a recrystallized, softer, band of material through which the crack will preferentially propagate.

The effect of small amounts of macroscopic intermetallic additions on otherwise superplastic materials is not generally known, but it has been postulated that dispersion hardening raises the fatigue life of alloys. [67] In addition, superplastic microstructures have been observed to exhibit higher fatigue lives than non-superplastic microstructures.[64] It is recommended that fatigue testing be performed on representative specimens to determine which of the two competing mechanisms is dominant in affecting the fatigue life of eutectic $\mathrm{Sn} / \mathrm{Pb}$.

\subsection{Microstructure}

Microstructural results of the untested joints agreed with previous studies.[11, 27] As the percentage of $\mathrm{Au}$ in the joint increased, the concentration of $\mathrm{AuSn}_{4}$ intermetallics increased. As the percentage of $\mathrm{Sn}$ used in the $\mathrm{AuSn}_{4}$ intermetallics increased, the percentage of larger $\mathrm{Pb}$-rich phases was observed to increase. This "most obvious in the highest All concentration joints, is most likely the "coarsening" effect observed by Foster.[27] Etching of some creep joints showed that the relative grain sizes of the eutectic background did not increase with increasing Au content. The chemical etch used tended to severely attack the Au-containing specimens, eating away at the possibly Au-depleted areas directly surrounding Au-rich areas before $\mathrm{Sn} / \mathrm{Sn}$ grain boundaries were fully and clearly revealed, so structure coarseness and disorganization were determined by relative $\mathrm{Sn}$-rich and $\mathrm{Pb}$-rich phase sizes and positions.

The concentration of voids in the joints was observed to increase with increasing Au content, as predic:ed by Foster.[27] The voids were generally located under the heel and at the toe of the joint in the reliability joints, and in the inner areas of the joint in the creep joints. There are at least three possible origins of these voids. First, a small amount of air may be trapped under or adjacent to the lead at the heel and the toe when the lead is placed on the solder paste, or under uneven plating on the outer coupons of the creep

$$
\text { Puge } 32
$$


specimens when the upper coupon of the creep specimen is placed on the pasted coupon. As the viscosity of the melt presumably increases from the increased Au content, the air is prevented from outgassing, as it does in the Au-free joints, and so forms voids. [40, 42, 92] A second source of the increased porosity may be the flux base the solder balls reside in while in paste form. Again, as the viscosity of the melt increases, the organic solvents in the paste find it increasingly difficult to boil off, and hence are trapped as voids. A third possible source of the voids may be from organic additives in the Au plating bath. The voids in this study, however, are found under the heel of the lead and at the toe of the lead rather than sitting on the solder/metallization interface, as observed by Duckett and Ackroyd, so this source for voids is not considered to be as likely as the first two.[21] It should be noted that the severity of the void concentration was greater in the creep joints than the reliability joints. This may result from two causes: 1) the specimen geornetries of the reliability joints and the creep joints are different, indicating that leadless chip carriers, represented by the creep specimen geometry, may have a greater problem with void formation than the leaded chip carrier joints; and 2) it is possible that the longer preheat time of the creep joints, relative to the reliability joints, resulted in consumption of the Au before the $\mathrm{Ni}$ was wet, resulting in de-wetting, as observed by Walker.[90] 


\subsection{Conclusions}

The objective of this study was to determine the effects moderately low Au concentrations, $\leq 10 \mathrm{wt} \% \mathrm{Au}$, have on the reliability and creep properties of eutectic $\mathrm{Sn} / \mathrm{Pb}$ joints. The three most important observations that occurred in this study are as follows: 1) superplasticity normally present at moderate temperatures and strain rates in eutectic and near-eutectic $\mathrm{Sn} / \mathrm{Pb}$ alloys was not present in the Au-containing creep specimens; 2) the void concentration greatly increased with Au concentration; and 3) crack propagation was found to follow $\mathrm{Sn} / \mathrm{Sn}$ grain boundaries from $\mathrm{Pb}$-rich island to $\mathrm{Pb}$-rich island rather than preferentially following AuSn4/matrix interfaces.

The loss of superplasticity in even the $0.2 \mathrm{wt} \%$ Au specimens could indicate a shorter lifetime for solder joints containing $\mathrm{Au}$ than those without $\mathrm{Au}$ from the knowledge that superplastic microstructures have shown longer isothermal fatigue lifetimes than nonsuperplastic microstructures. [64] This expectation is counterbalanced, however, by the theory that fatigue life is raised through intermetallic strengthening.[67] Fatigue testing of joints similar to creep joints tested in this study should take place to determine which, if either, of the two competing mechanisms dominates.

The drastic increase in the number of joints containing voids, as well as the general size of the voids, indicates a lower reliability in those joints containing Au. Again, this was not seen in the leaded joints as a result of the lead compliance. The creep joints, however, displayed a relative strength drop between 1.0 and $1.5 \mathrm{w} / \%$ Au. In addition, the void concentration and $\mathrm{Pb}$-rich phase concentration increase on increasing $\mathrm{Au}$ concentration were observed to influence crack propagation. These joints, whose geometry is more indicative of leadless joints, indicate that in the leadless chip carrier case reliability may be severely undermined if the void concentration cannot be lowered.

The rotation of the intermetallics that occurred during vibration testing of the 4.8 wt\% Au joints did not result in an easy fracture path in either the vibration, thermal, or creep strained high-Au concentration joints tested in this study. Crack propagation

\section{Page 34}


followed the same path as in eutectic and near-eutectic $\mathrm{Sn} / \mathrm{Pb}$ alloys, i.e., along $\mathrm{Sn} / \mathrm{Sn}$ grain boundaries from $\mathrm{Pb}$-rich phase to $\mathrm{Pb}$-rich phase. The additional intermetallics present in the thermally cycled joints had no obvious effect on the reliability of these joints. The compliance of the leads present on both types of reliability joints most likely resulted in the lead, rather than the solder joint, absorbing most of the strain during the respective tests.

\subsection{Future Work}

At this point the most important future work would be to perform isothermal fatigue testing on eutectic $\mathrm{Sn} / \mathrm{Pb}$ alloys containing moderately low Au concentrations. Such testing would assist in determining whether the theorized fatigue life increase from particulate strengthening or the fatigue life decrease from loss of superplasticity would dominate. Intermetallic rotation may become important, affecting both the fatigue life and the crack propagation mechanism. Simple shear testing of void. free 4.0 to $5.0 \mathrm{wt} \%$ Au quenched joints would allow a determination of how changes in intermetallic orientation may play a role in crack propagation. Testing of a specimen that allows in-situ observation of the intermetallics or interrupted testing would also be valuable in determining how the intermetallics change orientation. Void formation may also play a factor in fatigue life, if it is not controlled. Isothermal fatigue testing would allow separation of thermal cycling effects and strain cycling effects as well as comparison of results to the more well-known $\mathrm{Sn} / \mathrm{Pb}$ system. 


\subsection{References}

1. Ackroyd, M.L. and MacKay, C.A., Solders, Solderable Finishes and Reflowed Solder Coatings, Tin Research Institute Publication \#520, (1977)

2. Ainsworth, P.A., The Formation and Properties of Soft Soldered Joints, J. Metals and Materials, 5, 374-379, (November 1971)

3. Ainsworth, P.A., Soft Soldering Gold Coated Surfaces, Tin Research Institute Bulletin \#431, (1972)

4. Allen, B.M., Soldering Handbook, ILIFFE Books LTD, 52.55, (1969)

5. Bader, W.G., Dissolution of $A u, A g, P d, P l, C u$ and Ni in a Molten Tin-Lead Solder, Welding Research Supplement, 551s-557s, (December 1969)

6. Baker, B., X-Ray Inspection of Three-Dimensional Solder Joints, Electronic Mfg, 20-22, (February 1989)

7. Baker, E., Stress Relaxation in Tin-Lead Solders, MS\&E, 38, 241-247, (1979)

8. Baker, W.A., The Creep Properties of Soft Solders and Soft-Soldered Joints, Inst Metals J, 65, 277 $300,(1939)$

9. Becker, G., Impurities in Solder: Ilow They Influence Solderability and Strength of PCB Plated Through-Holes, Insulation/Circuits, 49-52, (March 1982)

10. Becker, G. and Allen, B.M., The Effect of Impurities on Soft Solder for Electrical Purposes, INTERNEPCON, II-52 - II-66, (1970)

11. Bester, M.H., Metallurgical Aspects of Soldering Gold and Gold Plating, INTERNEPCON, 211231, (October 1968)

12. Both, W. and Schlicßer, R., Metallurgical Behavior of Gold in Solder; Causes of Contact Failures in $O E$ (Metallurgische Reaktion von gold in Weichloten - Ursache der Kontaktdegradation optoelektronischer Bauelemente) Feingeratctcchnik, 35, 410-413, (1986) [orig. ref Landolt-Bornstein: Numerical data and functional relationships in science and technology, NY, Springer Verlag, 1980]

13. Brewer, D.H., Solders for Thick Gold Plaling, Welding Rescarch Supplement, 465s-470s, (October 1970)

14. Brown, C.E., Solder Cracking on Printed Wiring Boards, Causes and Cures, NEPCON, 649-654. (July 1968)

15. Combres, Y. and Levaillant, Ch., Quantitative Assessment of the Implications of Sirain-Induced Microstructural Changes in Superplasticity, Met Trans A, 22A, 83-96, (January 1991)

16. Crawley, A.F., Thresh, H.R., White, D.W.G., Edwards, J.O., and Meicr, J.W., Properlies of Molten Lead and Some Lead Alloys, Final Report, Part 2: Viscosity, Canada Department of Energy, Mines and Resources, Internal Report PM-R-67-17, LM-64, (November 1967)

17. Crawley, A.F., Thresh, H.R., White, D.W.G., Edwards, J.O., and Meier, J.W., Properties of Molien Lead and Some Lead Alloys, Final Report, Part I: Densily, Canada Department of Energy, Mines and Resources, Internal Report PM-R-67-16, LM-64, (Scptember 1967)

18. Crawley, A.F., Thresh, H.R., White, D.W.G., Edwards, J.O., and Meier, J.W., Properties of Molten Lead and Some Lead Alloys, Final Reporl, Parl III: Surface Tension, Canada Department of Energy, Mines and Resources, Internal Report PM-R-67-18, LM-64, (April 1968) 
19. de Kluizenaar, E.E., Reliability of Solder Joints: A Description of the State of the Art, Part 1, Soldering \& SMT, 4, 27-38, (February 1990)

20. de Kluizenaar, E.E., Reliability of Solder Joints: A Description of the State of the Art, Part 2, Soldering \& SMT, 5, 56-66, (June 1990)

21. Duckett, R. and Ackroyd, M.L., The Influence of Solder Composition on the Embritllement of SoftSoldered Joints on Gold Coatings, Electroplating and Metal Finishing, International Tin Research Institute Publication \#520, (1976)

22. Dyson, B.F., Diffusion of Gold and Silver in Tin Single Crystals, J Appl Phys, 37 (6), 2375-2379, (May 1966)

23. Dyson, B.F., Anthony, T., and Turnbull, D., Interstitial Diffusion of Copper and Silver in Lead, J Appl Phys, 37 (6), 2370-2374, (May 1966)

24. Evans, H.E., O'Hara, J.P., and Viswanadham, P., Reliability Aspects of Tape Automated Bonding Second Level Assembly, 9th Annual International Electronic Packaging Conference Proceedings, September 1989, 1375-1391، (1990)

25. Fazckas, D.A., Report on the Fleet Ilardware Assessment Project, A Survey of the Soldering Problems Observed in Navy Weapons Systems, 11 th Annual Electronics Manufacture Seminar Proceedings, 18-20 February 1987, China Lake, NWC TP 6789 (February 1987)

26. Fisher, H.J., and Phillips, A., Viscosity and Density of Liquid Lead-Tin and Antimony-Cadmium Alloys, Trans AIME (J Mctals), 1060)-1070, (September 1954); discussion: J Metals, 706, (May 1955), and J Mctals, 1264-1265, (November 1955)

27. Foster, F.G., Embrittlement of Solder by Gold from Plated Surfaces, Papers on Soldering, ASTM STP $319,13-19,(1962)$

28. Frear, D.R., Microstruclural Observasions of the Sn-Pb Snider/Cu System and Thermal Fatigue of the Solder Joint, Ph.D. Thesis, U.C. Berkeley, LBL-23879, (June 1987)

29. Frear, D., Grivas, D., and Morris, J.W., Jr., A Microstructural Study of the Thermal Fatigue Failures of 60Sn-40Pb Solder Joints, J Electronic Materials, 17 (2), 171-180, (1988)

30. Frear, D., Grivas, D., and Morris, J.W., Jr., Thermal Fatigue in Solder Joints, J Mctals, 40 (6), 18 22, (June 1988)

31. Frear, D., Grivas, D., and Morris, J.W., Jr., Parameters Affecting Thermal Fatigue Behavior of 60Sn-40Pb Solder Joints, J Electronic Materials, 18 (6), 671-680, (1989)

32. Fry Report No. 89-V11, Viscosity of Tin/Lead Solder

33. Gilkins, R.C., Grain Boundary Sliding and its Accommodation During Creep and Superplasticily, Met Trans A, 7a, 1225-1232, (1976)

34. Glazer, J., Kramer, P., and Morris, J.W., Jr., Effect of Au on the Reliability of Fine Pilch Surface Mount Solder Joints, Procedings, Surface Mount International, August 25.29 1991, San Jose CA, 629.639, (1991); J SMT, 4, 15-28, (October 1991)

35. Grivas, D., Deformation of Superplastic Alloys al Relatively Low Strain Rates, Ph.D. Thesis, U.C. Berkeley, LBL-7375, (Fcbruary 1978)

36. Grivas, D. and Morris, J.W., Jr., Steady State Creep of a Superplastic Lead-Tin Eutectic Alloy at Low Stress, LBL-2532, (December 1973) 
37. Hagge, J.K., Critical Component Requirements for Vapor Phase Soldering Leadless Components on Circuil Board Assemblies for Military Electronics, IEEE Trans, CHMT-6, No. 4, 443-454, (December 1983)

38. Haimovich, J., Intermetallic Compound Growth in Tin and Tin-Lead Platings over Nickel and Its Effects on Solderability. Welding Rescarch Supplement, 102s-111s, (March 1989)

39. Hall, P.M. and Morabito, J.M., Recent Advances in Solder Bond Technology for Microelectronic Packaging, Thin Solid Films, 72, 433-442, (1980)

40. Harmsen, U. and Meyer, C.L, Uber Weichlötungen an Gold, Z Metallkde, 56 (4), 234-239, (April 1965)

41. Hazzledine, P.M. and Newbury, D.E., Role of Grain Boundaries in Superplasticity, Ch. 7 Grain Boundary Structure and Properties, G.A. Chadwick and D.A. Smith eds, Academic Press, London, 235-264, (1976)

42. Heinzel, H. and Sacger, K.E., The Weltability and Dissolution Behavior of Gold in Soft Soldering, Gold Bulletin, 9 (1), 7-11, (January 1976)

43. Herzig, Chr. and Stracke, E., Atomic Transport of Gold and Silver in Lead in a DC Field, Phys Stat Sol (A), 27, 75-84, (1975)

44. Hu, C-K and Huntington, H.B., Atom Movements of Gold in Lead-Tin Solders, J Appl Phys, 58 (7), 2564-2569, (October 1985)

45. Huntington, H.B., Hu, C-K, and Mci, S.N., Alomic Transporl of Dilute Impurities in Lead-Tin Alloys, Diffusion in Solids: Recent Developments, TMS-AIME Proceedings, September 17, 1984

46. Hwang, J., Solder Paste in Electronics Packaging, Van Nostrand Reinhold, 115 Fifth Ave. Ny, NY 10003, (1989)

47. Jenkins, C.H.M., The Strength of a Cadmium-Zinc and of a Tin-Lead Alloy Solder, J Inst Metals, 40, 21-39, (1928)

48. Jones, W.R.D., and Davies, J.B., The Viscosity of Lead, Tin, and Their Alloys, J Inst Metals, 86, 164-166, (1957-1958)

49. Kanda, F.A., and Colburn, R.P., The Absolute Viscosity of Some Lead-Tin Alloys, Physics and Chemistry of Liquids, 1, 159-170), (1968)

50. Karnowsky, M.M., and Rosenzweig, A., The Gold-Tin-Lead Alloys - The Gold-Tin-Lead System. Trans AIME, 242, 2257-2261, (1968)

51. Keller, H.N., Significant Fealures of Solder Connections to Gold-Plated Thin Films, IEEE Trans, CHMT-No. 5, 408-419, (1982)

52. Keller, H.N., Solder Connections with a Ni Burrier, IEEE Trans., CHMT-9, No. 4, 433-439, (December 1988)

53. Keller, J.D., Prinled Wiring Surface Preparation Methods - Elimination of Cold Plating as a Surface Preparation for Printed Circuits and Development of a Contamination-Free Surface. Papers on Soldering, ASTM STP 319, 1-12, (1962)

54. Klein and Wassink, R.J.K., Soldering in Electronics, Electrochernical Publications Limited, 8 Barns Strect, Ayr, Scotland, 2nd edition, (1989) 
55. Knausenberger, W.H. and Pinnel, M.R., Interconnection Trends and Impact on Materials, Mat Res Soc Symp Proc, 72, (1986)

56. Knecht, S. and Fox, L.R., Constitutive Relation and Creep-Fatigue Life Model for Eutectic Tin-Lead Solder, IEEE Trans, 13 (2), 424-433, (June 1990)

57. Lampe, B.T., Room Temperature Aging Properties of Some Solder Alloys, Welding Research Supplement, 330s-340s, (October 1976)

58. Lea, C., A Scientific Guide to Surface Mount Technology, Electrochemical Publications Limited, 8 Barns Street, Ayr, Scolland, 2nd edition, (1988)

59. Manko, H.H., Selecting Solder Alloys for Hybrid Bonding, Insulation/Circuits, 27-30, (April 1977)

60. Marshall, J., Walter, S., Davidson, B., and Missele, C., Scanning Electron Microscopy Analysis of M11L98 Solder Process, Motorola Internal Report, (March 1984)

61. Mather, J.C., Precious Metals: The Nemesis of Solder Joints in High-Density Electronic Assemblies, Presented at the SAMPE Conference, April 12, 1983

62. McBee, C., Scanned-Beam Laminography, Circuits Mfg, 67-69, (January 1989)

63. Mei, Z., Grivas, D., Shinc, M.C., and Morris, J.W., Jr., Superplastic Creep of Eutectic Tin-Lead Solder Joints, J Elcctronic Matcrials, 19 (11), 1273-1280, (1990)

64. Mci, Z. and Morris, J.W., Jr., Faligue Lives of 60Sn/40Pb Solder Joinls Made with Different Cooling Rales, Presented at the ASME Winter Annual Mecting, 1.6 December 1991, Allanta, GA, Rpt 91-WA-EEP-20, (December 1991)

65. Mei, Z., Morris, J.W., Jr., and Shine, M.C., Superplastic Creep of Eutectic Tin-Lead Solder Joints, J Electronic Packaging, 113, 109-114, (June 1991)

66. Minelli, R.H. and Rickabaugh, L.J., Solder Dissolution Rates of Evaporated and Spultered Ti-Pd-Au and NiCr-Au Thin Films, $27 \mathrm{hh}$ Electronic Components Conference, 212-219, (1972)

67. Morris, J.W., Jr. and Mei, Z., Toward New Solders with Improved Fatigue Resistance, Ch. 6 in Solder Mechanics: A State of the Art Assessment, D. Frear, ct. al., Eds., TMS, (1991)

68. O'Clock, G.D., Peters, M.S., Pater, J.R., Kleese, G.A., and Martini, R.V., Pb-Sn Alloy Microstructure: Polential Reliability Indicasor for Interconnecls, IEEE Trans, CHMT-10, No. 1, 82. 88, (March 1987)

69. Prince, A., The Au-Pb-Sn Ternary System, J Less-Common Metals, 12, 107-116, (1967)

70. Quan, L.S., Tensile and Shear Behavior of Alloyed Sn-Pb Solder Joints, M.S. Thesis, U.C. Berkeley, LBL-25741, (August 1988)

71. Rose, J., Solder Joint Inspection System.s Aid Proc:ess Control Efforts, Conncction Technology, 2527, (February 1989)

72. Ross, W.M., and Lee, E.A.R., The Embritlement Problem of Gold in Soldered Joints, INTERNEPCON, 206-210, (October 1968)

73. Schubert, K., Breimer, H., and Gohlc, R., Zum Aufbau der Systeme Gold-Indium, Gold-Zinn, GoldIndium-Zinn und Gold-Zinn-Antimon, Z Mctallkde, 50 (3), 146-153, (1959)

74. Sherby, O. and Wadsworth, J., Superplasticity - Recent Advances and Future Directions, Progress in Materials Science, 33, 169.221, (1989) 
75. Shine, M.C. and Fox, L.R., Fatigue of Solder Joints in Surface Mount Devices, Low Cycle Fatigue, ASTM STP 942, 588-610 (1988)

76. Shoushanian, H., Tip Plating With Gold, NEPCON, 6-11, (1975)

77. Stephens, J.J., Kilgo, A.C., and Hlava, P.F., Melallographic and Electron Microprobe Characterization of MC4069 MOSFET LCC Package and Solder Bonds, Sandia Internal Report, (July 1990)

78. Stracke, E. and Herzig, Ch., Electromigration, Thermomigration, and Solubility of Copper in Lead, Phys Stat Sol (A), 47, 513-521, (1978)

79. Summers, T.S.E., Improving Fatigue Life in Near-Eusectic Sn Pb Solders, Ph.D. Thesis, U.C. Berkeley, LBL-30605, (May 1991)

80. Summers, T.S.E. and Morris, J.W., Jr., Isothermal Fatigue Behavior of Sn-Pb Solder Joints, Presented at ASME Winter Conference, San Francisco, CA, 10-14 December 1989, ASME 89. WA/EEP-39 (1989)

81. Thresh, H.R., The Viscosity of Liquid Zinc by Oscillating a Cylindrical Vessel, Trans Met Soc AlME, 233, 79-88, (January 1965)

82. Thwaites, C.J., Soft Soldering, Ch. 19 Gold Plating Technology, F.H. Reid and W. Goldie, eds., Electrochemical Publications Limited, 224-245, (1974)

83. Thwaites, C.J., Solderability of Coatings for Printed Circuits, Trans Inst Metal Finishing, 43 (4), $143-152,(1965)$

84. Thwaites, B.C.J. and Hampshire, W.B., Mechanical Strength of Selected Soldered Joints and Bulk Solder Alloys, Welding Research Supplement, 323s-329s, (October 1976)

85. Tribula, D., A Microstruclural Study of Creep and Thermal Fatigue Deformation in 60Sn-40Pb Solder Joints, Ph.D. Thesis, U.C. Bcrkelcy, LBL-29018, (June 1990)

86. Tribula, D. and Morris, J.W., Jr., Creep in Shear of Experimental Solder Joints, J Electronic Packaging, 112, 87-93, (June 1990)

87. Tribula, D., Grivas, D., Frear, D., and Morris, J.W., Jr., Microstructural Observations of Thermomechanically Deformed Solder Joints, Welding Journal, 68 (10), 404s-409s, (October 1989)

88. Tribula, D., Grivas, D., Frear, D., and Morris, J.W., Jr., Observations on the Mechanisms of Fatigue in Eutectic Pb-Sn Solder Joints, Presented at the ASME Winter Meeting, Chicago, IL, 27 November - 2 December 1988, ASME 88-WA/EEP-13, (1988)

89. Wadsworth, J., Kramer, P., Dougherty, S., and Nieh, T.G., Evidence of Dislocation Glide Controlled Creep in Niobium-Base Alloys, (to be published in Scripta Met, 1992)

90. Walker, G.A. and DeHaven, P.W., Initial Welting and Reaction Sequences in Soldering, Proceedings IEEE International Reliability Physics Symposium, 181-184, (1984)

91. Walker, G.A., DeHaven, P.W., and Goldsmith, C.C., Kinetics of Intermetallic Formation During Soldering of Chips to Substrates, 34th IEEE Electronic Components Conference, 125-128, (1984)

92. Wild, R.N., Effects of Gold on the Properties of Solders, NEPCON, 198-213, (June 1968)

93. Wild, R.N., Fatigue Properties of Solder Joints, Welding Research Supplement, 521s-526s, (November 1972) 
94. Wild, R.N., Some Fatigue Properlies of Solders and Solder Joints, NEPCON, 105-117, (1974)

95. Willard, H.H., Merrit, L.L., and Dean, J.A., Instrumental Methods of Analysis, D. Van Nostrand Company, Litton Educational Publishing, Inc., (1974)

96. Wright, C., The Effect of Solid-State Reactions Upon Solder Lap Shear Strength, IEEE Transactions on Parts, Hybrids, and Packaging, Vol. PHP-13, No. 3, 202-207, (September 1977)

97. Wright, E.A., and Wolverton, W. M., The Effect of the Solder Reflow Method and Joint Design on the Thermal Fatigue Life of Leadless Chip Carrier Solder Joints, IEEE, 149-155, (1984)

98. Yost, F.G., Soldering to Gold Films, Gold Bull., 10 (4), 94-100, (October 1977)

99. Zakraysek, L., Metallic Finish Systems for Microelectronic Components, IEEE Trans, CHMT-4, No. 4, (December 1981)

100. Private communication with Dr. J. Glazer 


\subsection{Figures}

a)

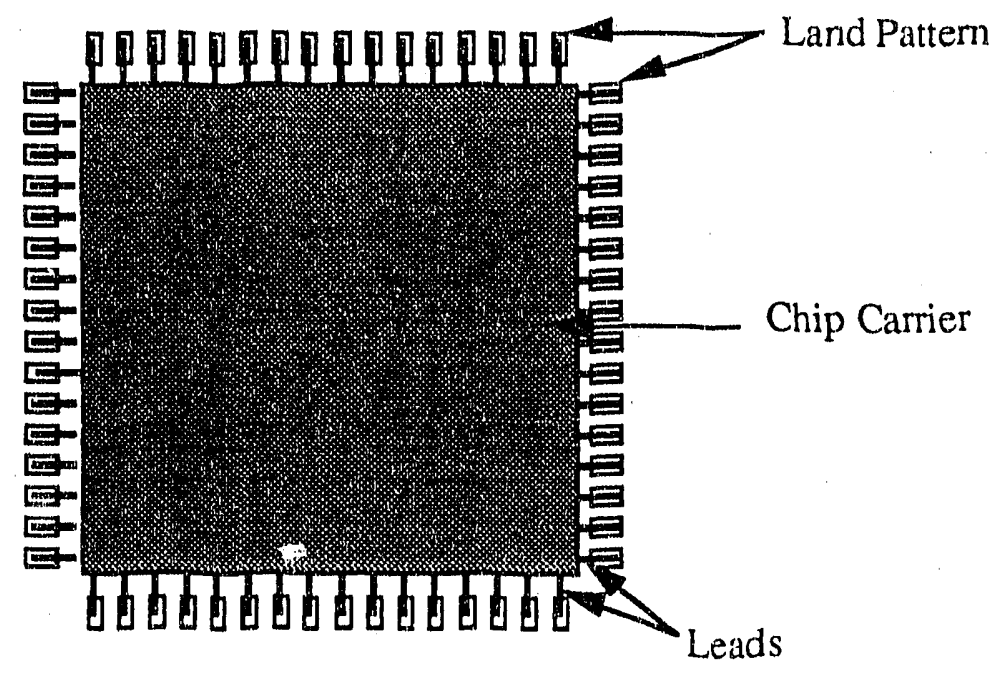

b)

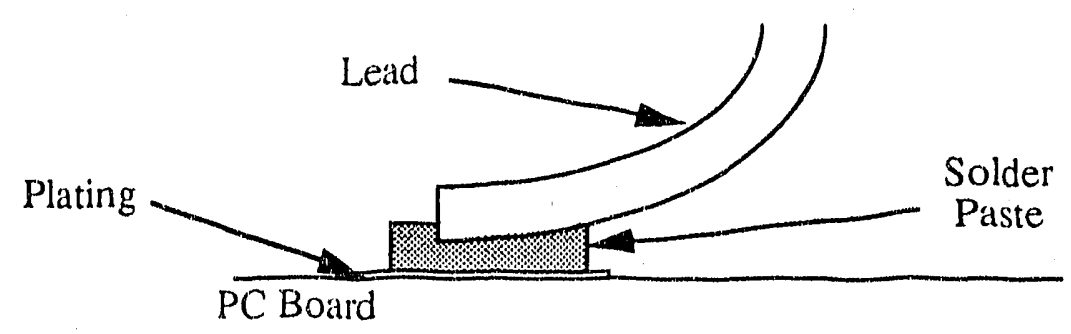

c)

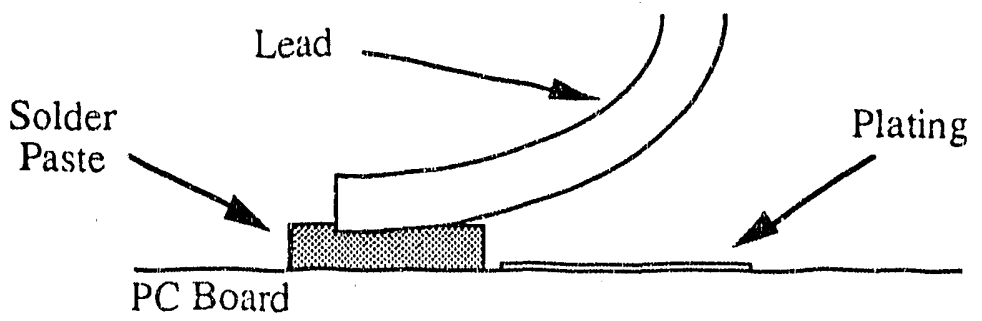

Figure 1

a) Top view schematic of land pattern and chip carrier.

b) Schematic showing desired contact between land pattern pad, solder paste, and chip carrier lead.

c) Schematic showing missed contact between land pattern pad and solder paste and chip carrier lead resulting from possible distortion of the land pattern from thermal shock. 


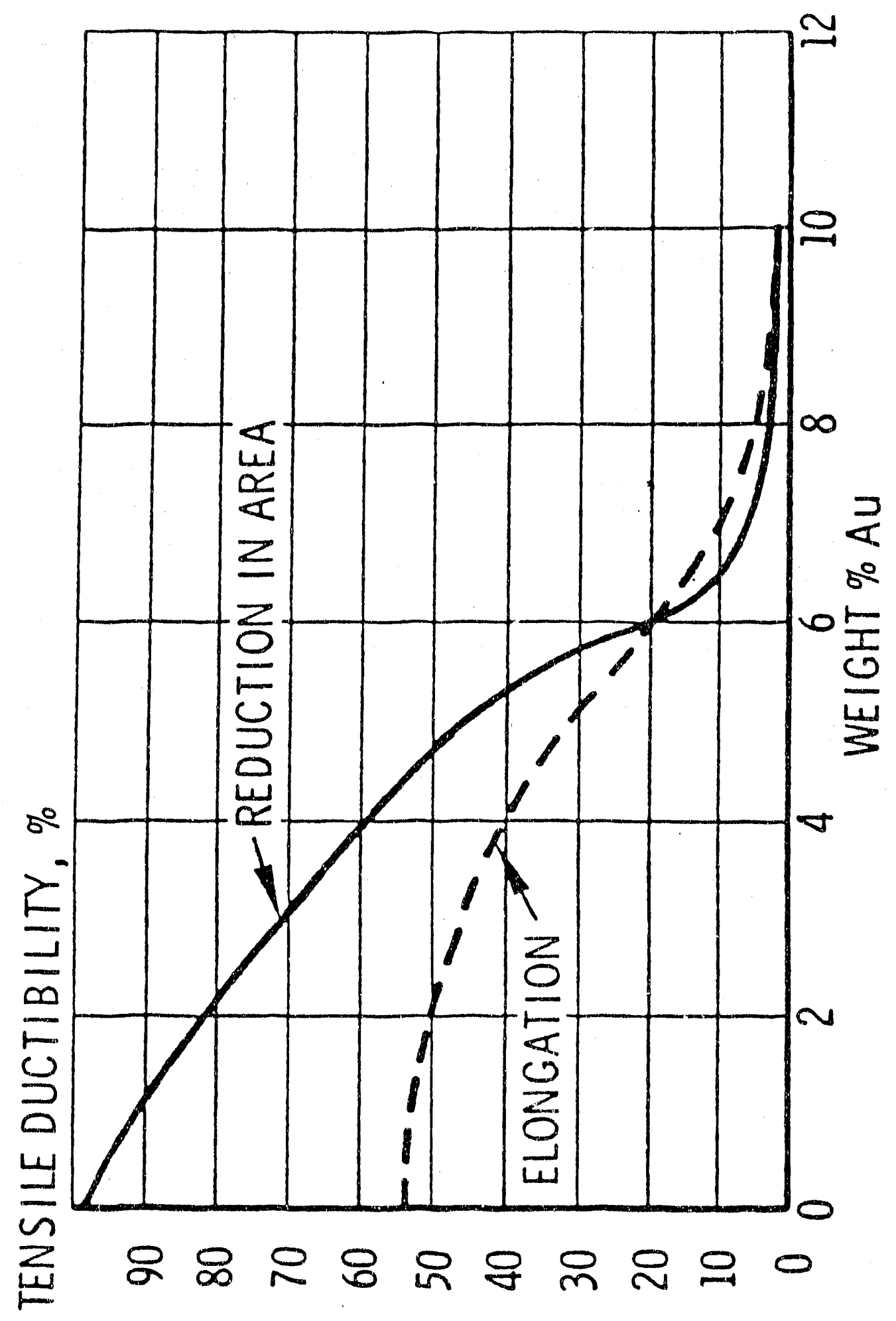

Figure 2

Plot of elongation and reduction in area vs. Au concentration 


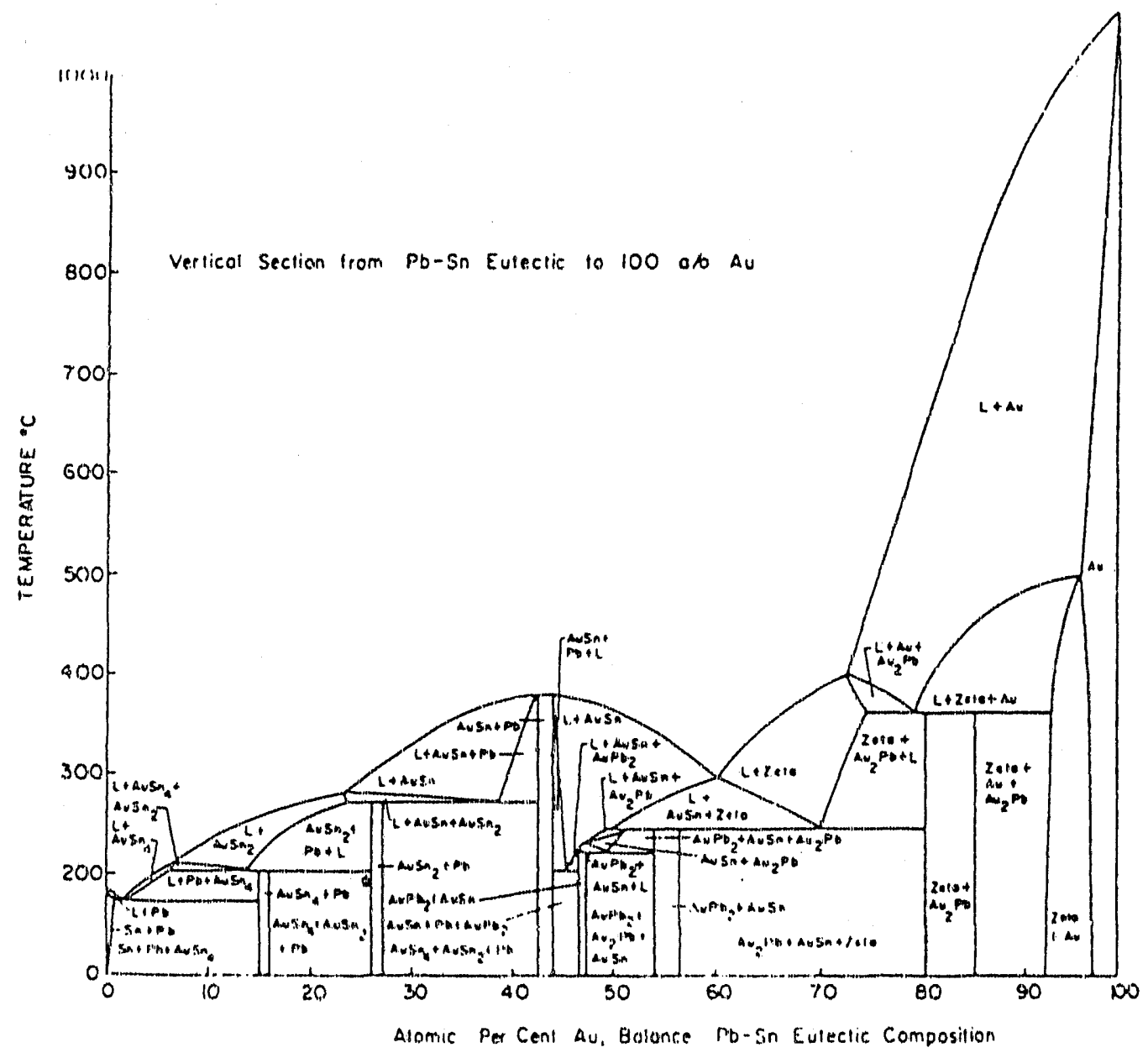

Figure 3

Pseudo-binary phase diagram of eutectic $\mathrm{Sn} / \mathrm{Pb}+\mathrm{Au}$ 
a)

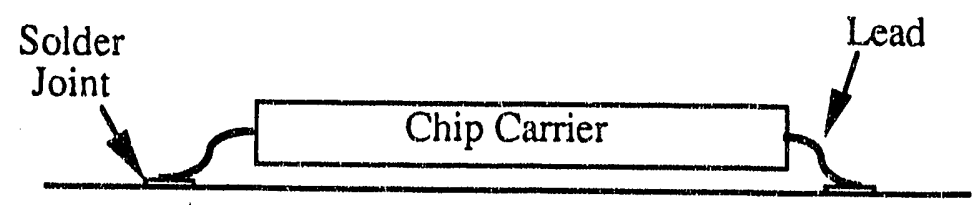

b)

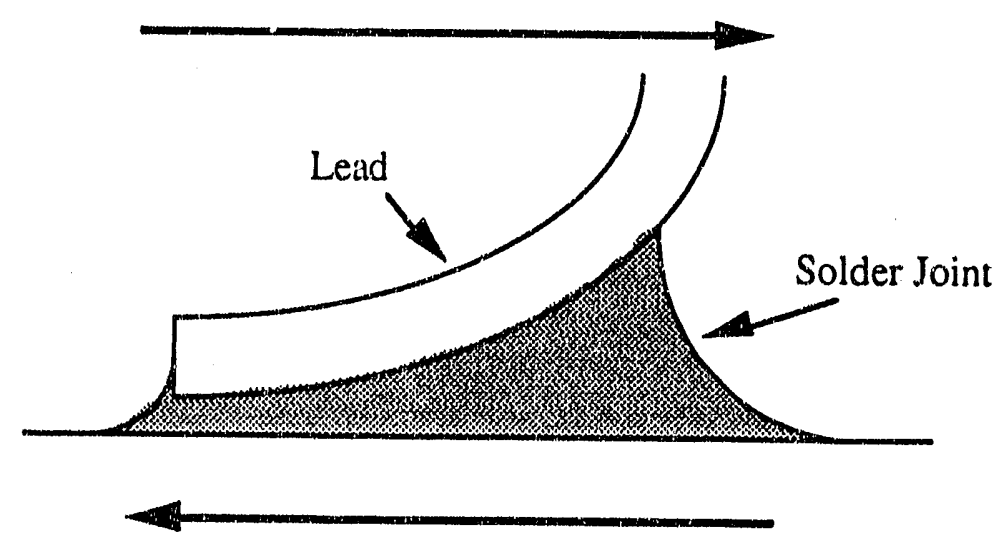

c)

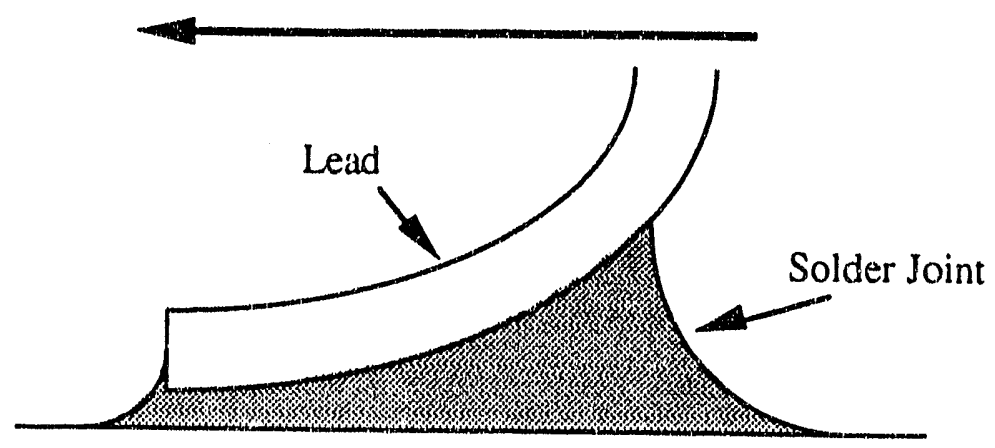

Figure 4

a) Cross-sectional side view of chip carrier with gull-wing leads.

b) Stress effects on the solder joint on heating of the board (turning on the component) originating from different thermal expansion coefficients of the PC board, the solder, the lead, and the chip carrier.

c) Stress effects on the solder joint on cooling of the board (turning off the component) originating from different thermal expansion coefficients of the PC board, the solder, the lead, and the chip carrier. 


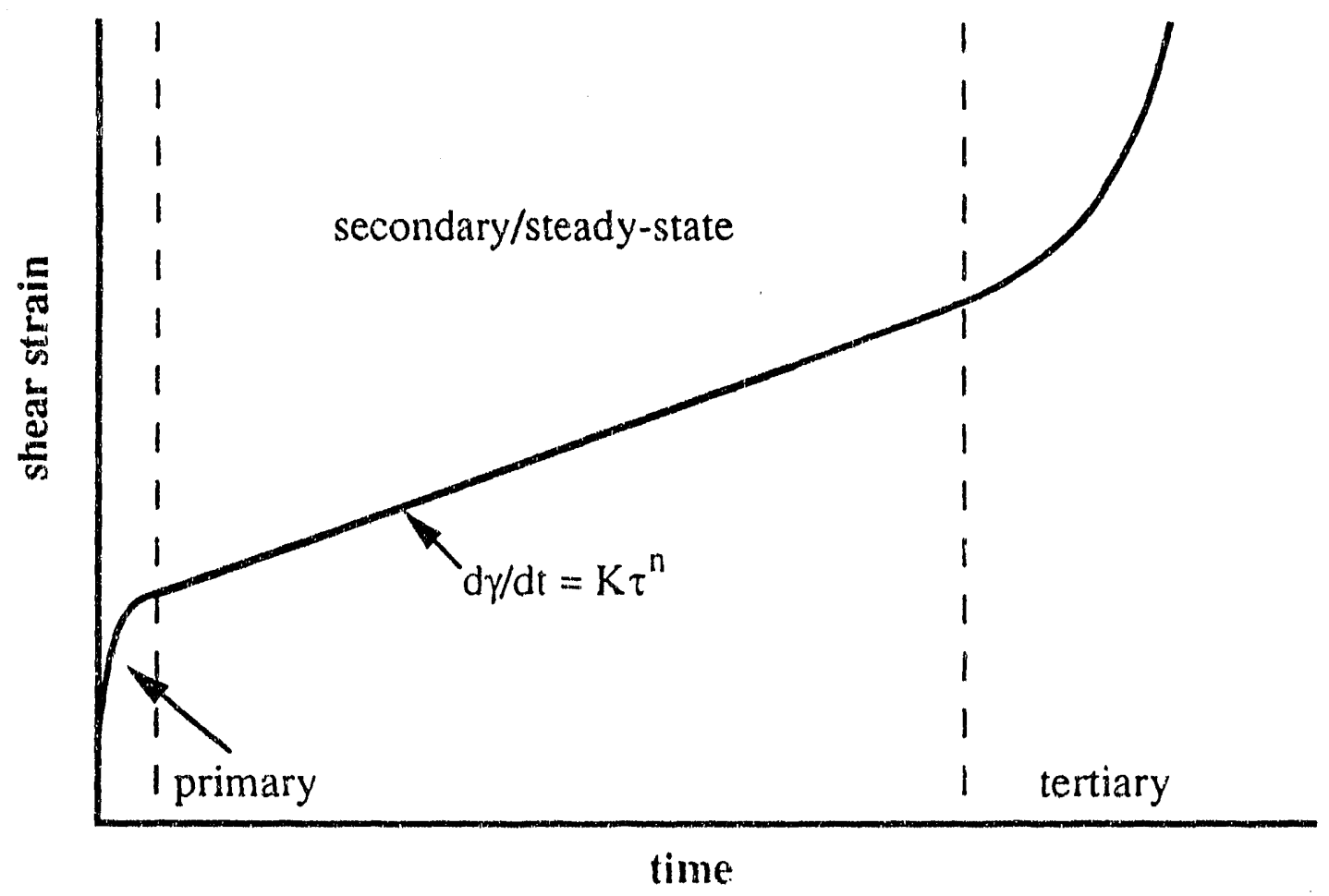

Figure 5

Characteristic creep curve showing steady state creep 


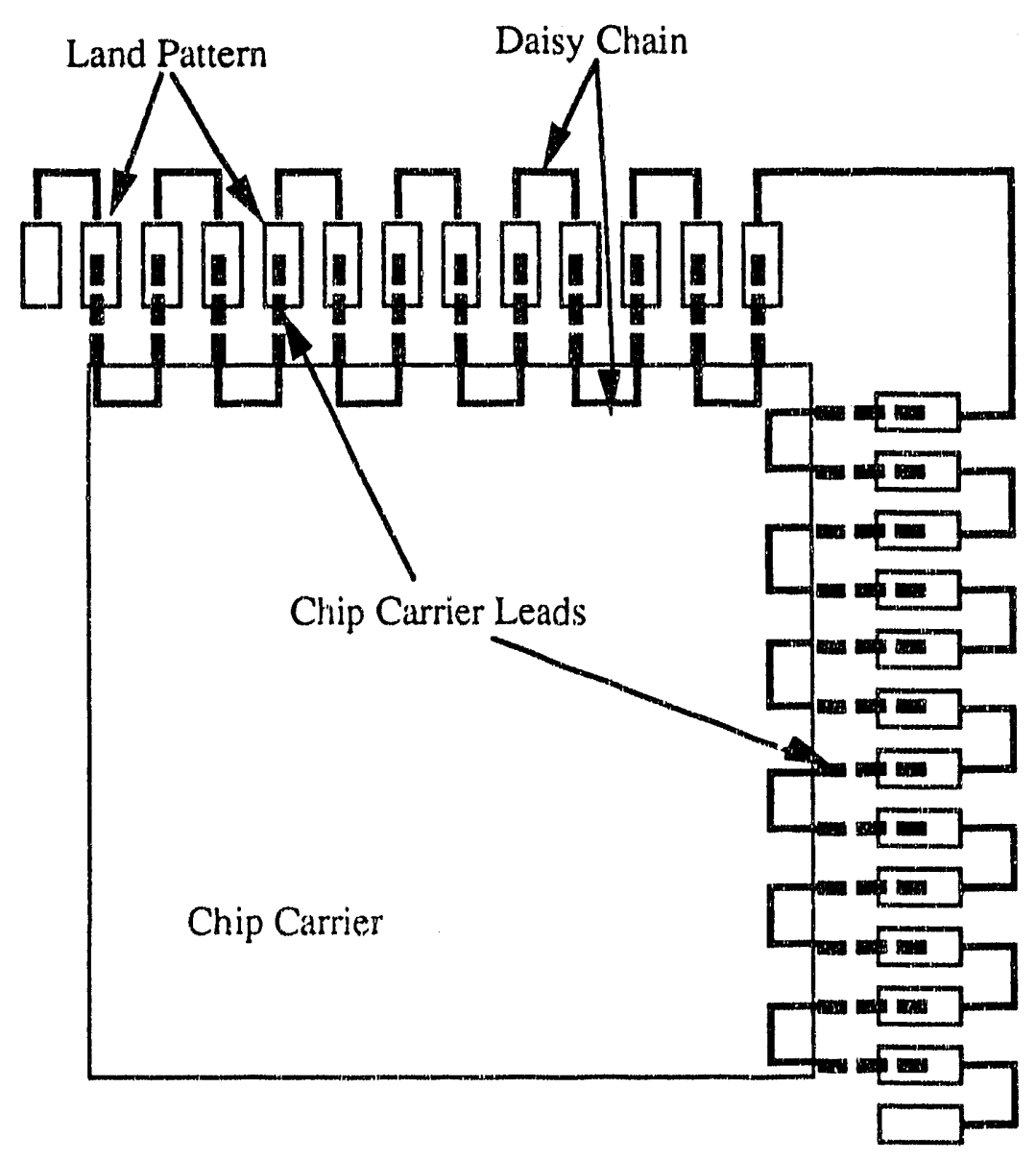

Figure 6

Enlarged schematic showing daisy chain pattern between the board and the chip carrier. This pattern allowed the recording computer to recognize when there was an open in the circuit, i.e., a failure in a joint or a lead. 

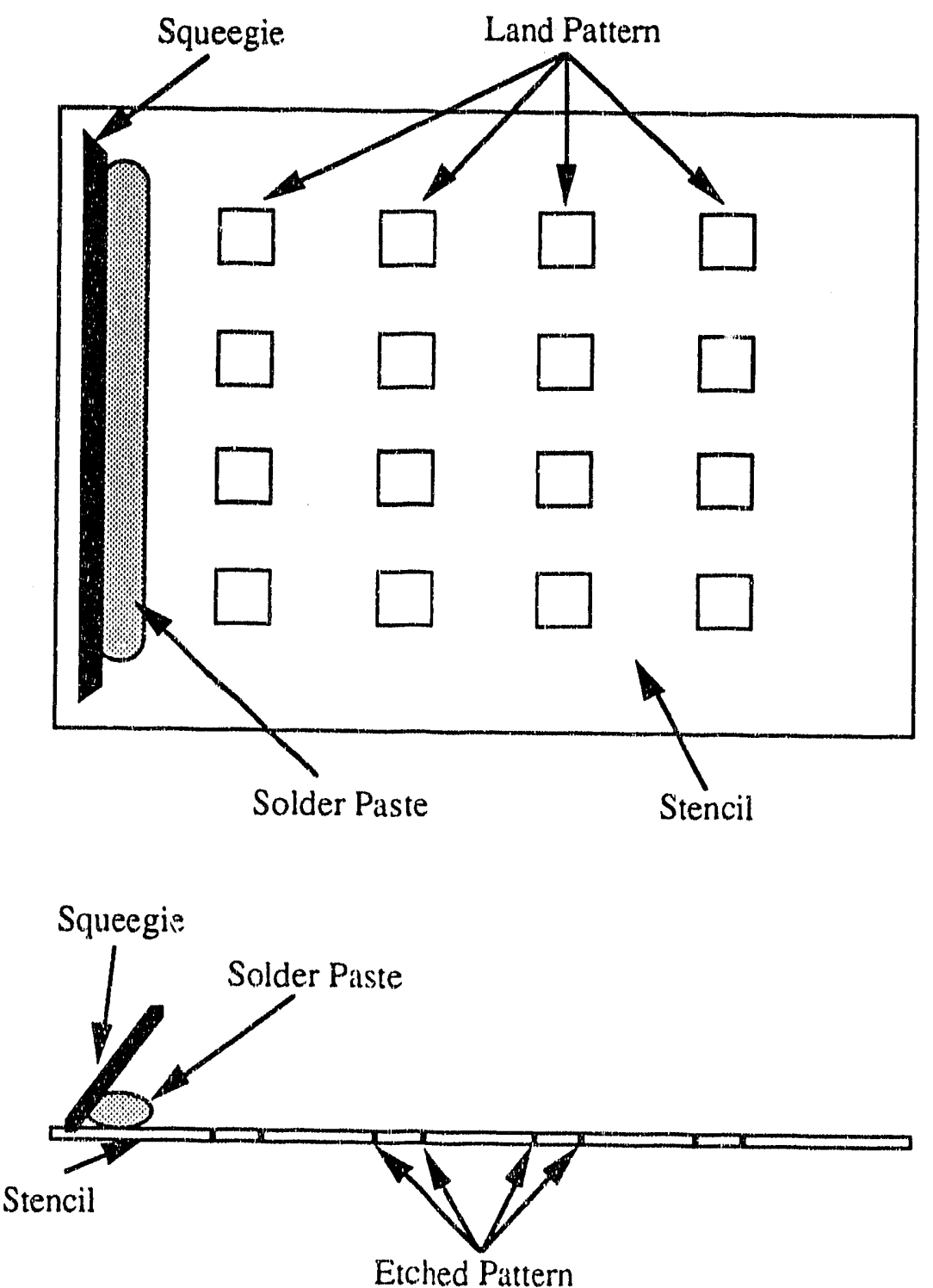

Figure 7

Schematics showing top and side views of the stencil paster used to paste the $\mathrm{PC}$ boards. The squeegee sweeps across the stencil, pushing the paste through the etched holes in the stencil onto the board beneath. 
$\checkmark$

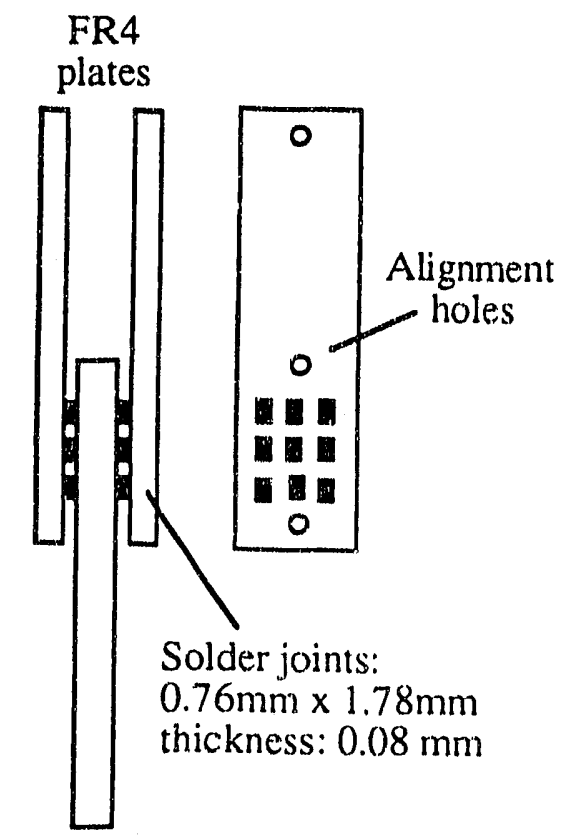

Fiber glass

plate

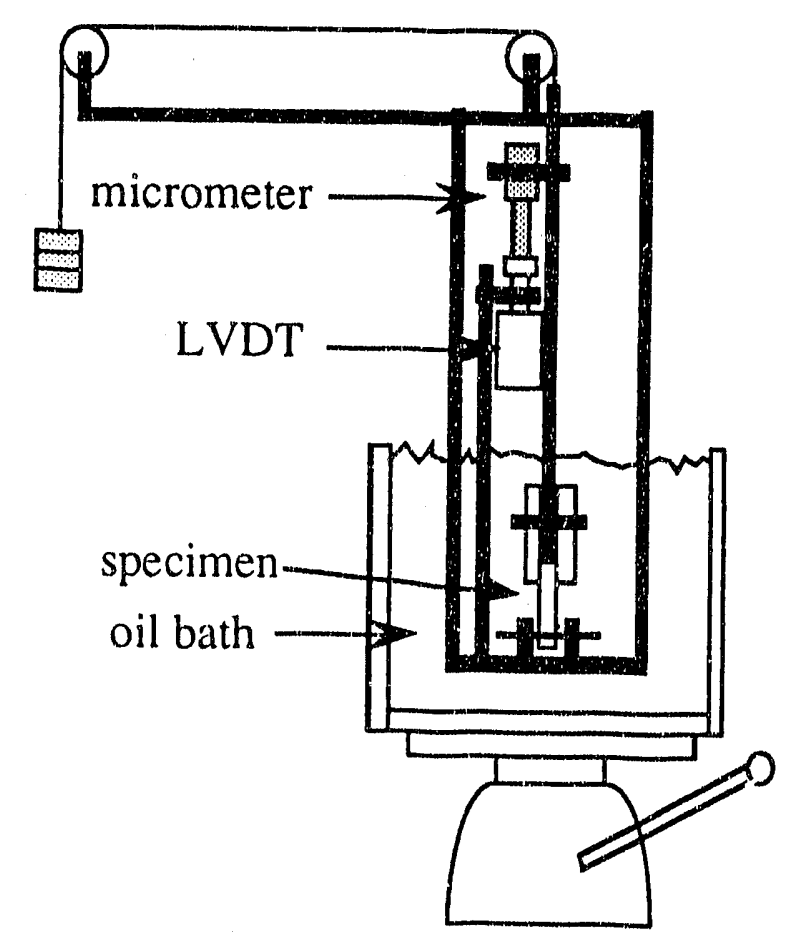

Figure 8

Schematics of double shear creep specimen and creep test machine 

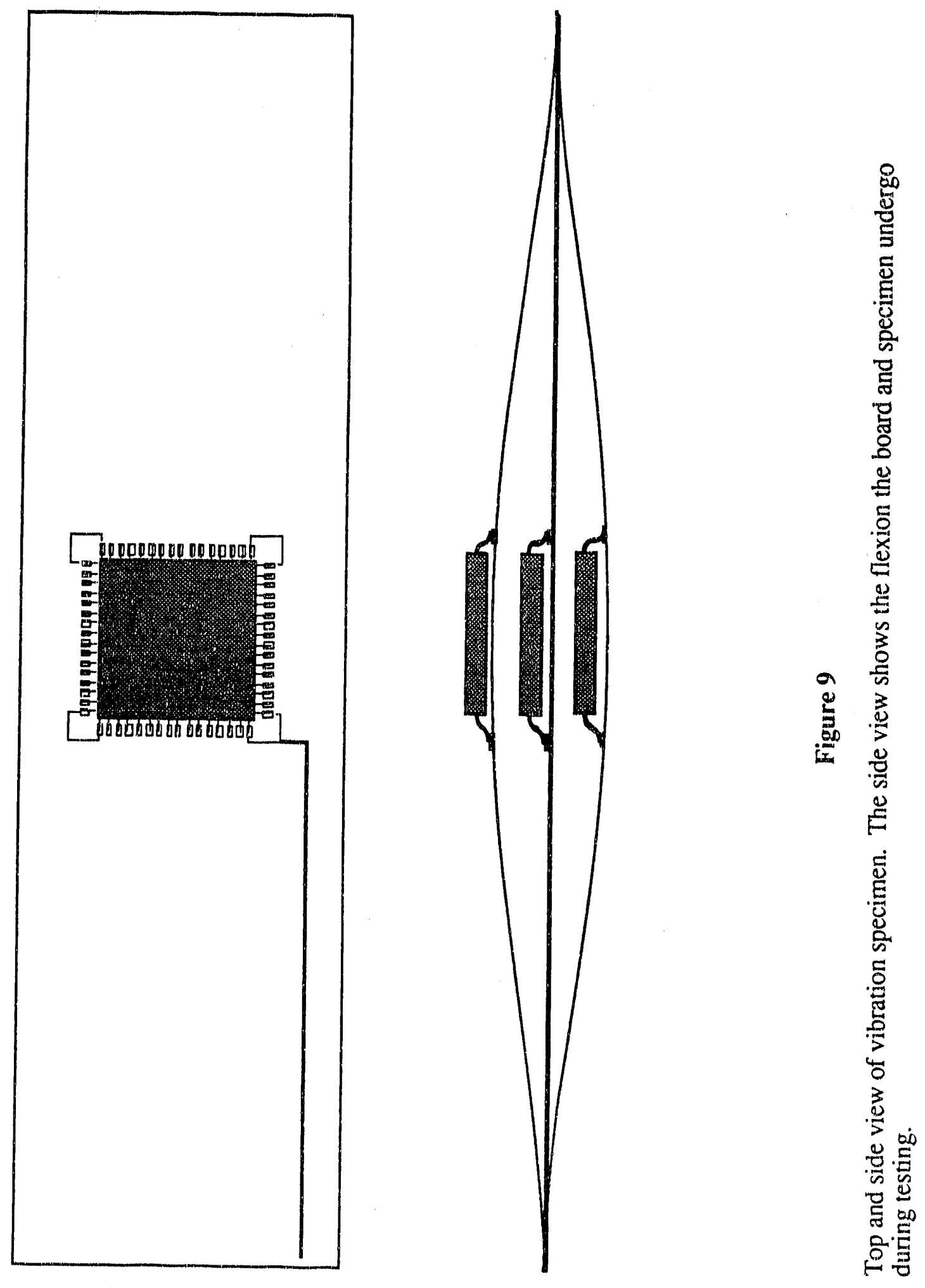

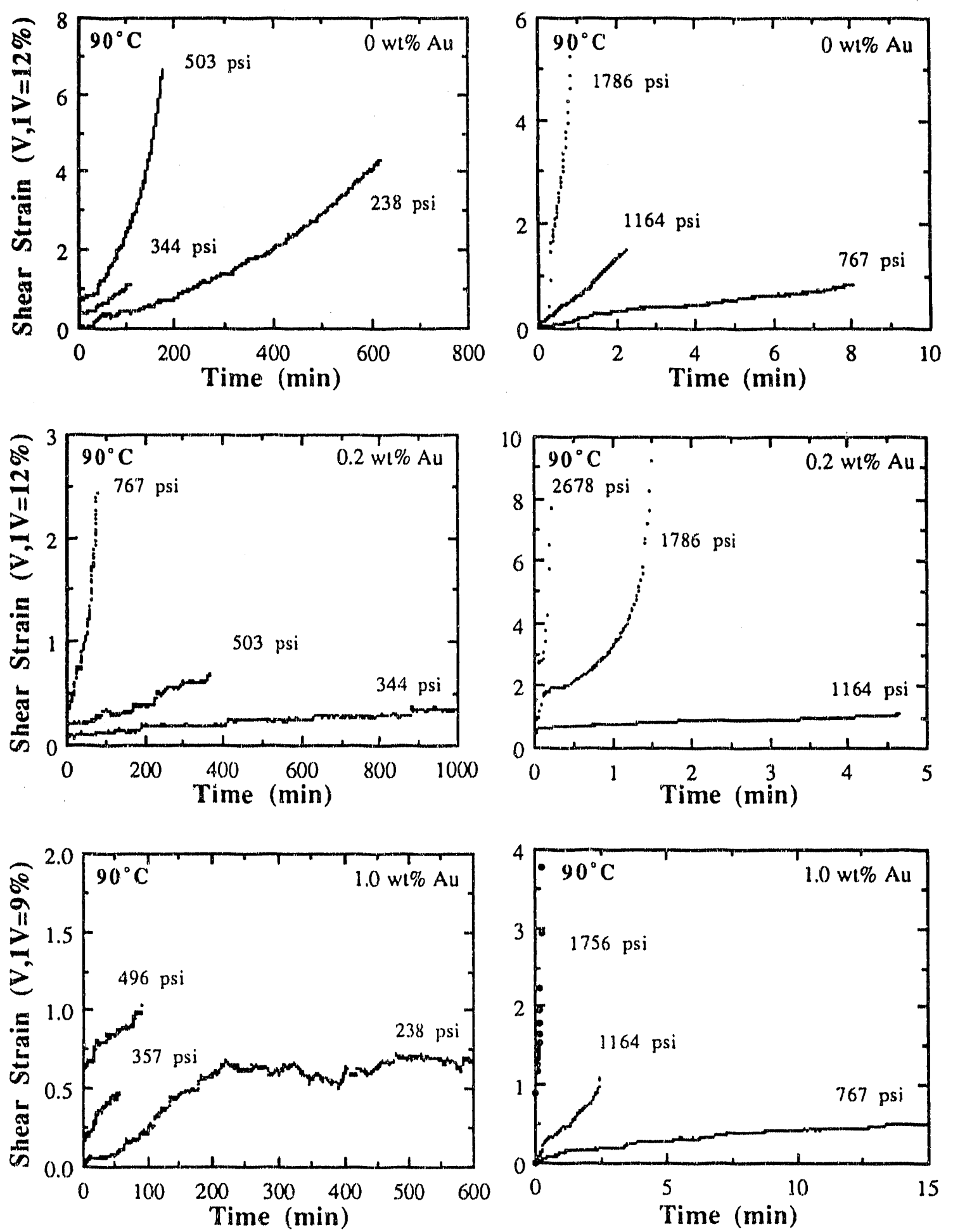

Figure 10

$0 \mu$ in, $5 \mu$ in $(0.2 \mathrm{wt} \%)$, and $10 \mu$ in $(1.0 \mathrm{wt} \%)$ Au creep tests at $90^{\circ} \mathrm{C}$. 

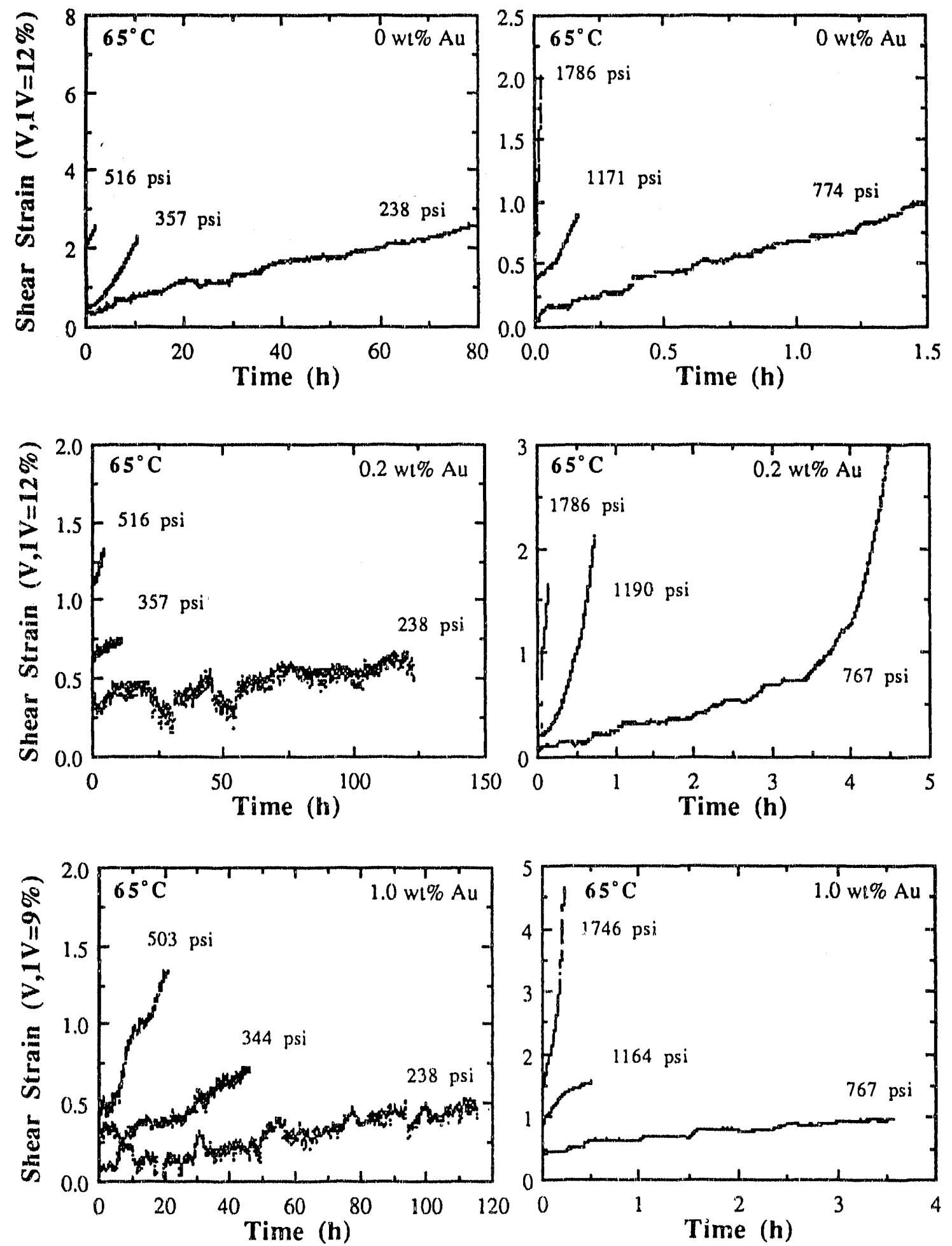

Figure 11

$0 \mu$ in, $5 \mu$ in $(0.2 \mathrm{wt} \%)$, and $10 \mu$ in $(1.0 \mathrm{wt} \%)$ Au creep tests at $65^{\circ} \mathrm{C}$.

Page 52 

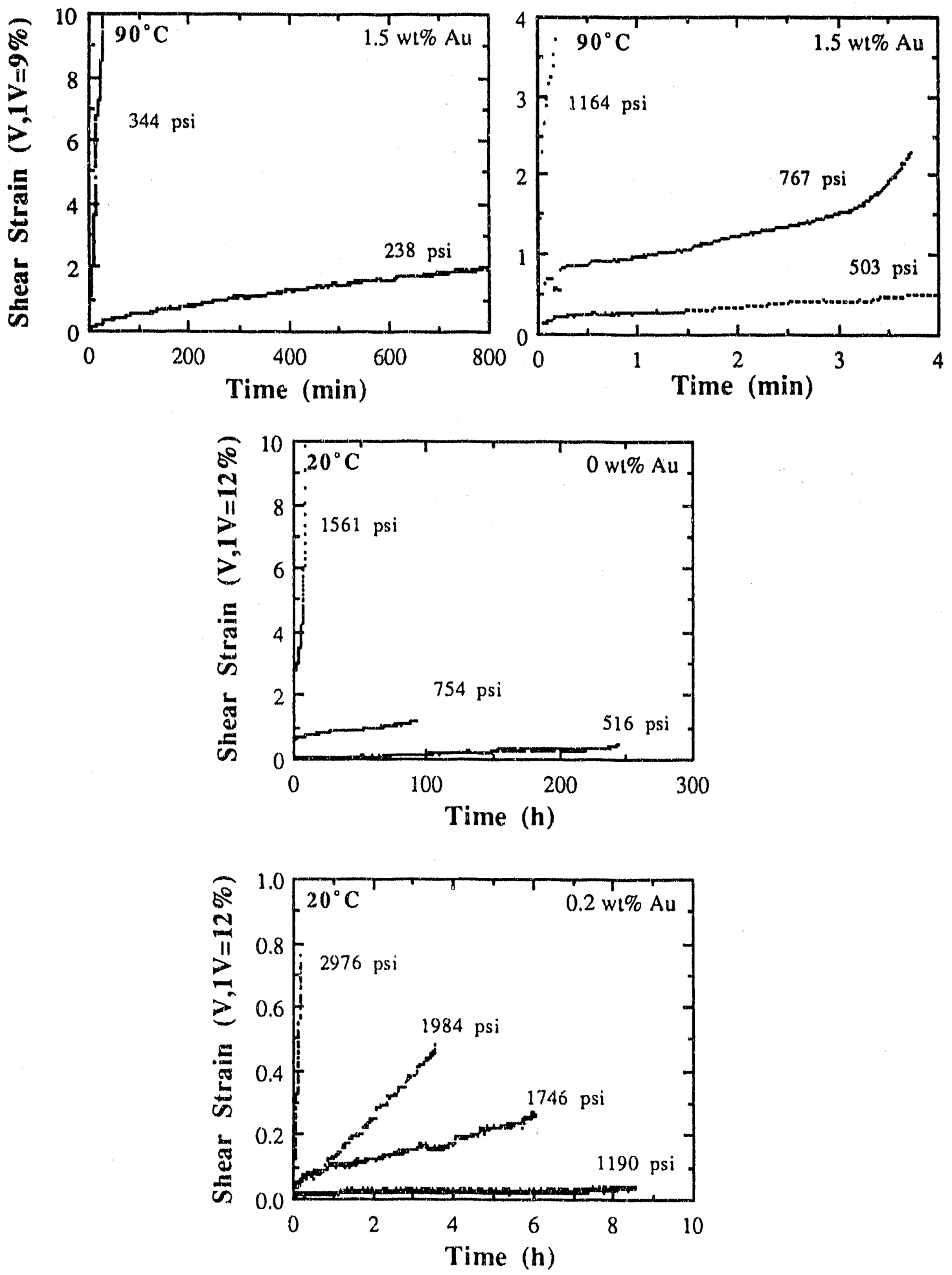

Figure 12

$20 \mu$ in $(1.5 w t \%)$ Au creep tests at $90^{\circ} \mathrm{C} ; 0 \mu$ in and $5 \mu$ in $(0.2 w t \%)$ Au creep tests at $20^{\circ} \mathrm{C}$. 

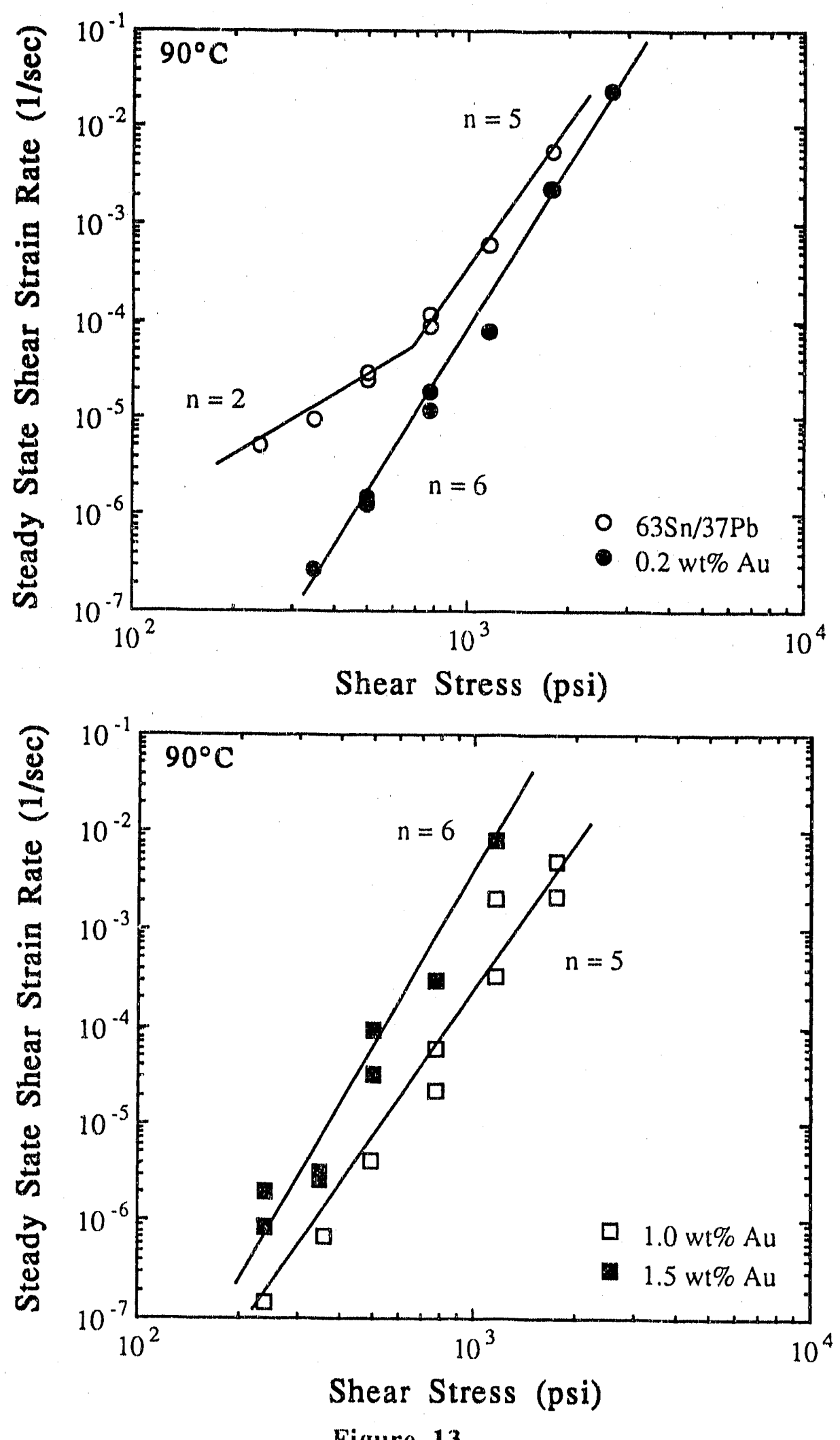

Ln shear stress vs. In steady state shear strain rate of ouin and $5 \mu$ in $(0.2$ wt\%) Au, and $10 \mu$ in $(1.0 w t \%)$ and $20 \mu$ in $(1.5 w t \%)$ Au at $90^{\circ} \mathrm{C}$.

Page 54 

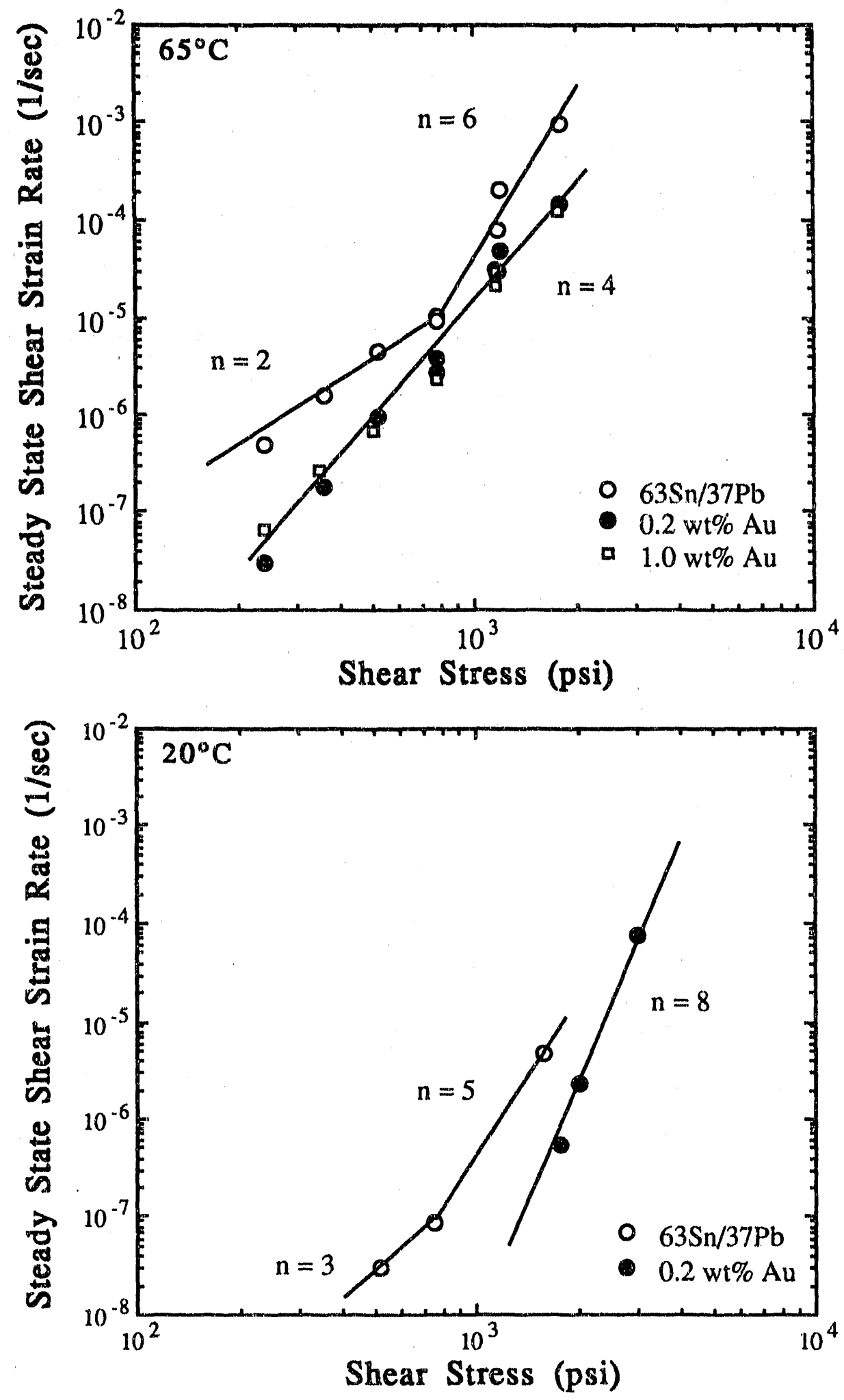

Figure 14

Ln shear stress vs. In steady state shear strain rate of $0 \mu \mathrm{in}, 5 \mu \mathrm{in}(0.2 \mathrm{wt} \%)$, and $10 \mu \mathrm{in}(1.0 \mathrm{wt} \%) \mathrm{Au}$ at $65 \mathrm{KC}$ and $0 \mu \mathrm{in}$ and $5 \mu \mathrm{in}(0.2 \mathrm{wt} \%) \mathrm{Au}$ at $25 \mathrm{KC}$.

Page 55 

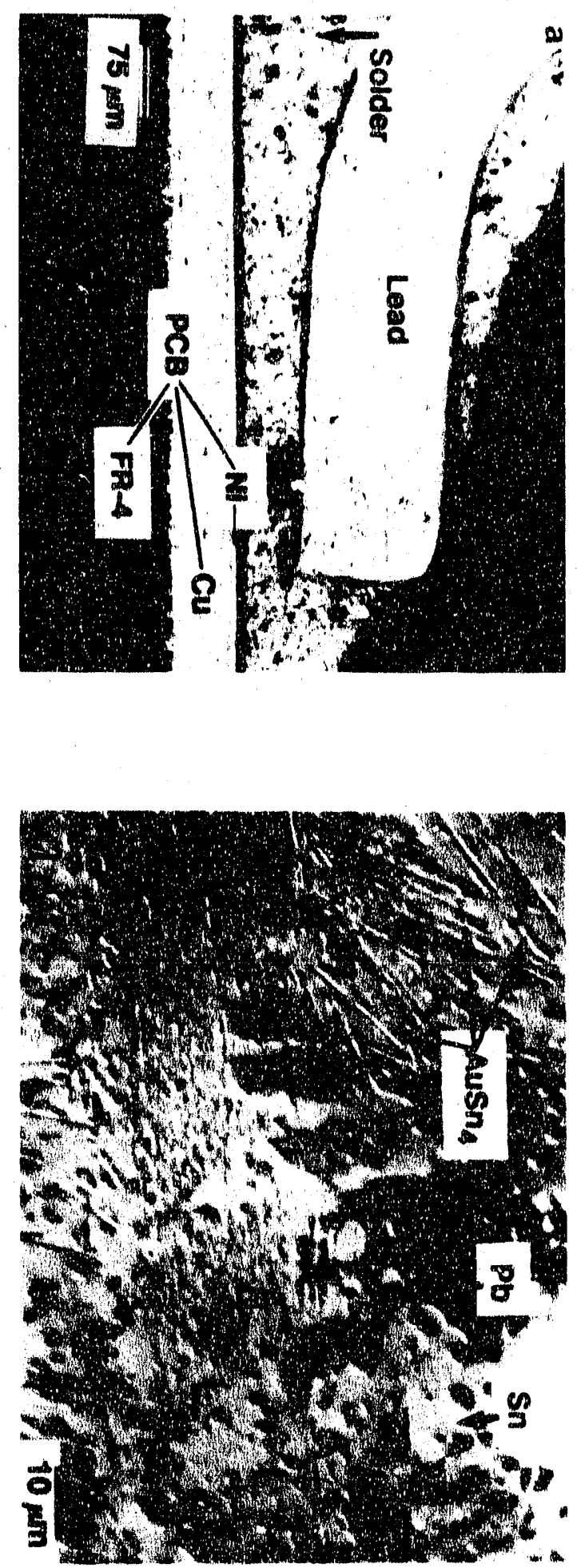

Figure 15

Optical photographs showing a) joint and b) microstructural components. (XBB 917-5144) 

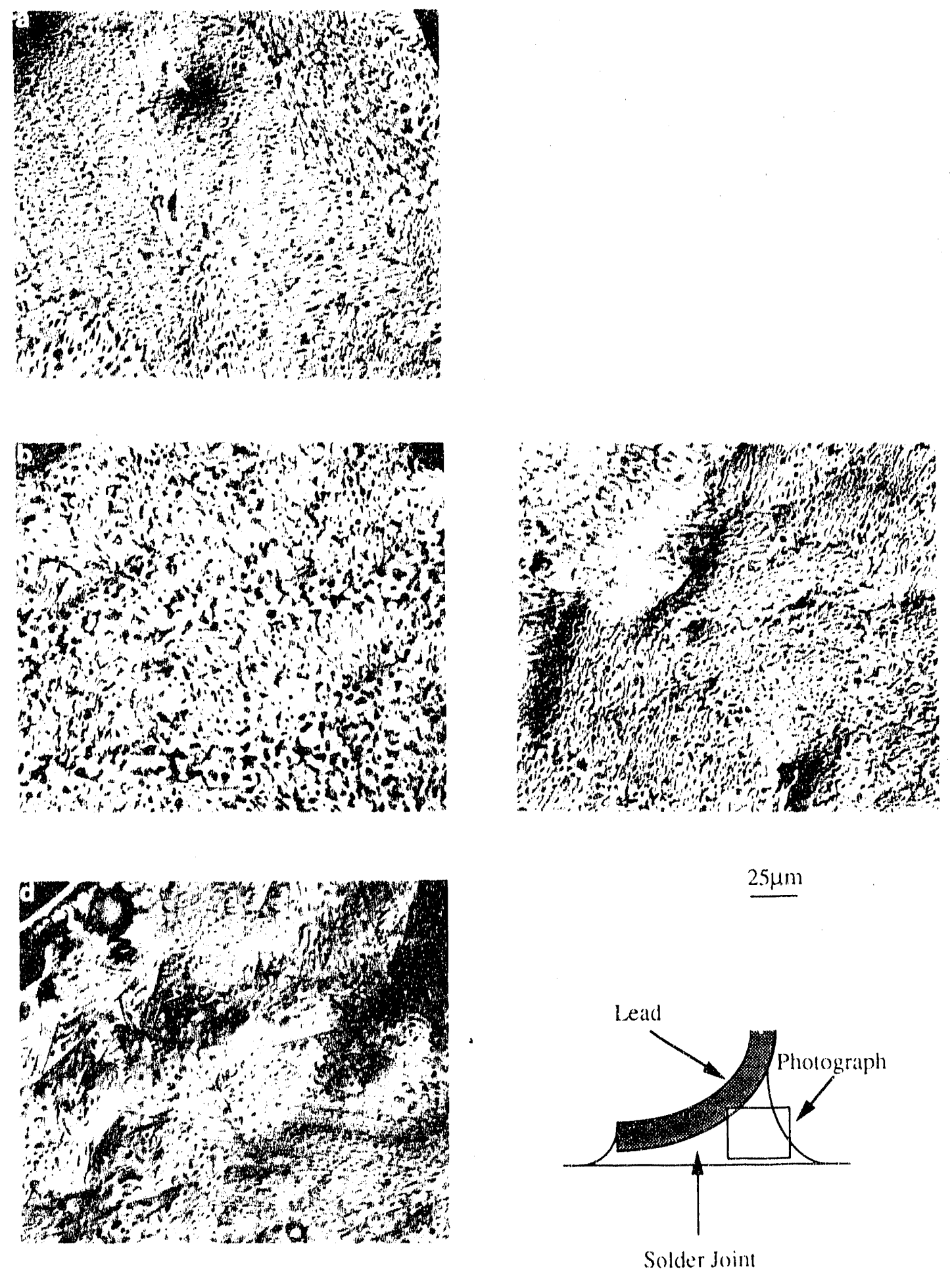

Figure 16

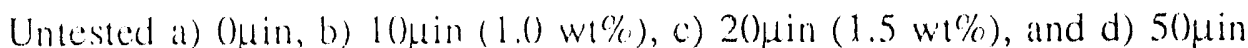
$(4.8 \mathrm{w}(\%)$ Au vibration joints showing microstructural variation throughout the joint. (XBB $924-2748$ ) 

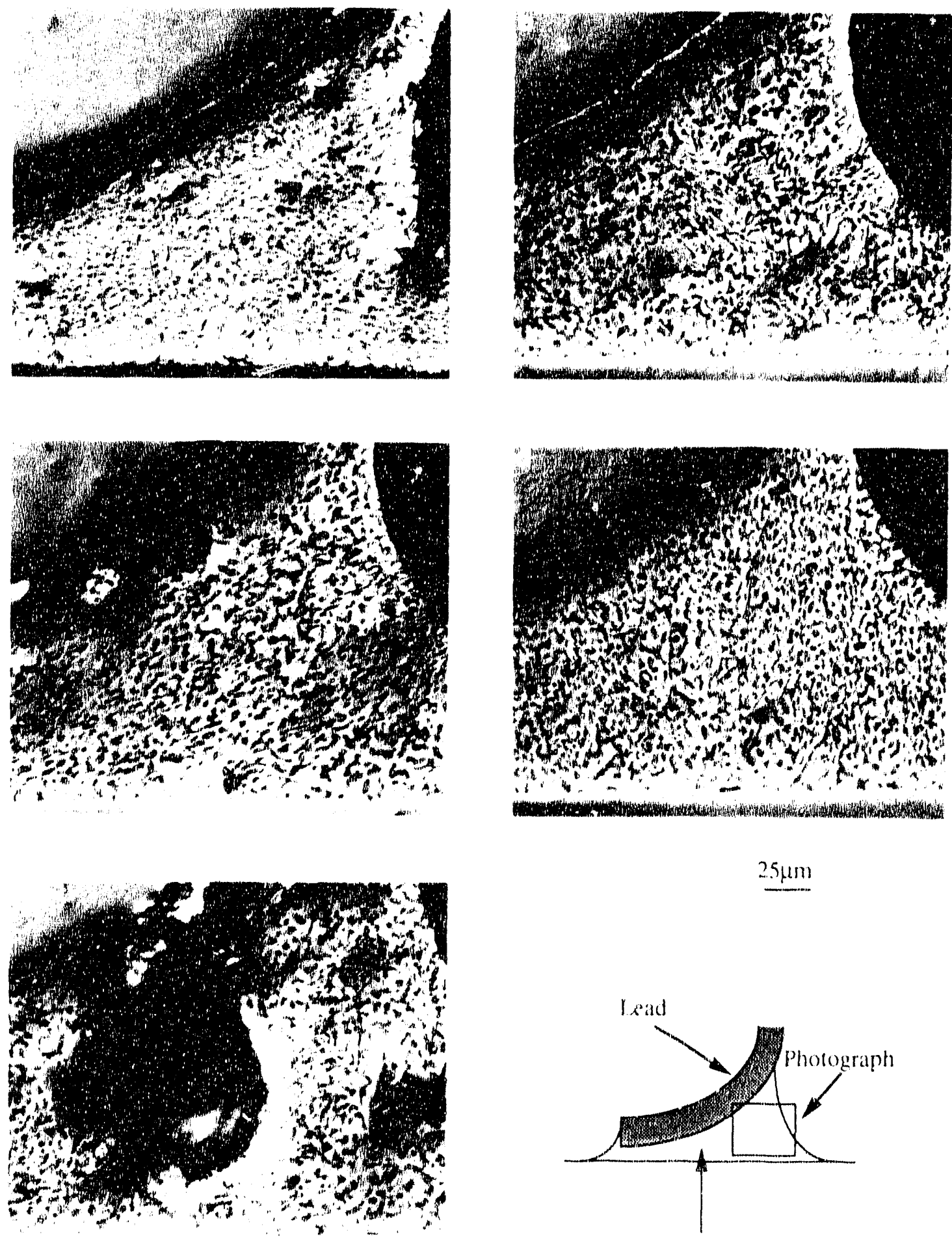

Solder Joint

Figure 17

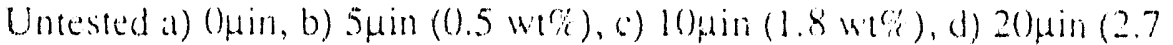

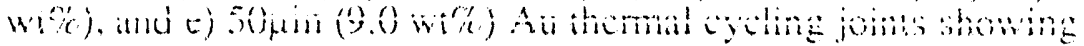
microstructual variation throughout the joint. (XBBBY2-275.5) 

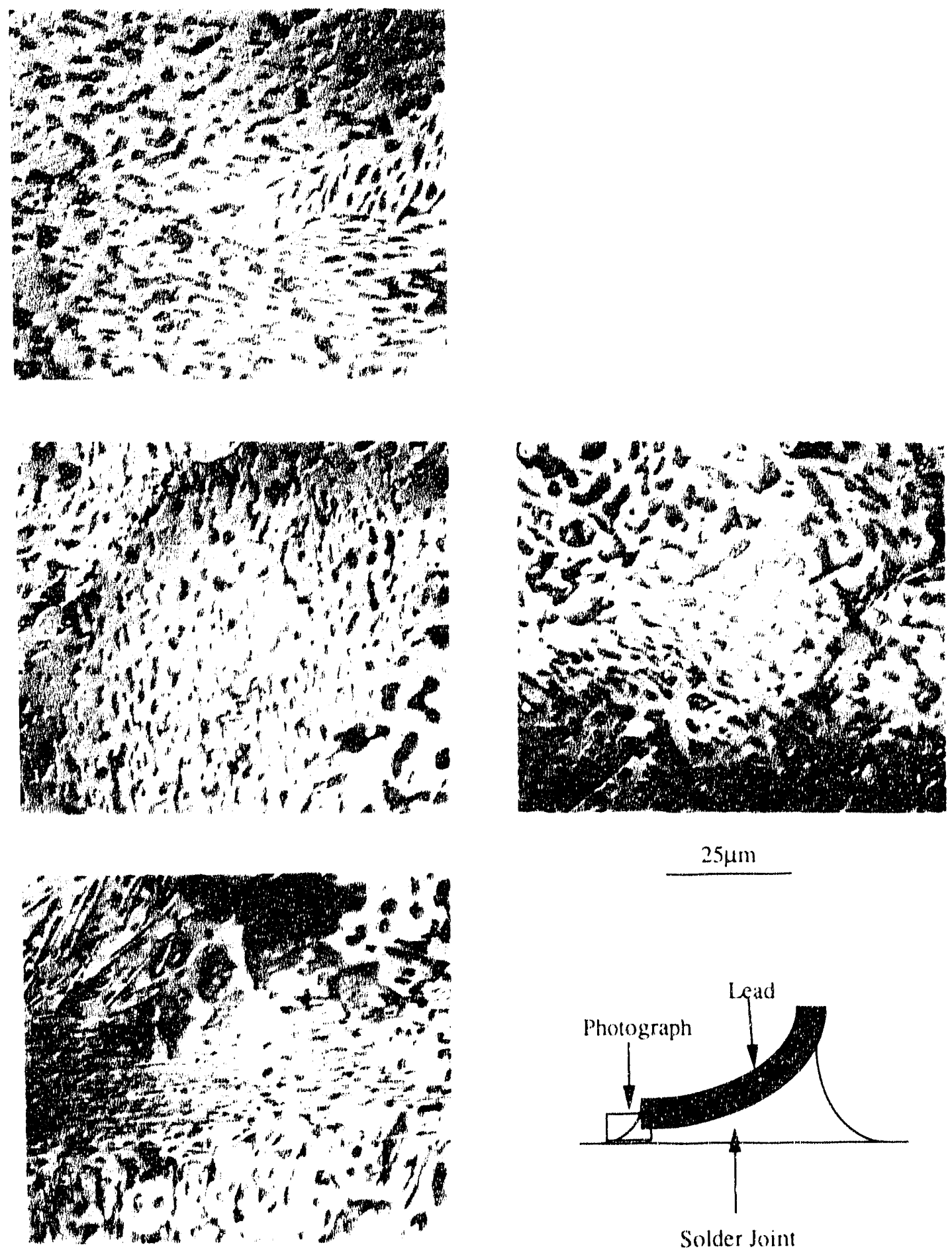

ligure 18

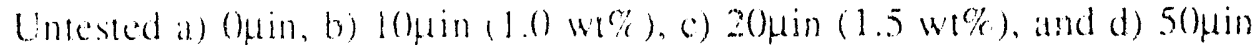
(4.8 wl\%) Auvibration joints. (XBB924-2749) 

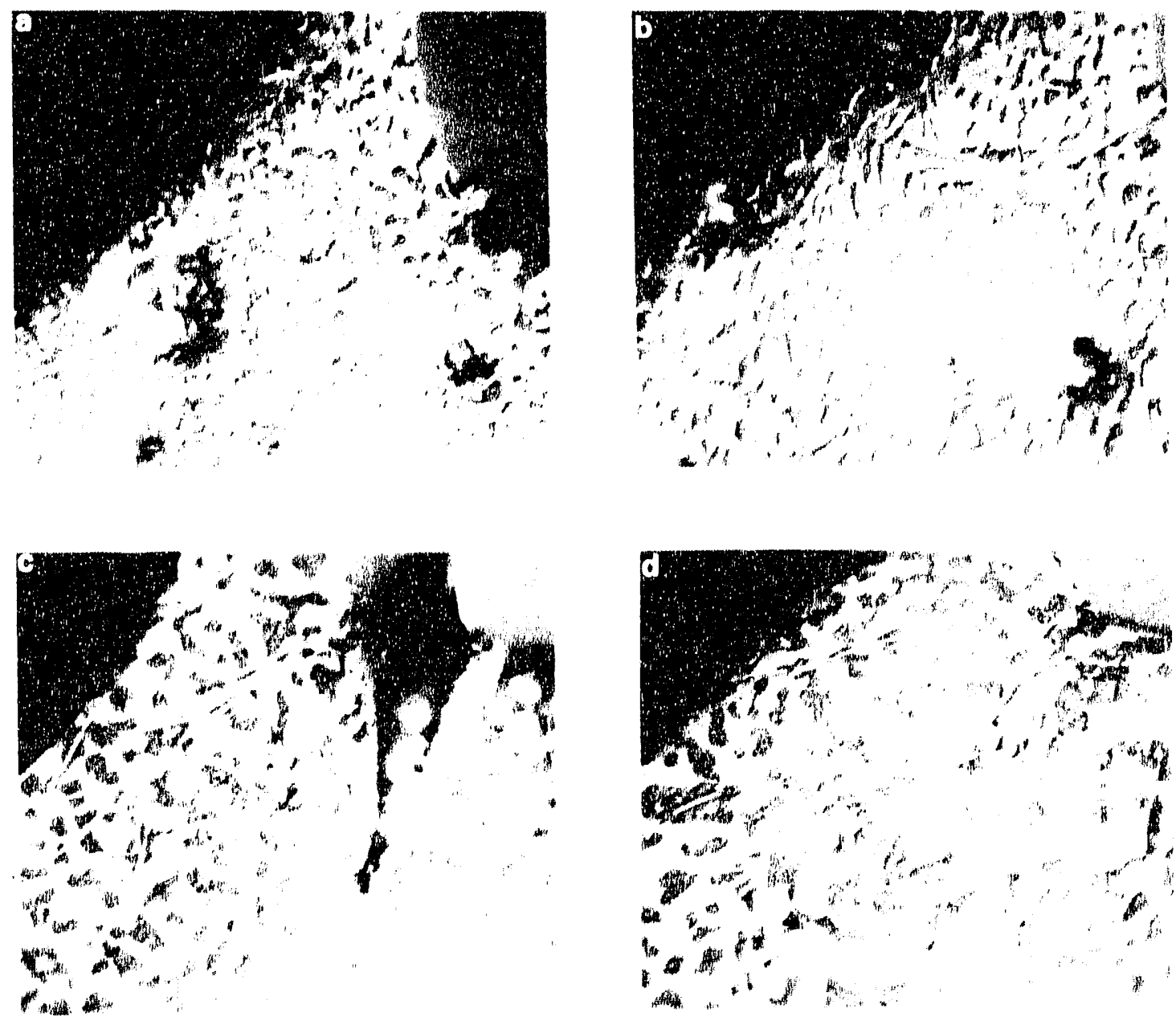

1.

14)

*is

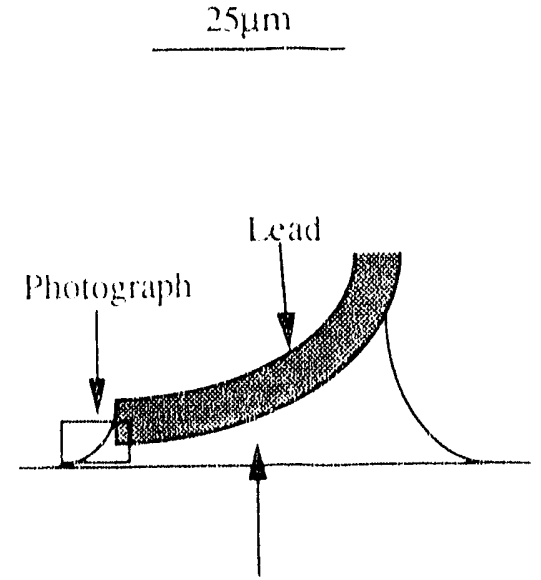

Solder Joinil

Figure 19

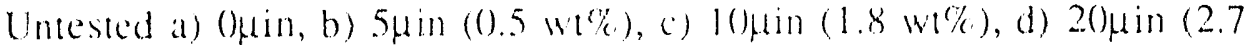

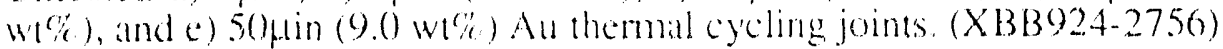



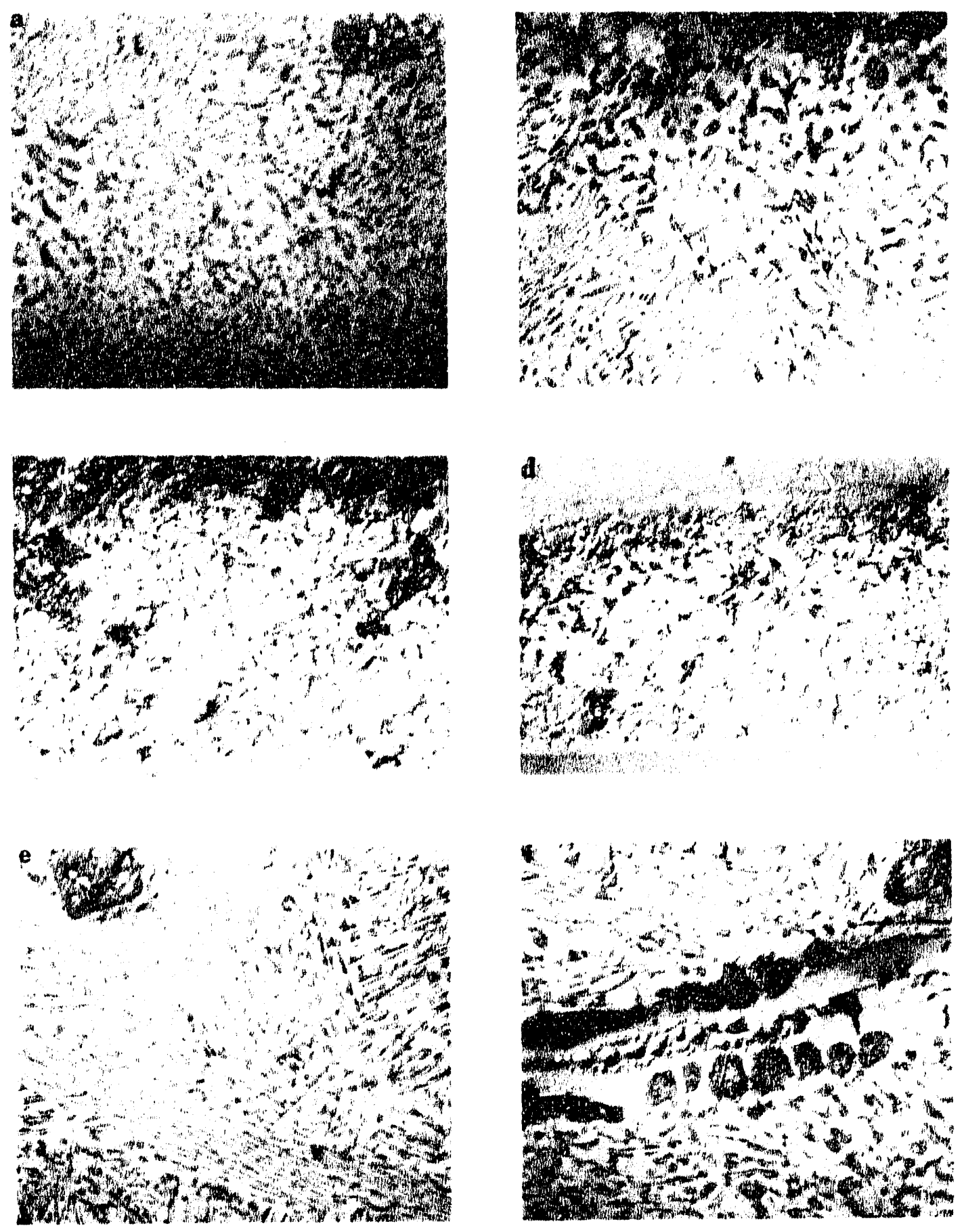

$25 \mu \mathrm{m}$

Figure 20

Untested a) (O)in, b) $5 \mu \mathrm{in}(0.2 \mathrm{wt} \%)$, c) $10 \mu \mathrm{in}(1.0 \mathrm{wt} \%$, d) 2(0) in (1.5 wt\%), and e) and f) $5($ ) pin (5.3 wt\%) Au creep joints. (XBB924-2765) 

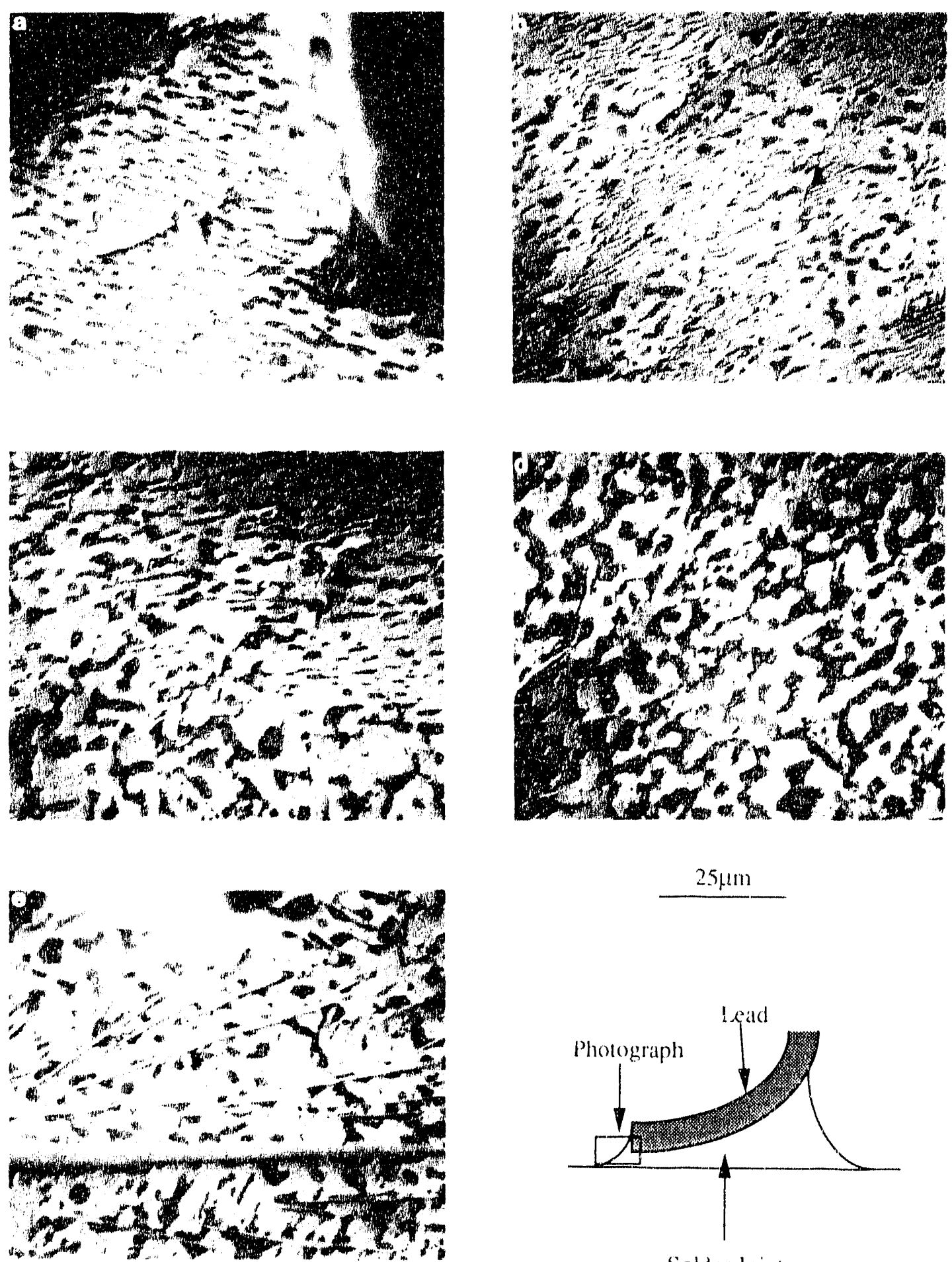

Figure 21

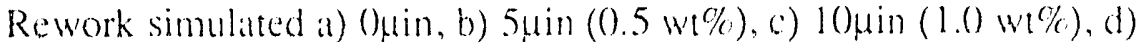
20 uin $(1.5 \mathrm{wt} \%)$, and e) 50 uin $(4.8 \mathrm{wr} \%)$ Au untested vibration joints. (XBB(2) 2-275()) 

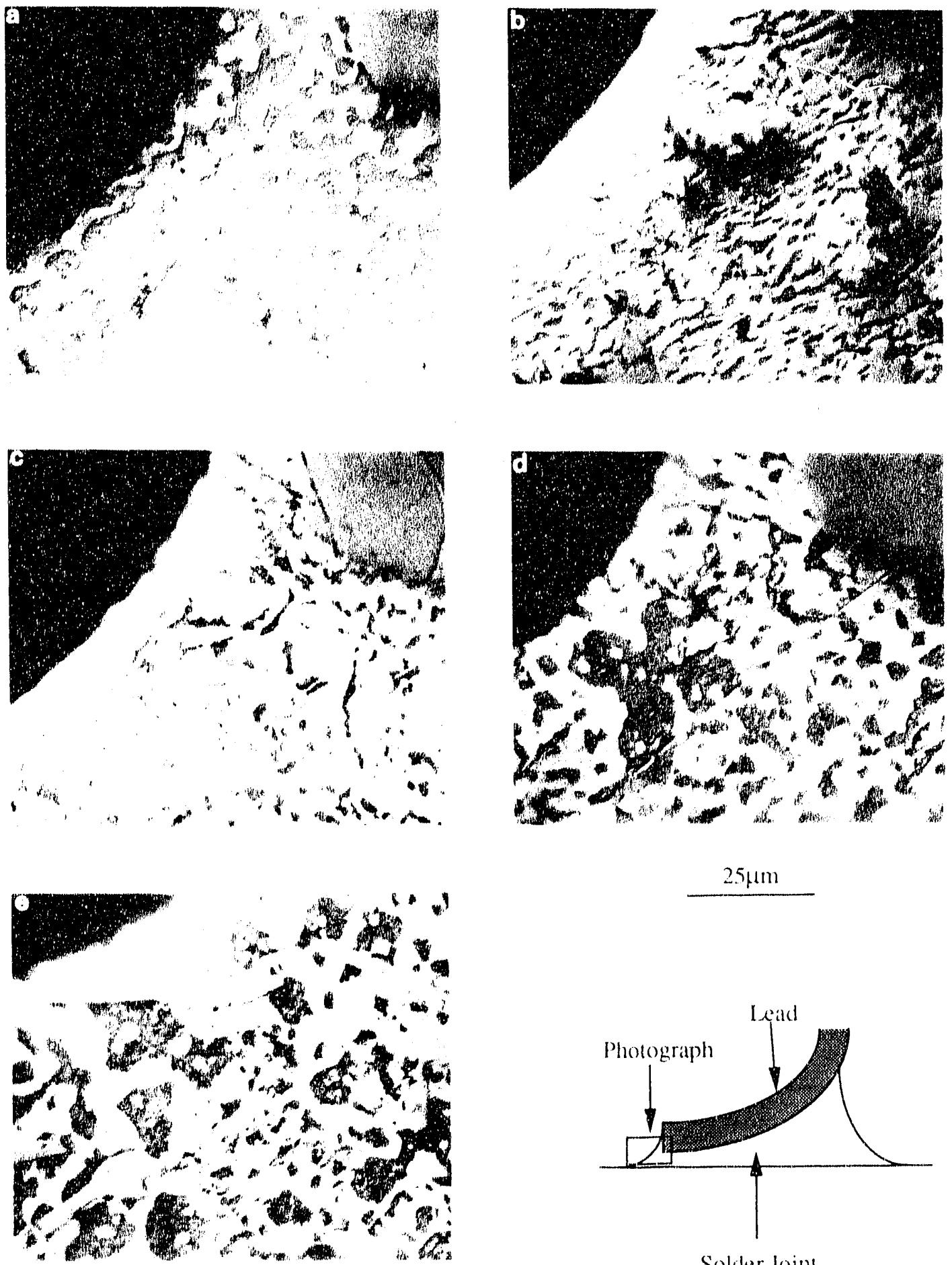

Solder Join

Figure 22

Rework simulated a) () pin, b) $5 \mu$ in $(0.5 \mathrm{wt}(\%)$, c) $1(0)$ in $(1.8 \mathrm{wt} \%)$, d) 2()$\mu$ in $(2.7 \mathrm{wt} \%)$, and e) 5()$\mu \mathrm{in}(9.0 \mathrm{wt} \%$ ) Au untested thermal cycling joints. (XBBS24-2757) 

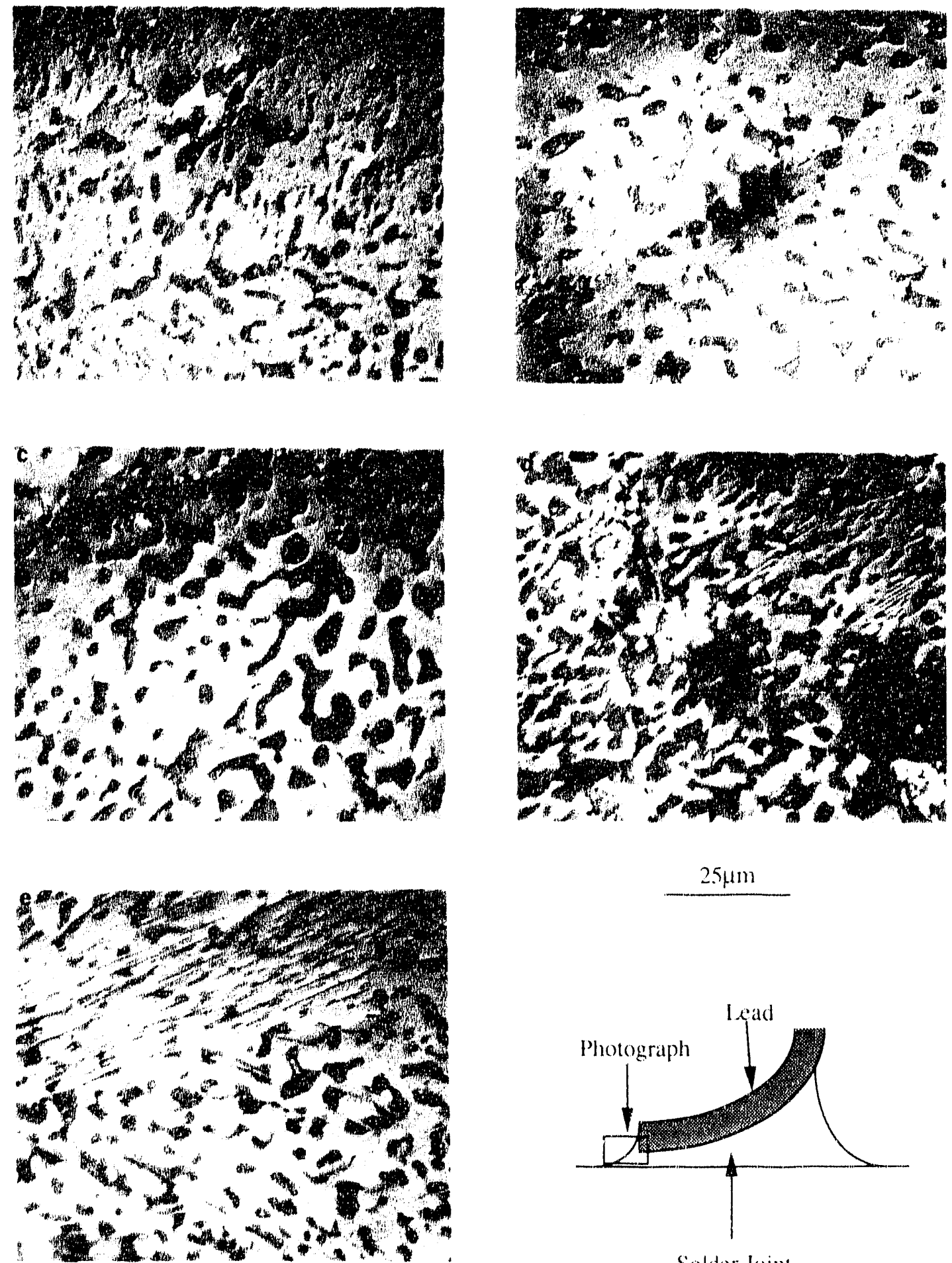

rigure 23

Solder Joint

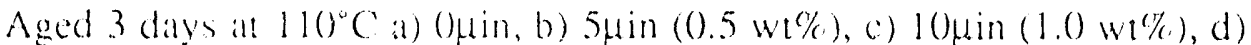
2()uin (1.5 w/ and e) 50 uin $(4.8$ wt\%) Au untested vibration joints. $(X B B 924-2751)$ 

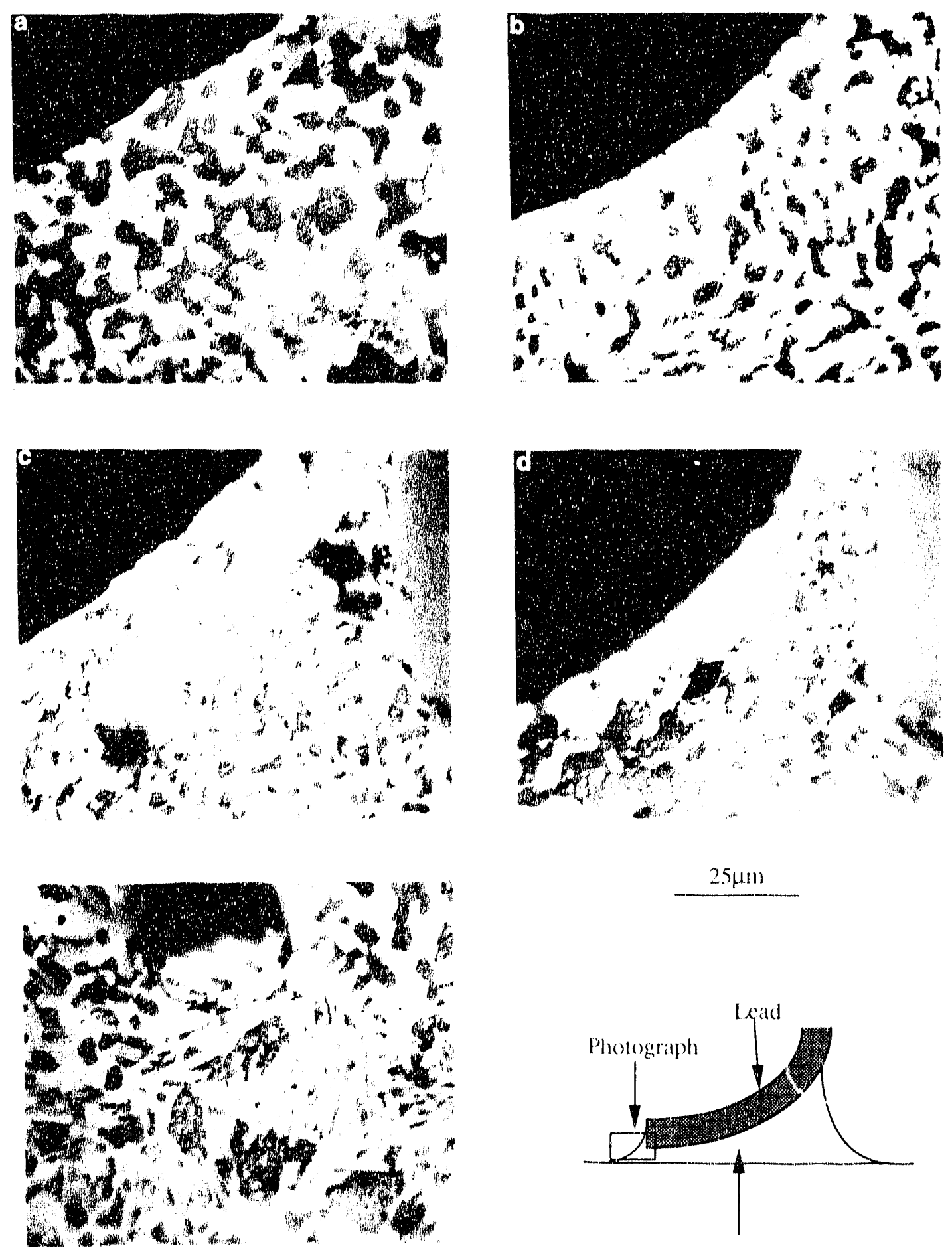

Solder Joint

Figure 24

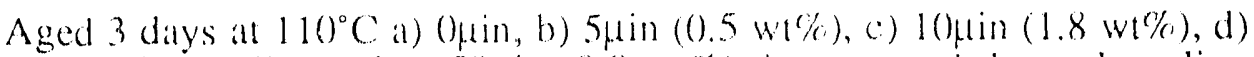
2()$\mu \mathrm{in}(2.7 \mathrm{wt} \%)$, and (:) 5()$\mu \mathrm{in}(9.0)$ wi\%) Au unlested thermal cycling joints. (XBB924-2758) 


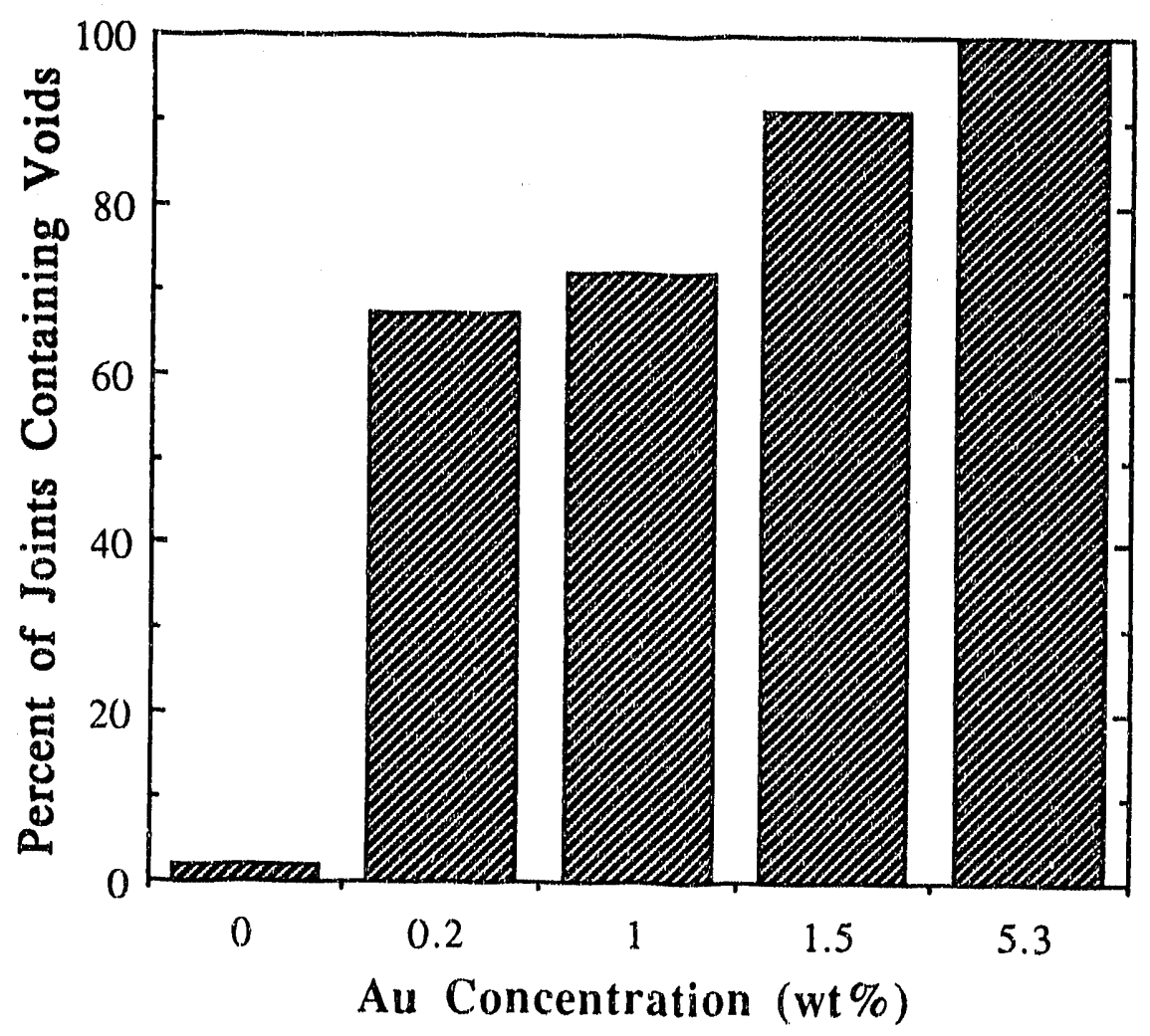

Figure 25

Plot of the percentage of creep joints containing voids. 


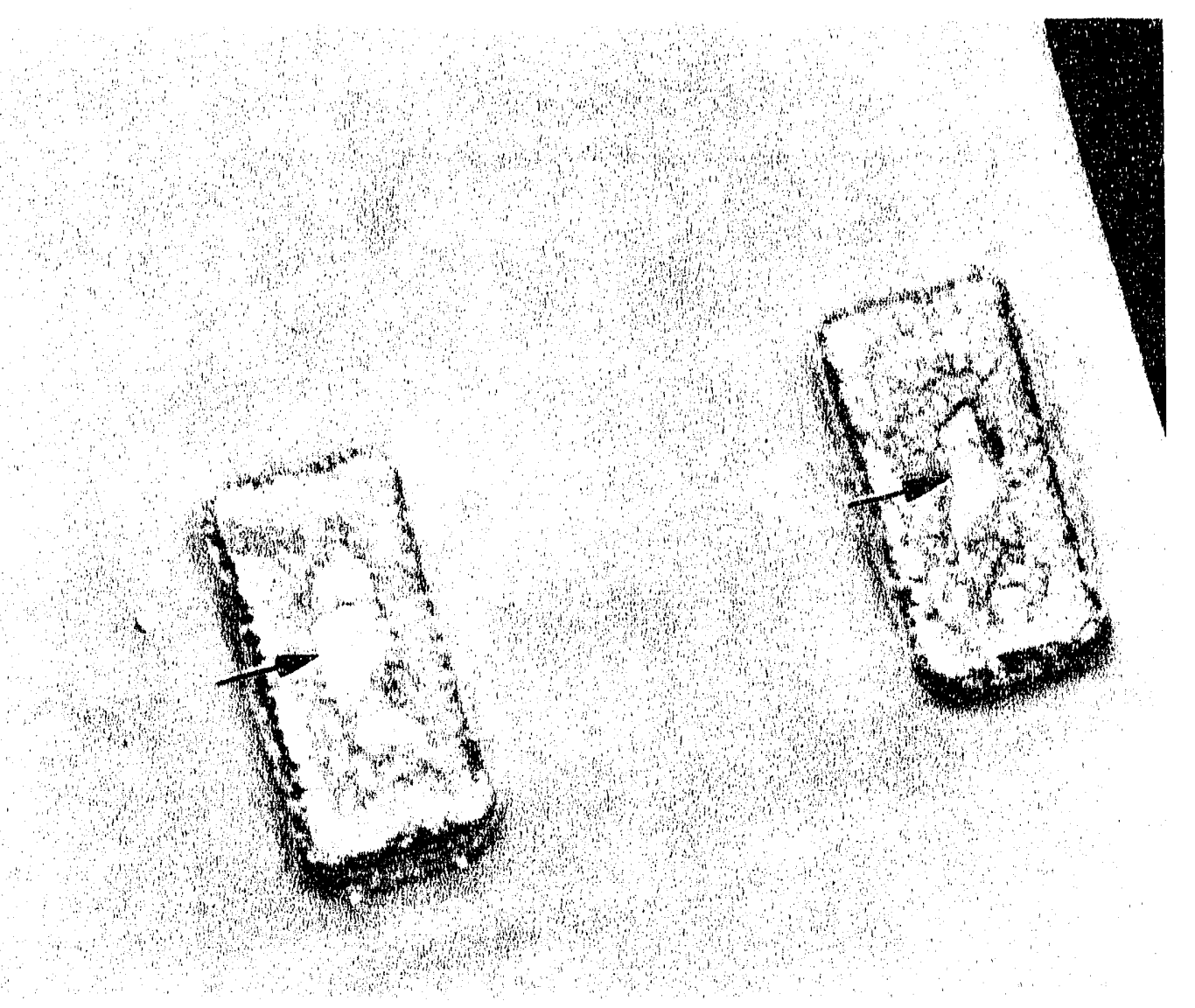

Figure 26

Top view of $50 \mu$ in $(5.3 \mathrm{wt} \%)$ Au creep joints containing voids. Voids are shown by atrows. (XBB925-3172) 

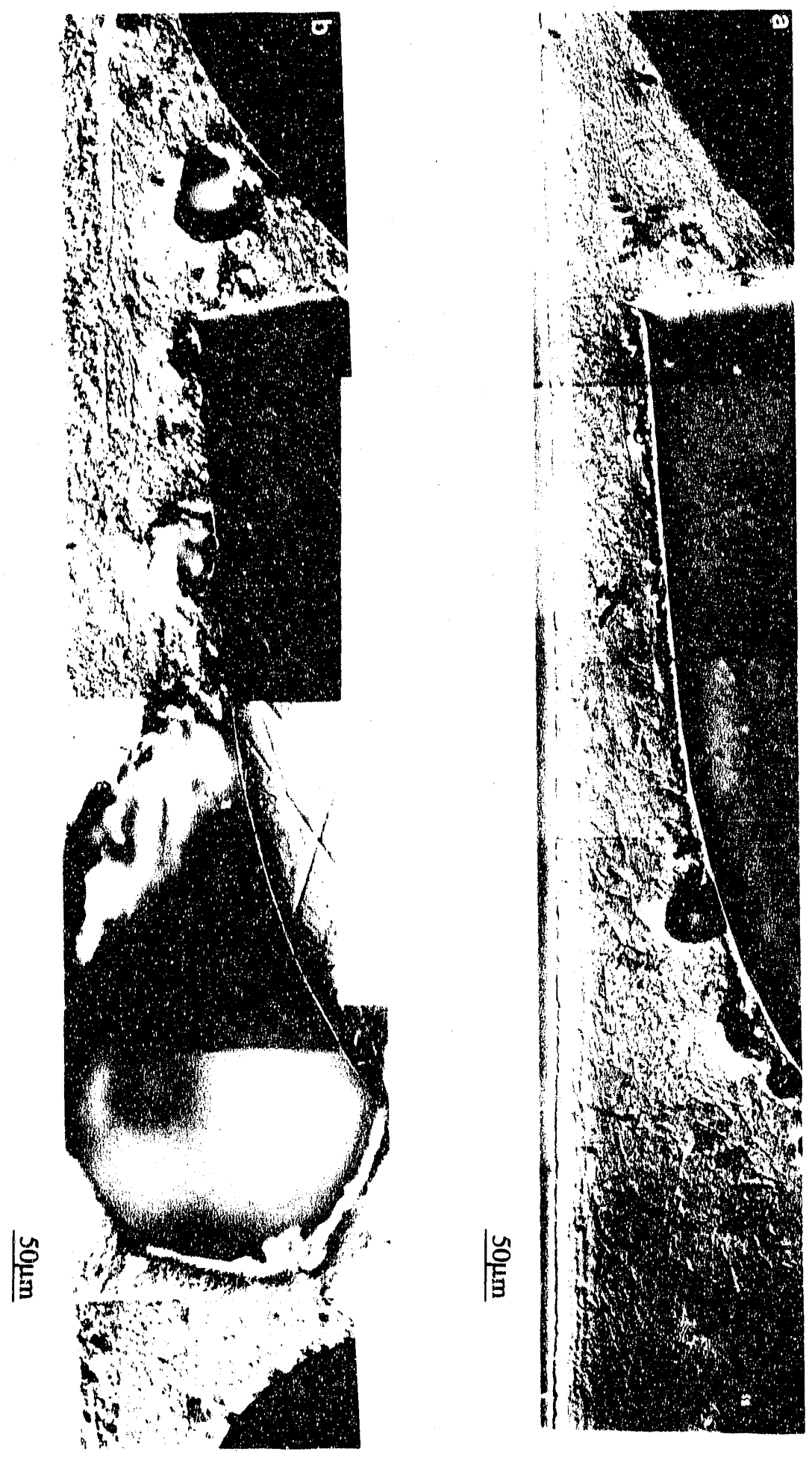

Figure 27

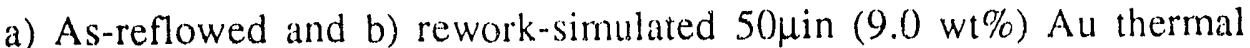
cycling joints showing void coalescence and growth.(XBB911-246) 

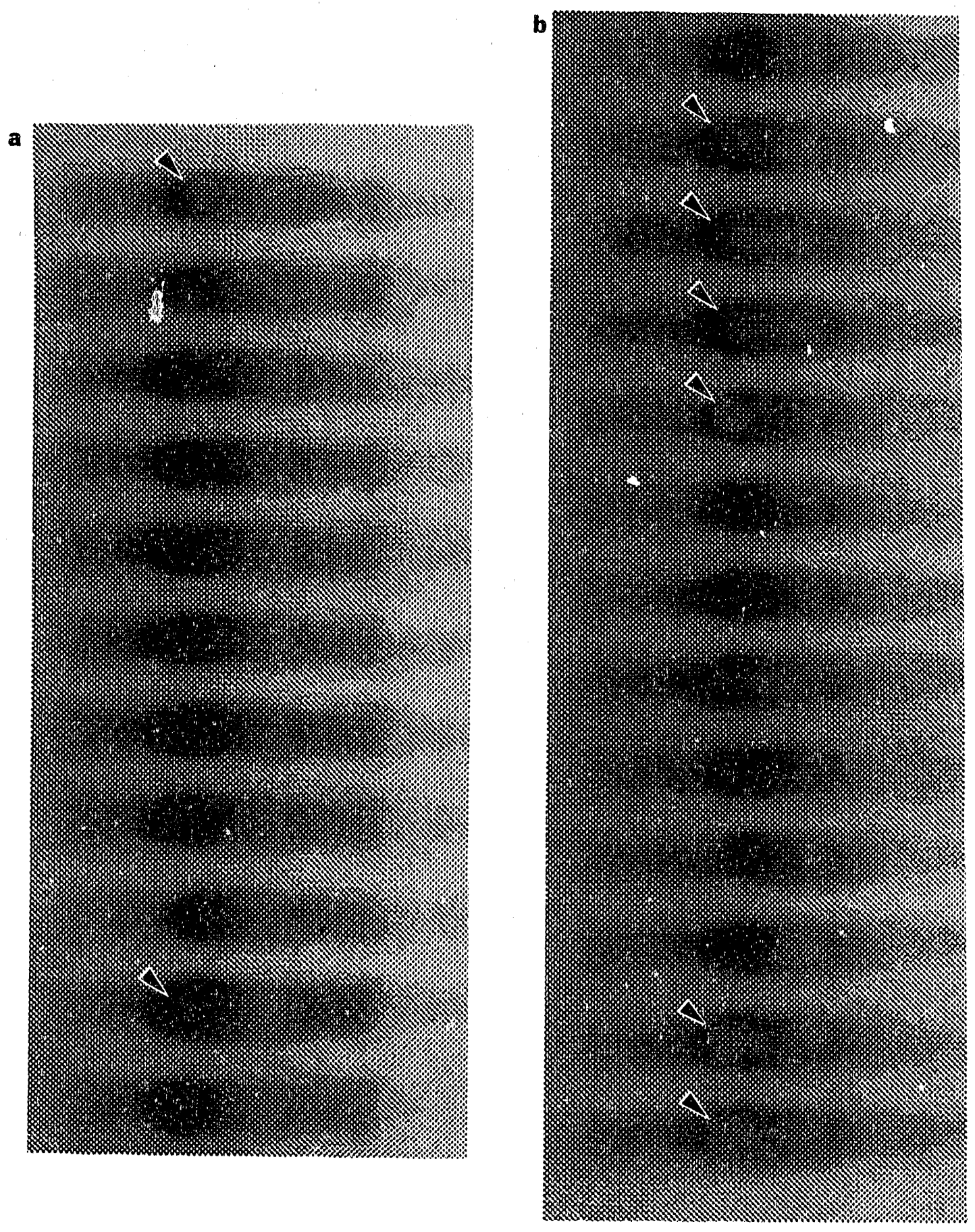

Figure 28

$\mathrm{X}$-ray laminography of a) as-reflowed and b) rework simuiated $50 \mu$ in (4.8 wt\%) Au vibration reliability joints. Voids are shown by arrows. 

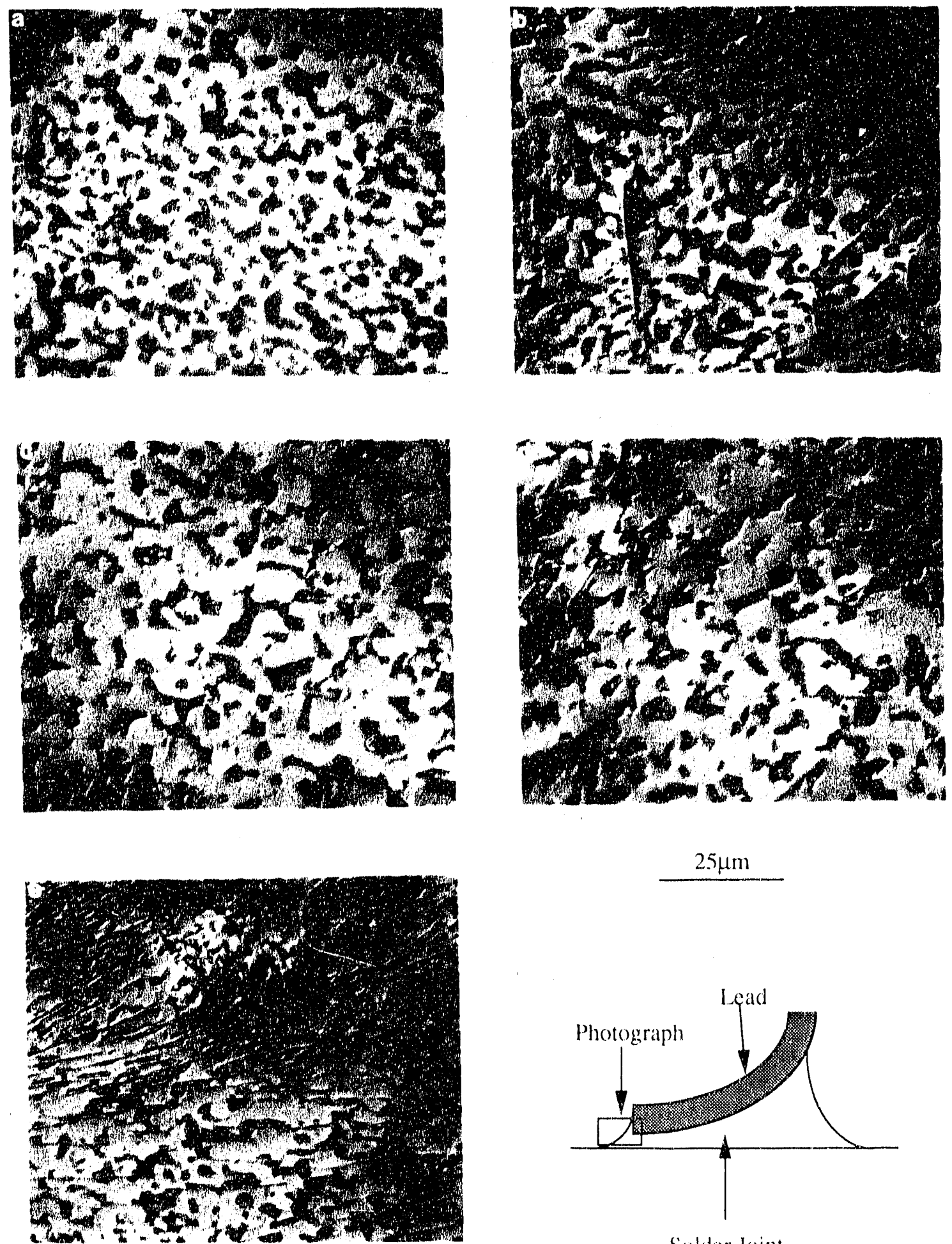

Figure 29

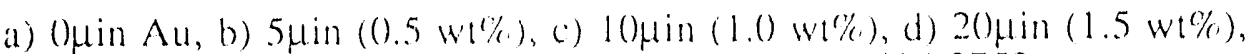
and e) $5($ ulin $(4.8 \mathrm{wt} \%$ ) vibralion kested joinls. (XBB)24-27.52) 

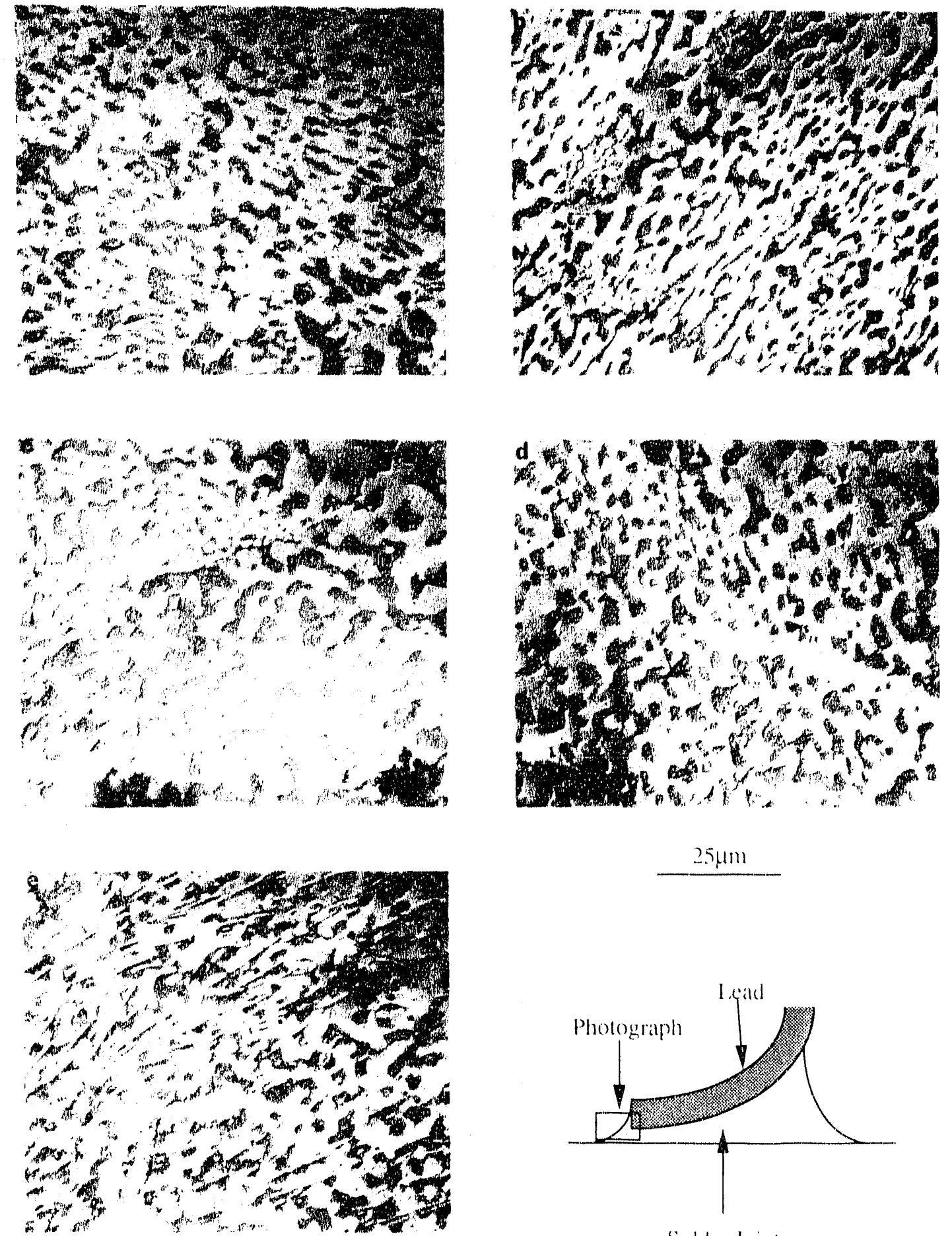

Solder Joint

Figure 30

Rework simulated a) () uin, b) $5 \mu \mathrm{in}(0.5 \mathrm{wt} \%)$, c) $1(0 \mu \mathrm{in}(1.0 \mathrm{wt} \%)$, d) $20 \mu \mathrm{in}(1.5 \mathrm{wt} \%)$, e) $5(0) \mathrm{in}(4.8 \mathrm{wt} \%)$ and Au vibration tested joints. (XBB924-2753) 


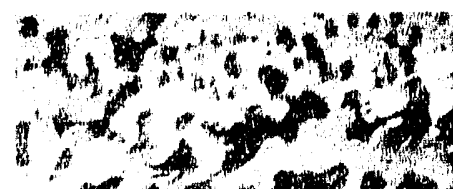

(1)

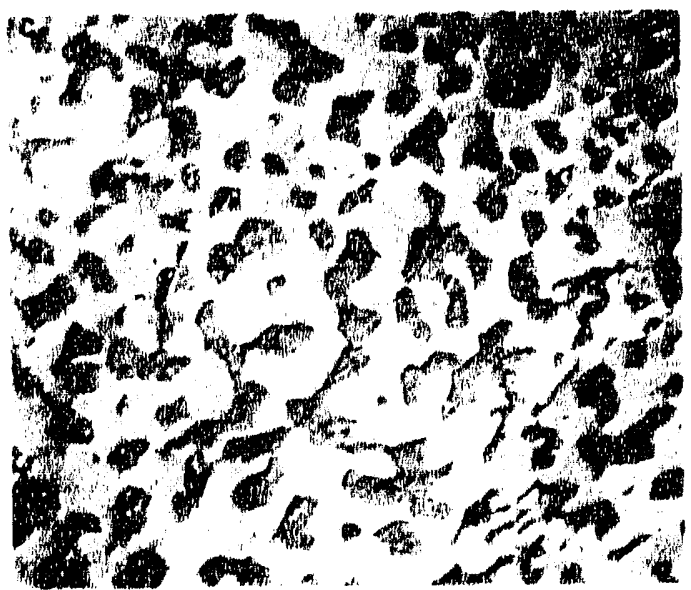

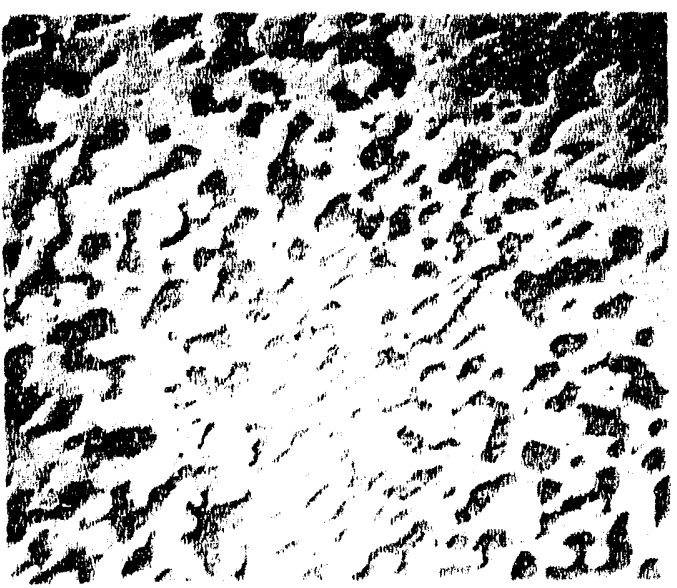

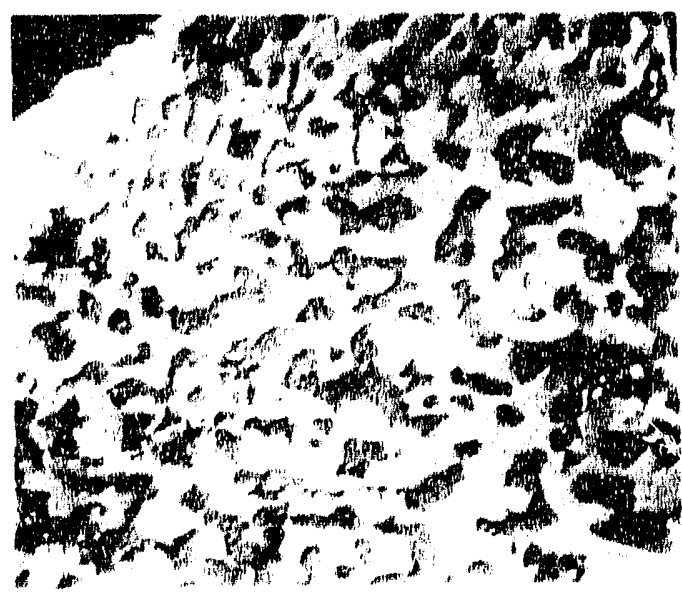

\section{$25 \mu \mathrm{m}$}

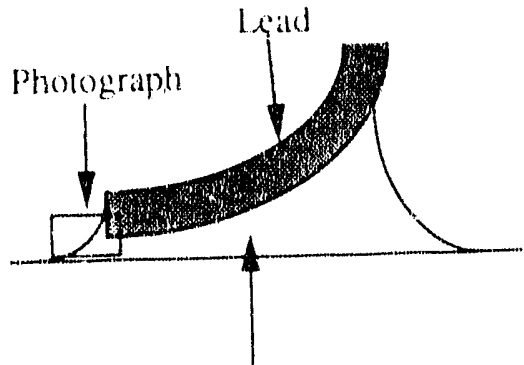

Sulder Joint

Figure 31

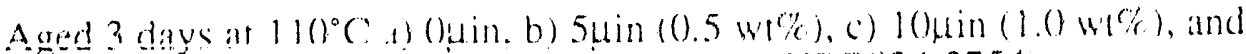

d) 20 Hin (1.5 wt \%) Au vibration tested joints. (XBB'24-2754) 


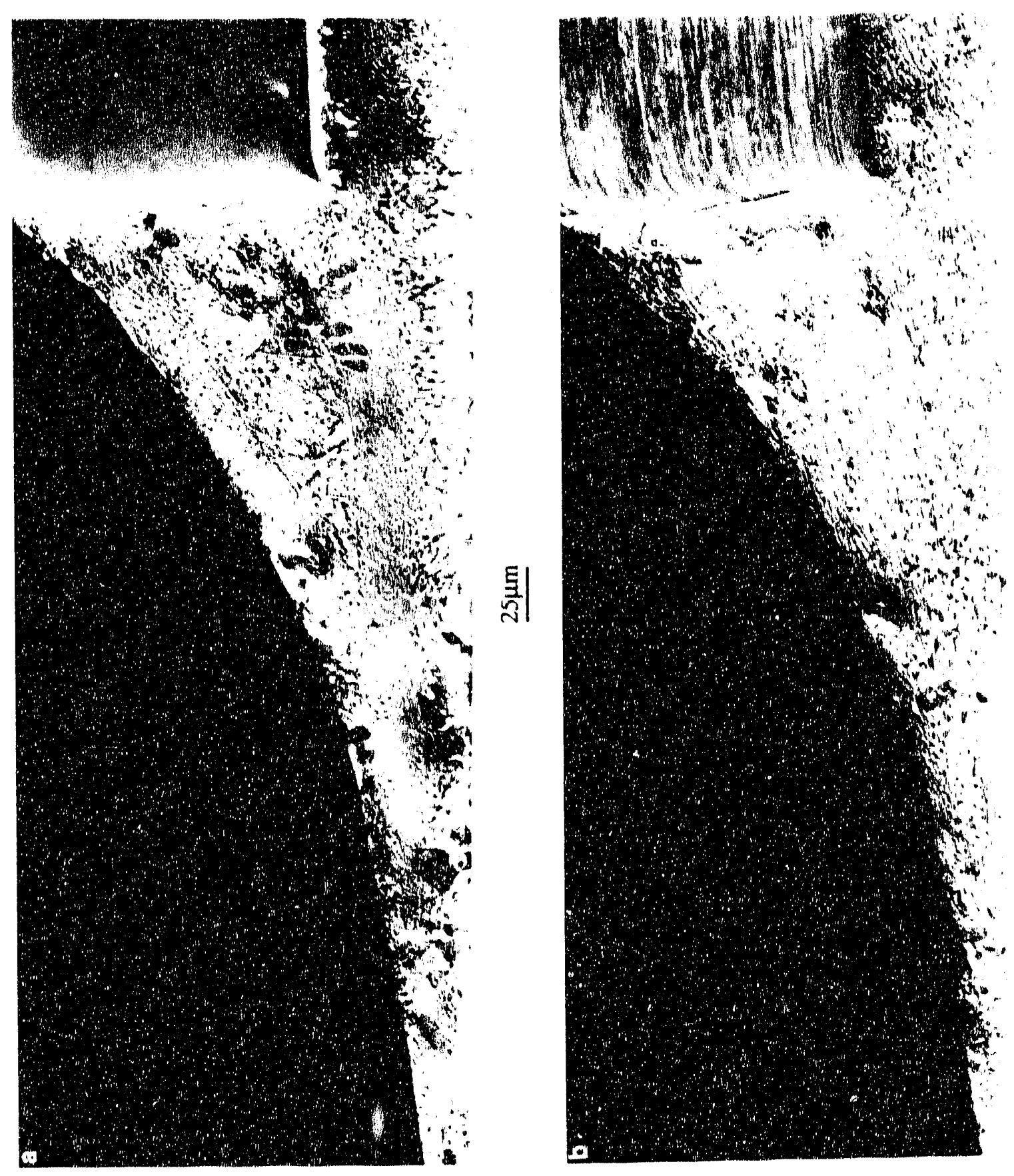

Figure 32

a) Untested and b) tested 50 pin $(4.8$ w1\%) All vibration joints showing intermerailic rotation in the tested juint. (XBBSi 1 -24.5) 

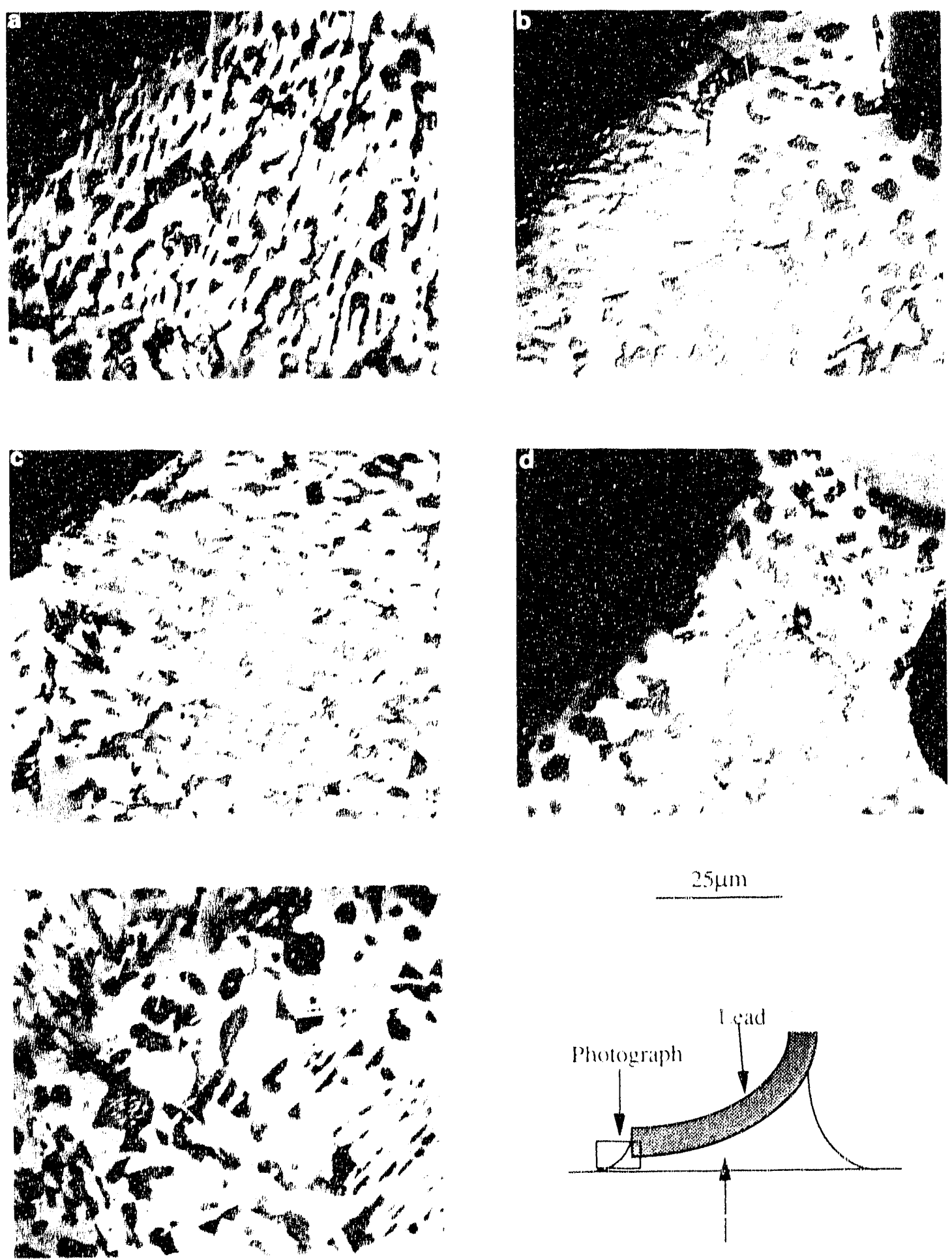

Soluer Joint

Figure 33

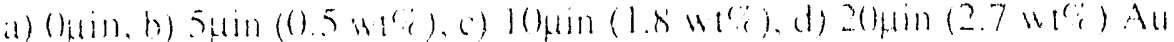

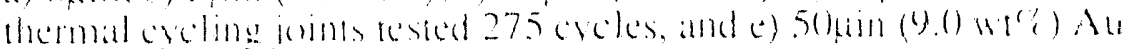

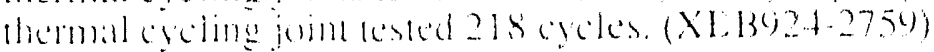

Pigec 74 

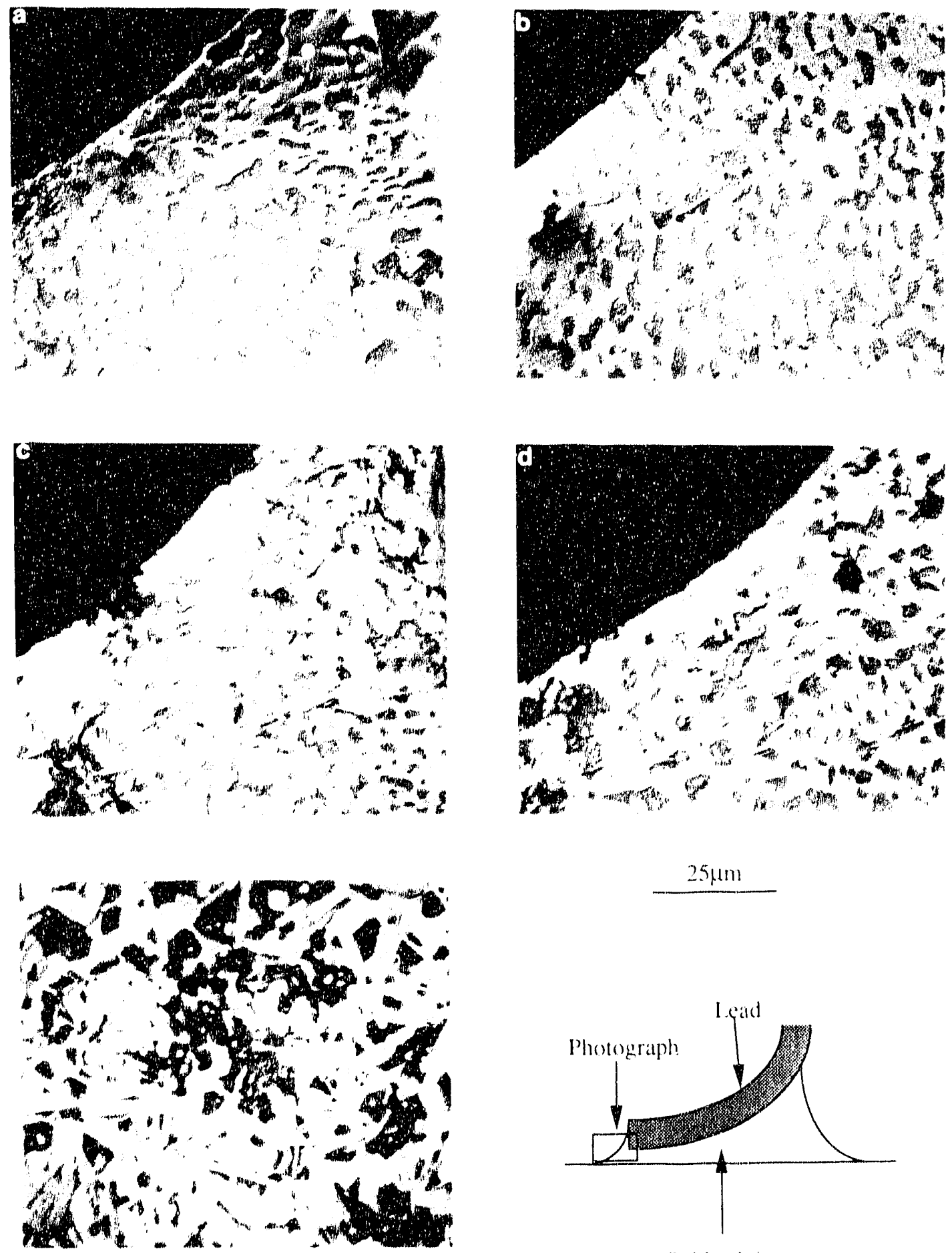

Solder bom

Figure 34

Rework sumulated b) 5 pin $(0.5 \mathrm{w} \%)$, c) $1(0 \mu \mathrm{in}(1.8 \mathrm{wt} \%)$, and d) 20 pin $(2.7 \mathrm{w} \%$ ) Au thermal cyeling joints tested 27.5 cyeles, and a) (opin and e)

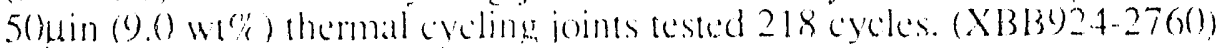



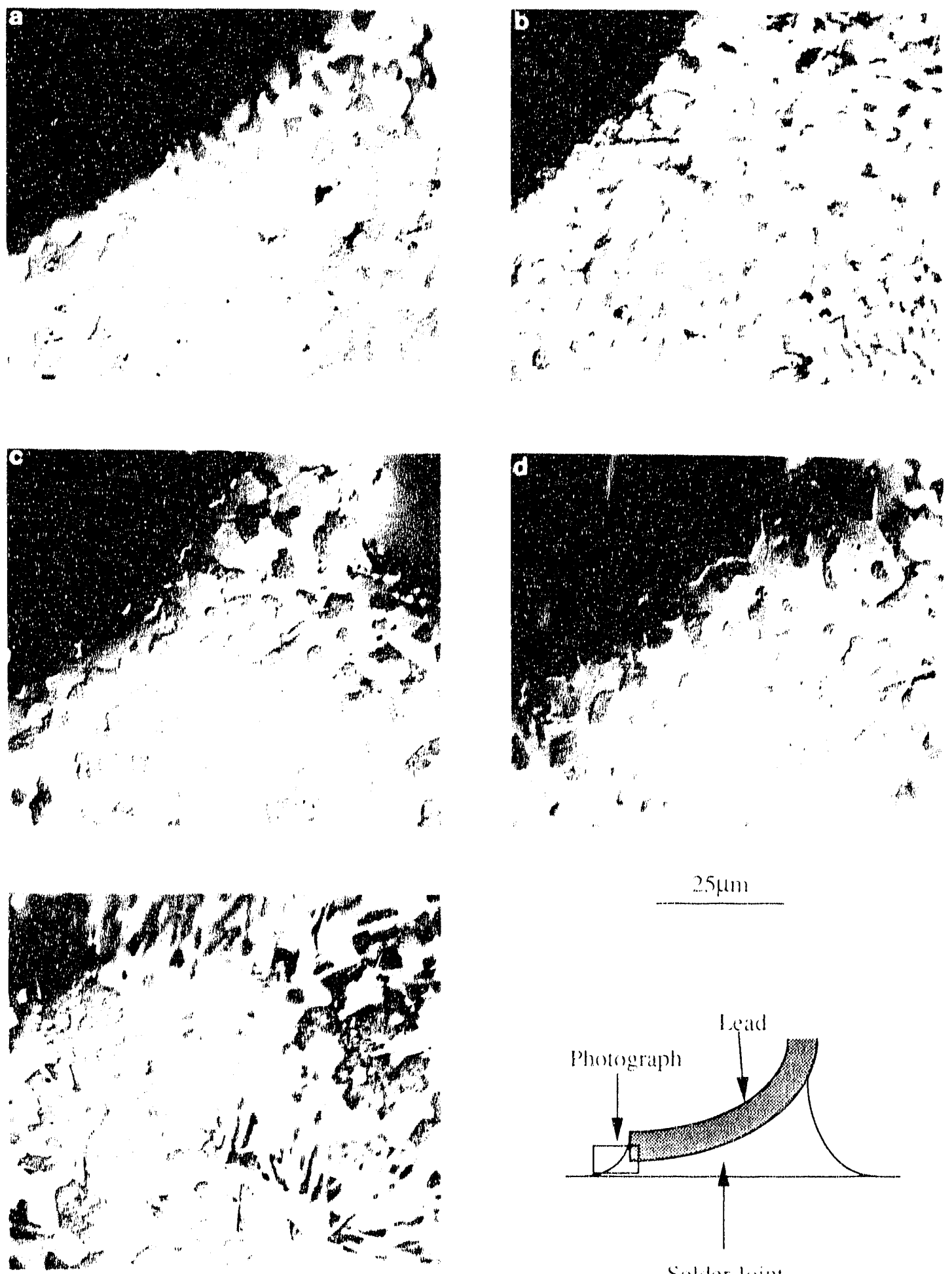

Figure 35

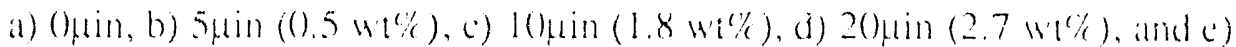

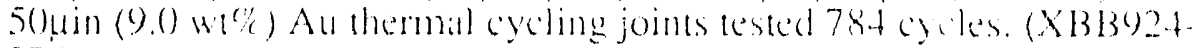
276 i) 

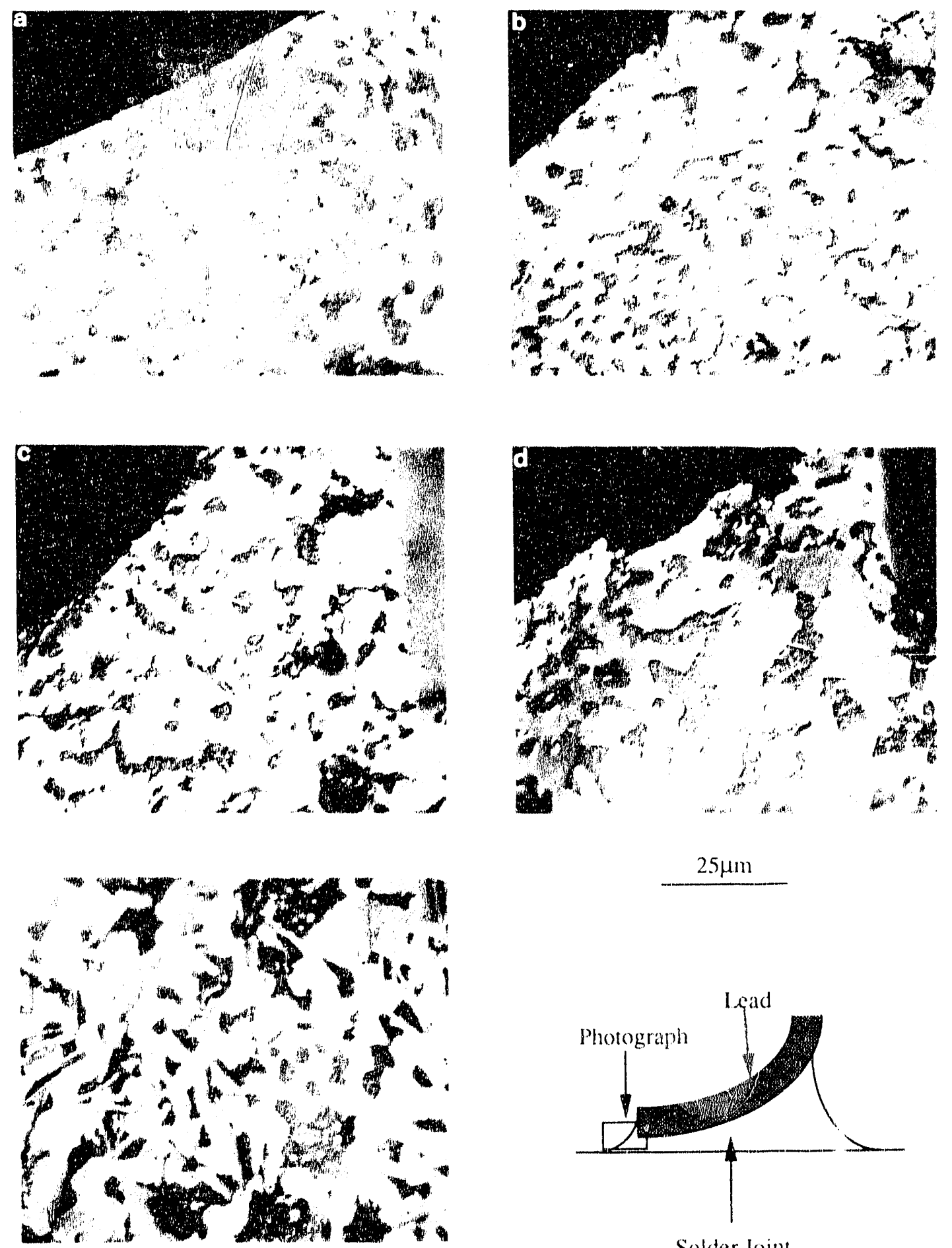

Solder Joint

Figure 36

Rework simulated it) (1) in, b) 5 min (0.5 wt \% ) c) $10 \mu$ in $(1.8 \mathrm{wi} \%$, d)

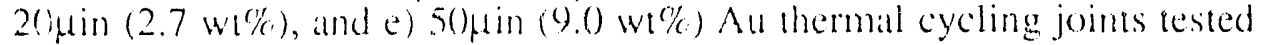
784 cycles. (X13B924-2762) 

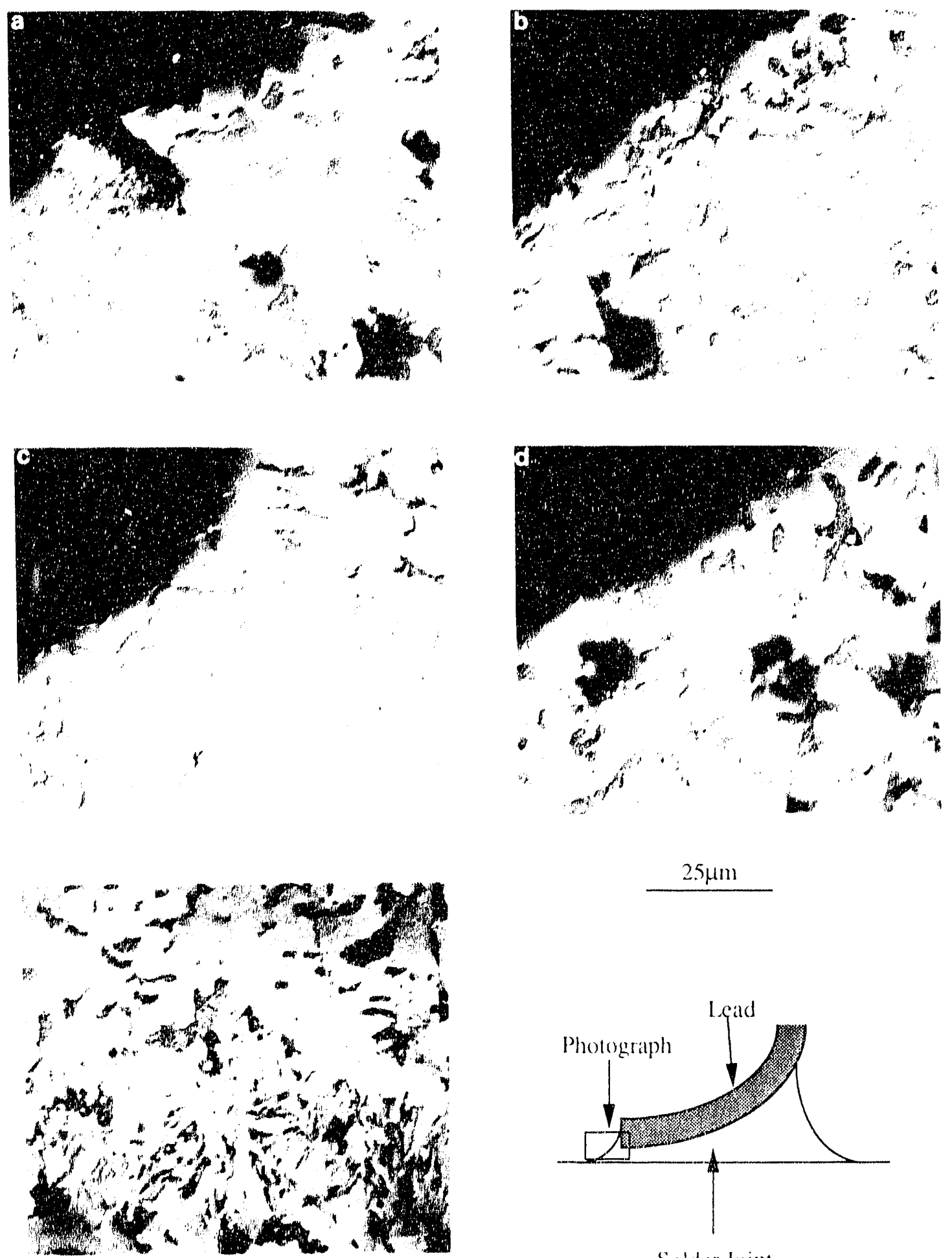

\section{$2.5 \mu \mathrm{m}$}

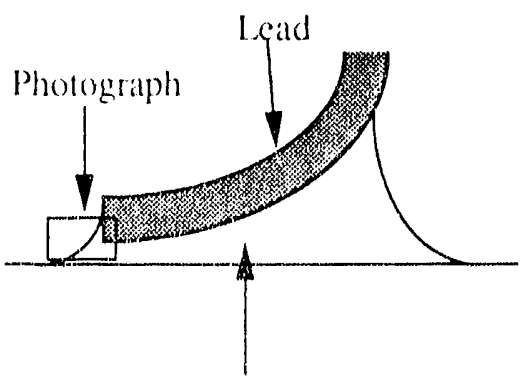

Solder Joint

Figure 37

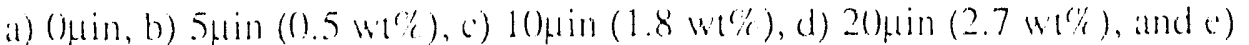

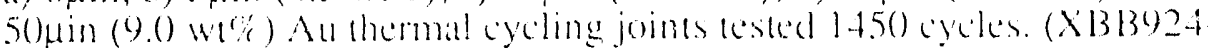
$276.3)$ 

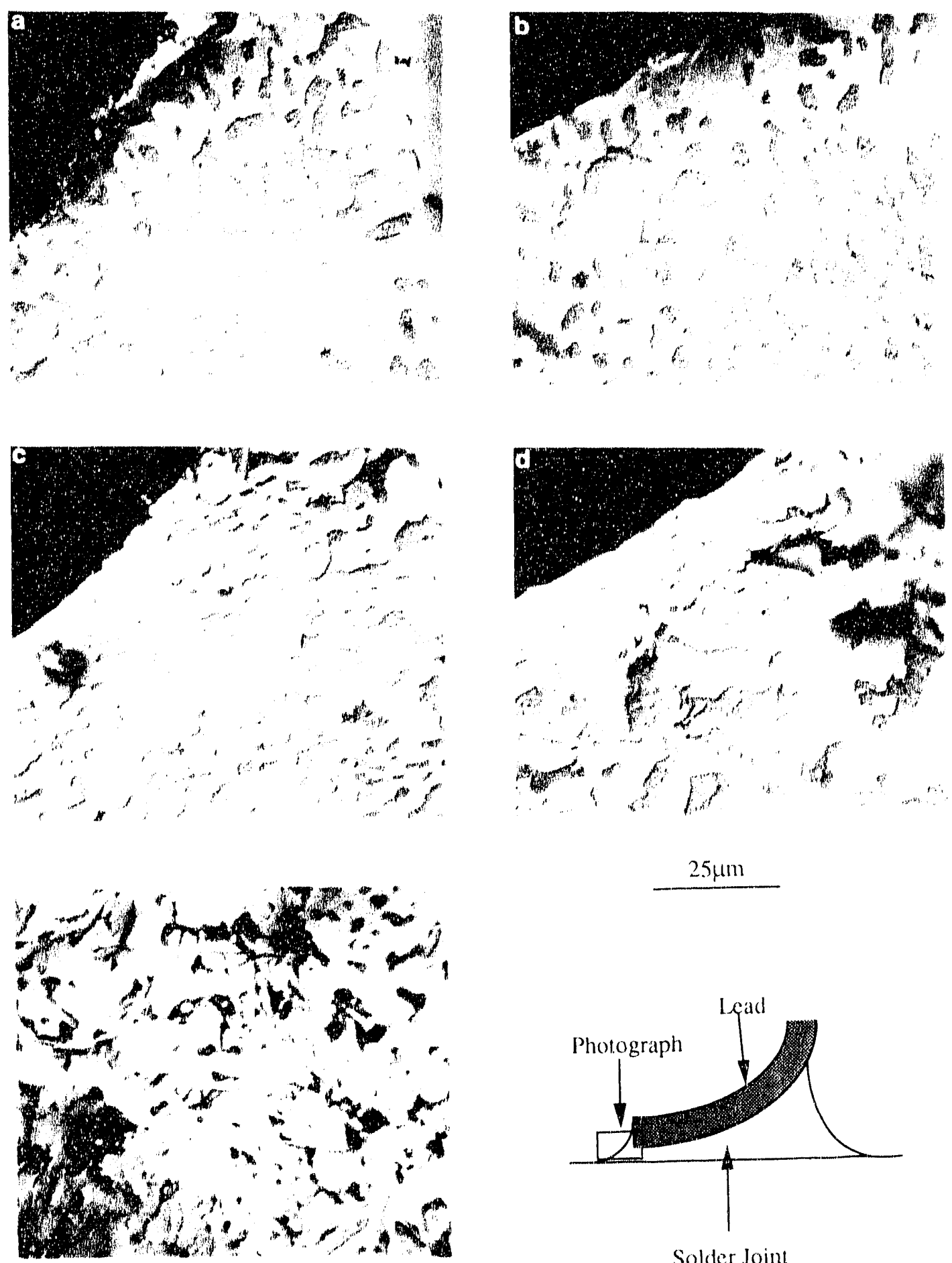

Solder Joint

ligure 38

Rework simulated a) Opin, b) $5 \mu \mathrm{in}(0.5 \mathrm{wl} \%$, c) $1(0 \mu \mathrm{in}(1.8 \mathrm{wt} \%$, d)

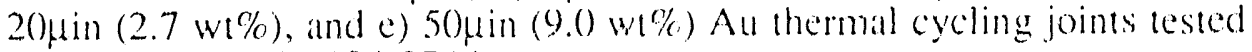
1450 cycles. (XBB924-2764) 

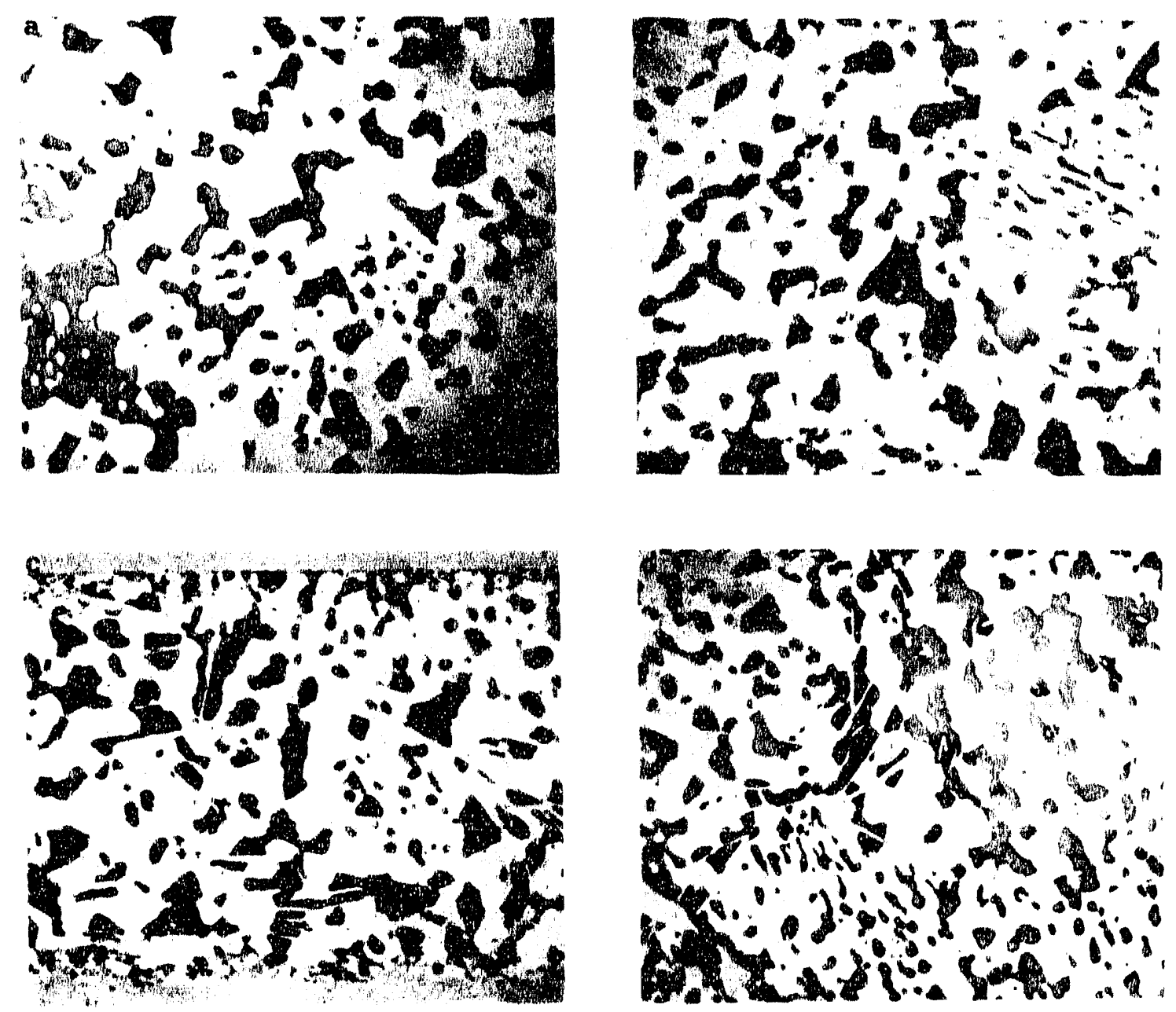

Figure 39

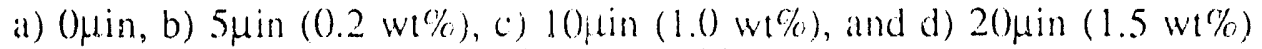

Au creep specimens tested at $90^{\circ} \mathrm{C}$. (XBB925-3174) 

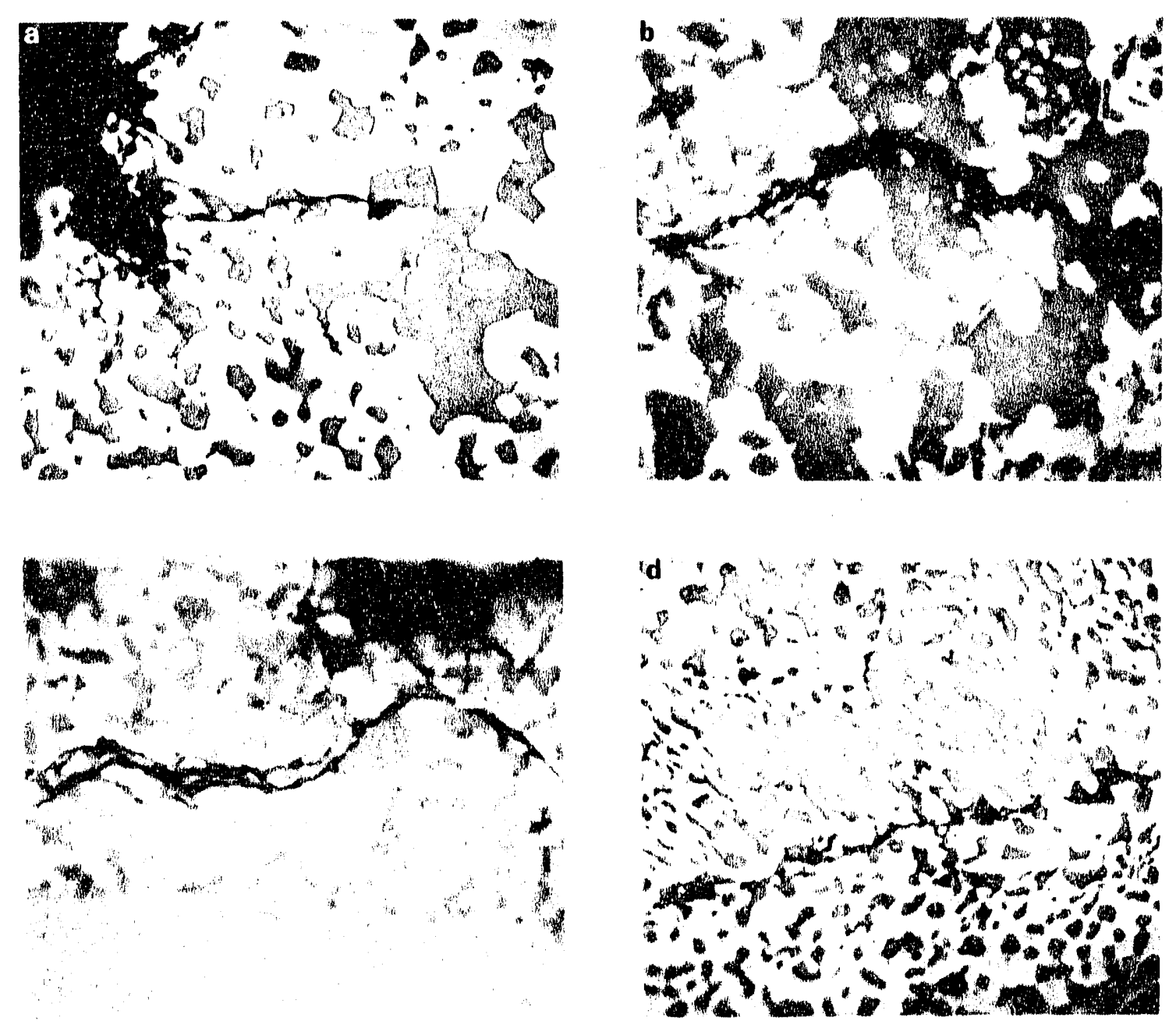

Figure 40

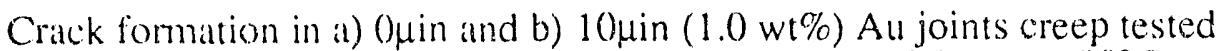
at 90$)^{\circ} \mathrm{C}$ and $5 \mu$ in $(() .2 \mathrm{wt} \%)$ joints creep tested at c) $65^{\circ} \mathrm{C}$ and d) 9()$^{\circ} \mathrm{C}$. (XBB925-3173) 
$\nabla$
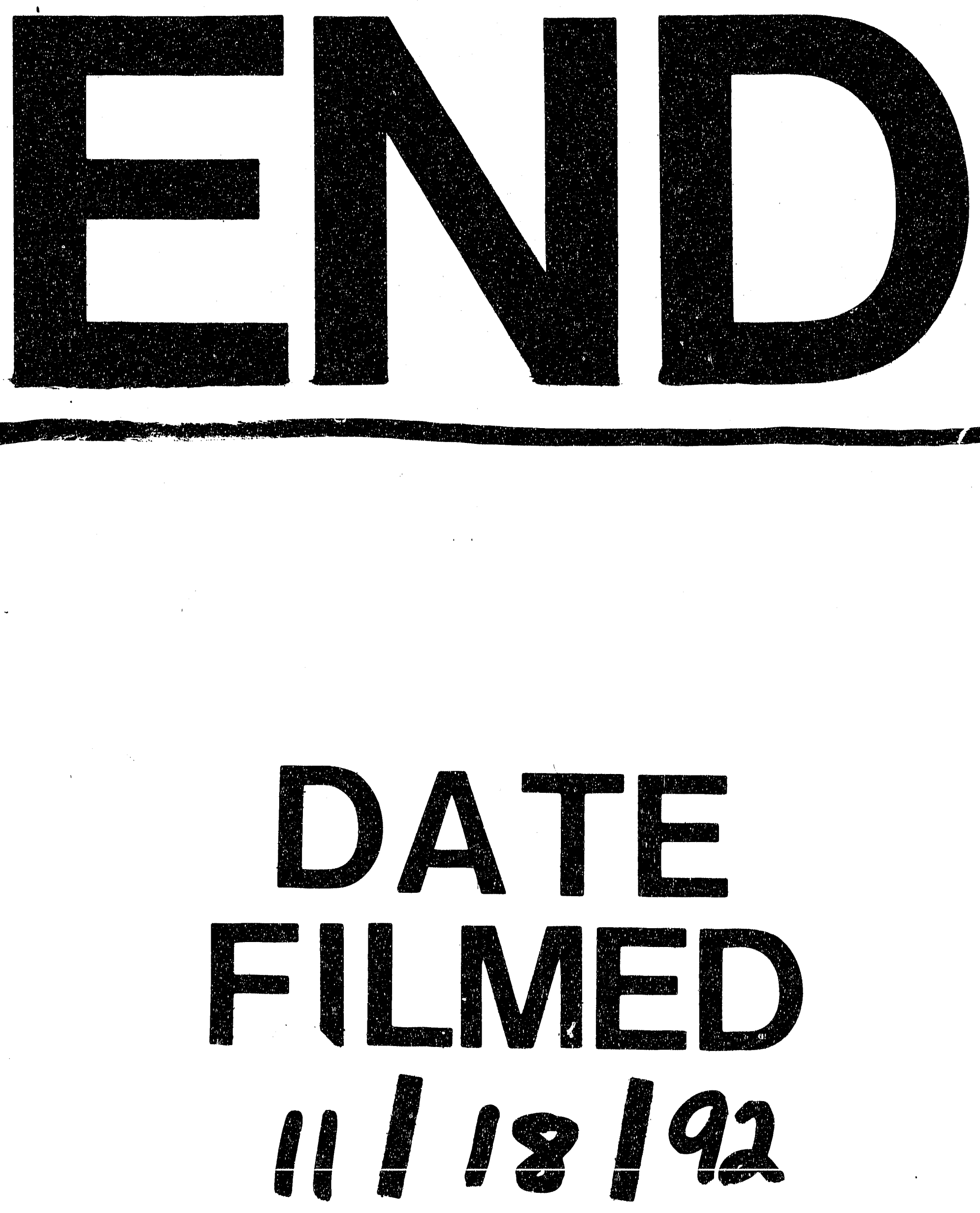
